NISTIR 7294

\title{
Performance of Thermal Exposure Sensors in Personal Alert Safety System (PASS) Devices
}

Nelson Bryner

Daniel Madrzykowski

David Stroup

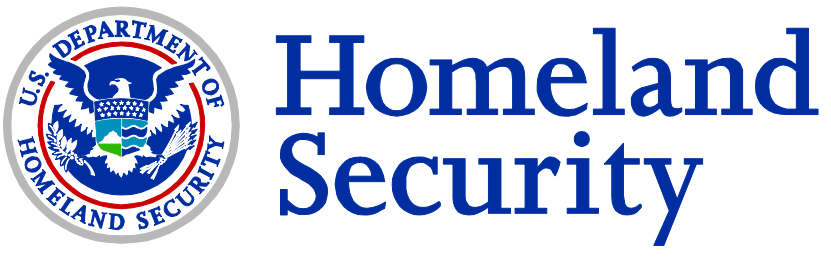

National Institute of Standards and Technology

Technology Administration, U.S. Department of Commerce 
NISTIR 7294

\title{
Performance of Thermal Exposure Sensors in Personal Alert Safety System (PASS) Devices
}

\author{
Nelson Bryner \\ Daniel Madrzykowski \\ David Stroup \\ Building and Fire Research Laboratory \\ National Institute of Standards and Technology \\ Gaithersburg, MD 20899-8661
}

September 2005
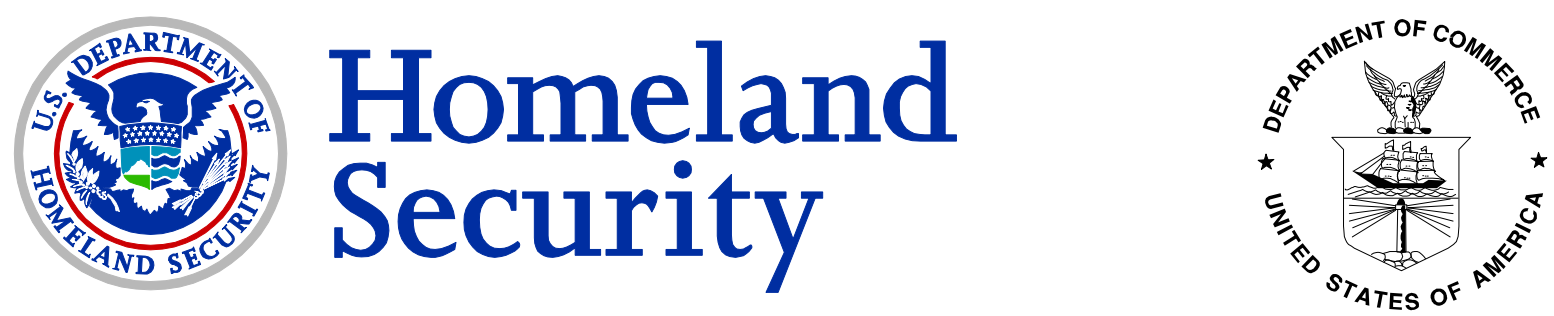

Department of Homeland Security

U.S. Department of Commerce

Michael Chertoff, Secretary

Carlos M. Gutierrez, Secretary

U.S. Fire Administration

R, David Paulison, Administrator

Technology Administration Michelle O'Neill, Acting Under Secretary of Commerce for Technology

National Institute of Standards and Technology

William A. Jeffrey, Director 


\section{Table of Contents}

List of Figures.............................................................................................................................................................. iii

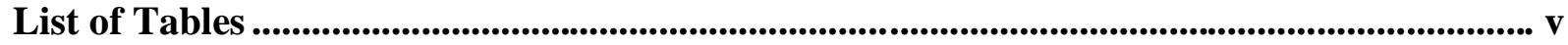

List of Tables ..................................................................................................................................... $v$

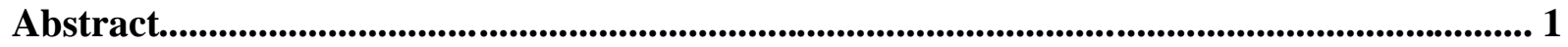

II. Thermal Exposure Sensors in PASS Devices ........................................................................... 3

III. Experimental Apparatus ......................................................................................................... 6

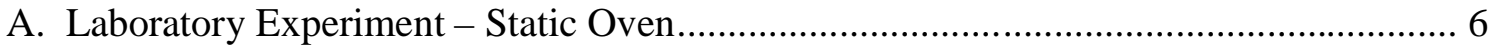

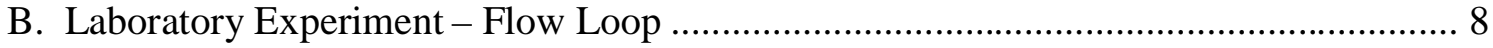

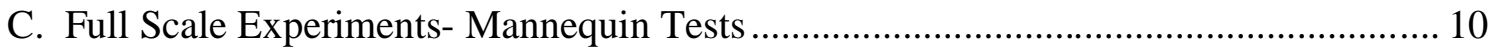

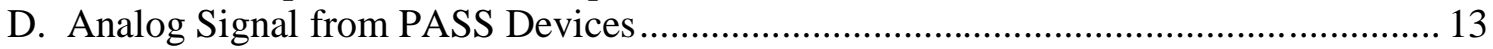

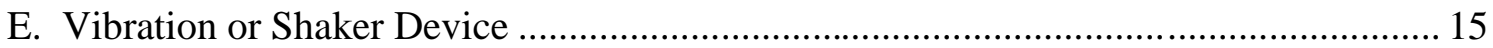

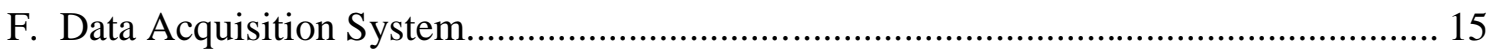

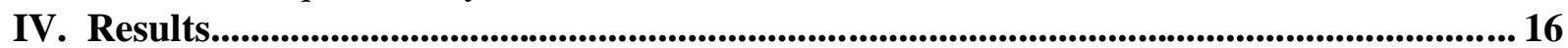

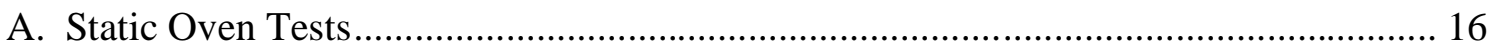

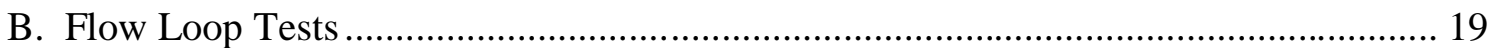

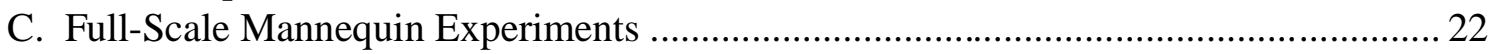

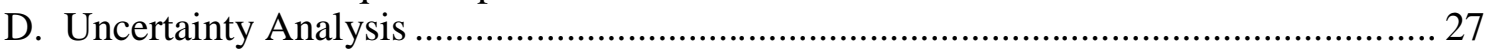

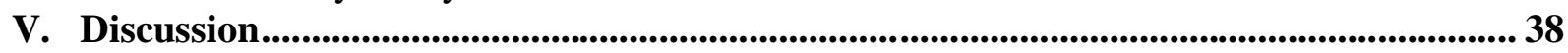

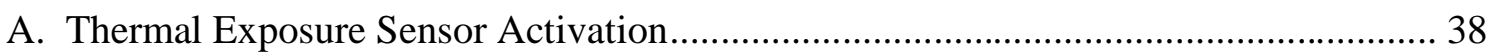

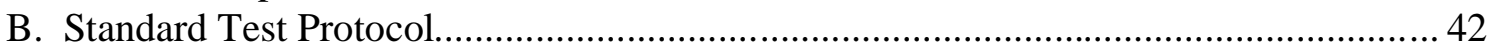

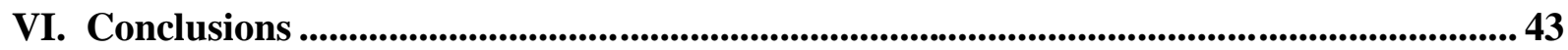

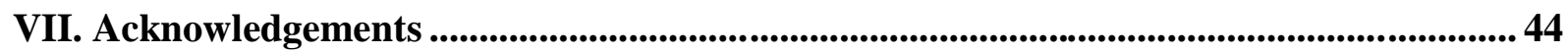

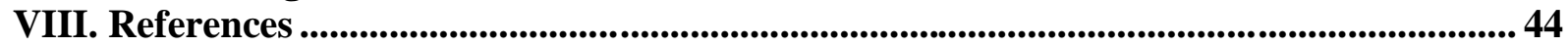

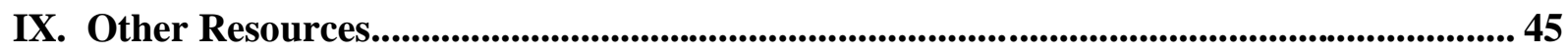




\section{List of Figures}

Figure 1. Personal Alert Safety System (PASS) devices from various manufacturers. ............... 4

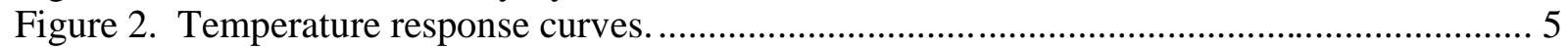

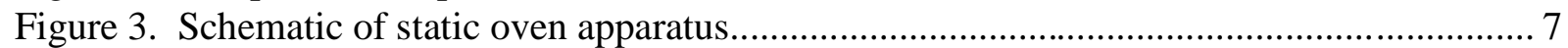

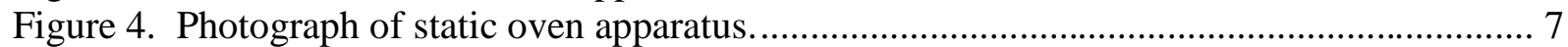

Figure 5. Schematic of flow loop experimental apparatus. ..................................................... 9

Figure 6. Photograph of flow loop experimental apparatus.................................................. 9

Figure 7. Instrumented mannequin for full-scale field experiments....................................... 11

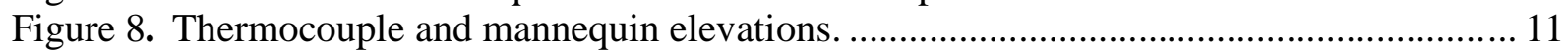

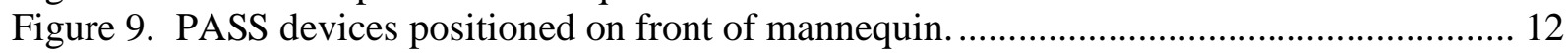

Figure 10. PASS devices positioned on rear of mannequin................................................. 12

Figure 11. Full-scale townhouse fire test used to expose instrumented mannequin.................... 13

Figure 12. Diagram of townhouse floor plan................................................................... 14

Figure 13. Static oven gas temperature versus PASS analog signal for device A-2 . ................ 17

Figure 14. Static oven gas temperature versus PASS analog signal for device B-3 ................... 17

Figure 15. Static oven gas temperature versus PASS analog signal for device C-2 .................. 18

Figure 16. Flow loop gas temperature versus PASS analog signal for device A-1 ................... 18

Figure 17. Flow loop gas temperature versus PASS analog signal for device B-4 .................... 20

Figure 18. Flow loop gas temperature versus PASS analog signal for device C-3................... 20

Figure 19. Gas temperatures versus time for full-scale townhouse burn in Unit 1 ................... 23

Figure 20. Thermal heat flux versus time for full-scale townhouse burn in Unit 1.................... 23

Figure 21. Temperature (Room) and thermal sensor activation for PASS device A in Unit

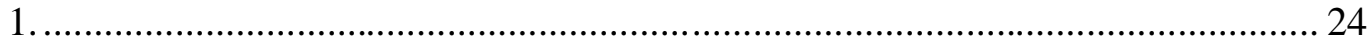

Figure 22. Temperature (Room) and thermal sensor activation for PASS device C in Unit

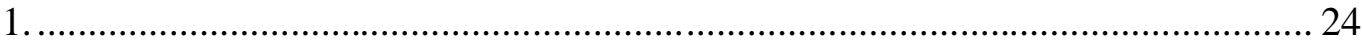

Figure 23. Temperature (Mannequin front and rear) and thermal sensor activation for PASS device A in Unit 1............................................................................... 25

Figure 24. Temperature (Mannequin front and rear) and thermal sensor activation for

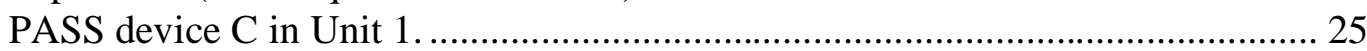

Figure 25. Gas temperatures versus time for full-scale townhouse burn in Unit 2.................... 30

Figure 26. Thermal heat flux versus time for full-scale townhouse burn in Unit 2 .................... 30

Figure 27. Temperature (room) and thermal sensor activation for PASS device A in Unit

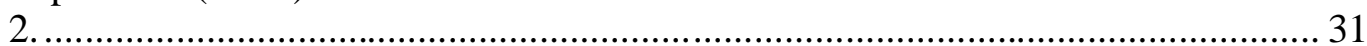

Figure 28. Temperature (room) and thermal sensor activation for PASS device C in Unit 2 ..... 31

Figure 29. Temperature (mannequin front and rear) and thermal sensor activation for

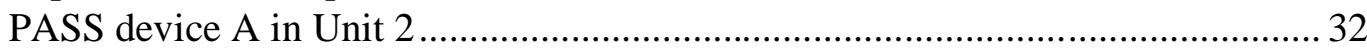

Figure 30. Temperature (mannequin front and rear) and thermal sensor activation for

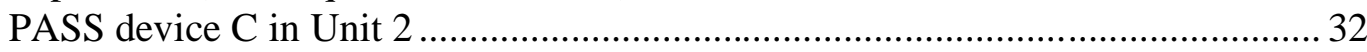

Figure 31. Gas temperatures versus time for full-scale townhouse burn in Unit 3.................. 33

Figure 32. Thermal heat flux versus time for full-scale townhouse burn in Unit 3................... 33

Figure 33. Temperature (room) and thermal sensor activation for PASS device A in Unit

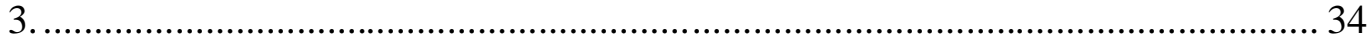




\section{List of Figures cont'd}

Figure 34. Temperature (room) and thermal sensor activation for PASS device C in Unit 3.

Figure 35. Temperature (mannequin front and rear) and thermal sensor activation for PASS device A in Unit 3

Figure 36. Temperature (mannequin front and rear) and thermal sensor activation for PASS device $\mathrm{C}$ in Unit 3 


\section{List of Tables}

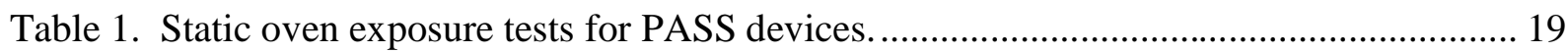

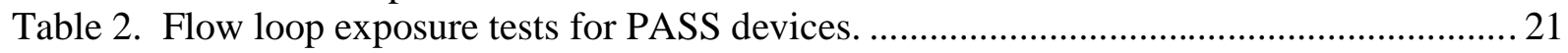

Table 3. Full-scale townhouse exposure tests for PASS devices (room peak temperatures). ..... 28

Table 4. Full-scale townhouse exposure tests for PASS devices (mannequin peak

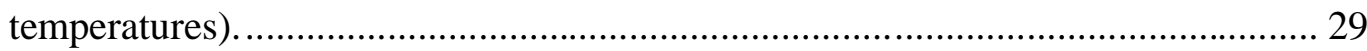

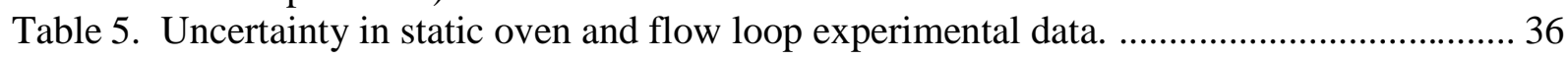

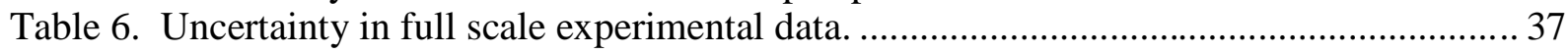




\title{
Performance of Thermal Exposure Sensors in Personal Alert Safety System (PASS) Devices
}

\author{
by
}

\author{
Nelson Bryner \\ Daniel Madrzykowski \\ David Stroup
}

\begin{abstract}
Fire fighters can be overcome by heat or smoke of a fire and may be unable to alert other fire ground personnel to their need for assistance. Personal Alert Safety System (PASS) devices are designed to signal for aid if a fire fighter becomes incapacitated. Thermal exposure sensor technology has already been included in a number of PASS devices, but no standard exists for testing the performance of the thermal sensor.

A series of static oven, flow loop, and full-scale experiments were conducted to demonstrate the performance of different PASS devices. This limited set of temperature versus thermal sensor activation data indicates that sensors respond differently under static, flowing, and radiation intense conditions. The full-scale data demonstrate that current thermal sensing/PASS implementations are unlikely to provide a fire fighter with sufficient warning of an acute thermal hazard. Current PASS devices may provide information to fire fighters about their longer term exposure to thermal conditions, but there is a significant delay of $25 \mathrm{~s}$ to $120 \mathrm{~s}$ before the fire fighter receives this alarm or information.

This limited series of experiments demonstrates the need to develop a standard testing protocol to insure that all PASS devices provide adequate protection for fire fighters. This testing protocol must evaluate the performance of thermal sensors under a range of fire environments that fire fighters may realistically encounter on a routine basis. This experimental data was used to develop a prototype standard test protocol which can used to quantify the thermal sensor performance.
\end{abstract}

Keywords: Personal Alert Safety System, PASS, PASS device, thermal exposure, thermal sensor, thermal response data 


\section{Introduction}

Fire fighters can be quickly overcome by the heat or smoke of a fire and may be unable to alert other fire ground personnel to their need for assistance. Personal Alert Safety System (PASS) devices are designed to signal for aid if a fire fighter becomes incapacitated on the fire ground. From 1994 to 1998, an average of 725 fire fighters per year were caught or trapped in structure fires that resulted in injury or death of fire fighters, according to an analysis of National Fire Incident Reporting System (NFIRS) data by the National Fire Protection Association (NFPA) [1]. Fire fighters fatalities resulting from being caught or trapped in structures caused 15 deaths out of a total of 97 fire fighter fatalities according to NFPA statistics for 2002 [2] and represented the third leading cause of fire fighter fatalities after stress/overexertion and struck by objects [2]. US Fire Administration statistics for 2003 indicate that caught/trapped or collapse accounted for 12 fire fighter fatalities in 2003 [3]. Two NFPA studies examined fatalities due to structural collapse for 1979-1988 [4] and for 1983-1992 [5] and reported that $60 \%$ of fire fighter deaths in structures were caused by being caught or trapped in the structure. Brassell and Evans [6] reported that this percentage increased to over $85 \%$ for the period 1994 to 2002. Fire fighter becoming caught or trapped in structures has been a major hazard for fire fighters for the past 20 years. If properly implemented, the PASS device can serve as a platform for the incorporation of additional and more innovative technology to help reduce fatalities and injuries resulting from caught or trapped fire fighters.

Personal Alert Safety System devices are designed to signal for aid via an audible alarm signal if a fire fighter becomes incapacitated on the fire ground. Typically, PASS devices sense movement or lack of movement and activate a 95-decibel alarm signal if the lack of motion exceeds a specific time period. The loud alarm signal alarm alerts other personnel that a fire fighter has become motionless and may be incapacitated. The loud alarm helps to guide rescue personnel to the location of the incapacitated fire fighter. Performance standards and testing protocols for motion or lack of motion detectors is described by NFPA Standard 1982 [7]. While the current NFPA Standard for PASS devices (NFPA 1982) requires only a motion detector, some PASS device manufacturers are beginning to incorporate additional technology into PASS devices to improve fire ground safety. If properly implemented, new technology including thermal sensors could significantly improve the safety and effectiveness of fire fighters on the fire ground.

Thermal exposure sensor technology has already been included in a number of models of PASS devices. However, there are currently no standards or testing protocols with which to assess the performance of these thermal exposure sensors. While it is commendable that manufacturers seek to include more technology in order to increase the safety of fire fighters, the fire service does not have the resources to evaluate the thermal exposure sensor performance in PASS devices. There is a need for a well-designed testing protocol that would include different fire conditions that fire fighters typically encounter. This would allow the fire service to understand better the performance characteristics of the thermal sensors. In addition, a standardized testing protocol would allow the manufacturers to match the performance of their devices with the requirements of the fire service.

In the future, additional capabilities and technologies may be incorporated into PASS devices. Emerging technologies which would provide valuable capabilities to the fire service include fire fighter location and tracking, fire ground accountability, toxic gas analyzers, and 
physiological and stress monitors. It would also be useful if future PASS devices could incorporate the capability to communicate information such as location, gas concentrations, and heart rate to the incident commander outside the structure. It is critical that a standardized testing protocol be in place as each these technologies are integrated into PASS devices so that the fire service understands the performance as well as the limitations of their equipment. The overall goal of this work is to improve the safety and effectiveness of fire fighters. To accomplish this goal, the fire service must be able to incorporate state-of-the-art technology into all of its equipment. But, in order for the fire service to integrate new technology safely, it must be able to understand the performance and the limitations of this new technology.

The first part of this study examines the performance of the thermal exposure sensors in a series of laboratory as well as real scale experiments. Exploring new technologies, such as fire fighter locator, fire ground accountability, toxic gas analyzers, and physiological monitors, which might enhance performance of future PASS devices and developing a prioritized plan to incorporate new technology will be addressed in a separate report.

\section{Thermal Exposure Sensors in PASS Devices}

Thermal exposure sensor technology has been incorporated into motion detector PASS devices by a number of manufacturers, but not all PASS suppliers have incorporated thermal sensors into their devices. Examples of different PASS devices* are shown in Figure 1. Some of the PASS devices that are shown in Figure 1 have been modified by adding external wires which allowed the alarm signal to be monitored externally. This modification is discussed later in this report. Not all the devices shown in Figure 1 incorporate thermal exposure sensors. This thermal sensing capability is not required by NFPA Standard 1982. Currently, the lack of an equipment standard or testing protocol for the thermal sensors has resulted in each manufacturer developing their own specific implementation of thermal sensing technology. Typically, the thermal sensor utilizes a single, small sensing element, usually less than $3.2 \mathrm{~mm}$ ( 0.125 in) in diameter. The temperature-sensing component is located inside the case of each PASS device. Each thermal sensor monitors a temperature and if the temperature exceeds a predetermined value for a specific period of time, the PASS device is designed to go into alarm. The electronics necessary to process the temperature data are typically incorporated onto the circuit board that collects and processes the information from the motion detector. The PASS device generates a 95-decibel alarm signal when either the temperature sensor or motion detector has been activated.

Fire fighters wear protective gear that effectively insulates them from the thermal environment around them. At times, it is difficult for the fire fighter to appreciate how much heat flux or thermal stress they have been exposed to during fire fighting operations. Thermal sensor equipped PASS devices are worn on the outside of the protective gear and monitor the thermal exposure. Thermal sensors continuously track the thermal environment and are designed to alarm at pre-set exposure values when the set-point temperature is exceeded for a

\footnotetext{
${ }^{*}$ Certain trade names and company products are mentioned in the text or identified in an illustration in order to specify adequately the experimental procedure and equipment used. In no case does such identification imply recommendation or endorsement by the National Institute of Standards and Technology, nor does it imply that the products are necessarily the best available for the purpose.
} 
specified time period. The thermal environment can range from slightly elevated temperatures, $66{ }^{\circ} \mathrm{C}\left(150{ }^{\circ} \mathrm{F}\right)$ up to pre-flashover temperatures, $650{ }^{\circ} \mathrm{C}\left(1200^{\circ} \mathrm{F}\right)$. A fire fighter may be able to work for longer periods in slightly elevated temperatures, but must quickly escape high temperature situations. Consequently, thermal sensing PASS devices must be able to warn the fire fighter for a range of exposures; short duration at high temperatures and long duration at slightly elevated temperatures.

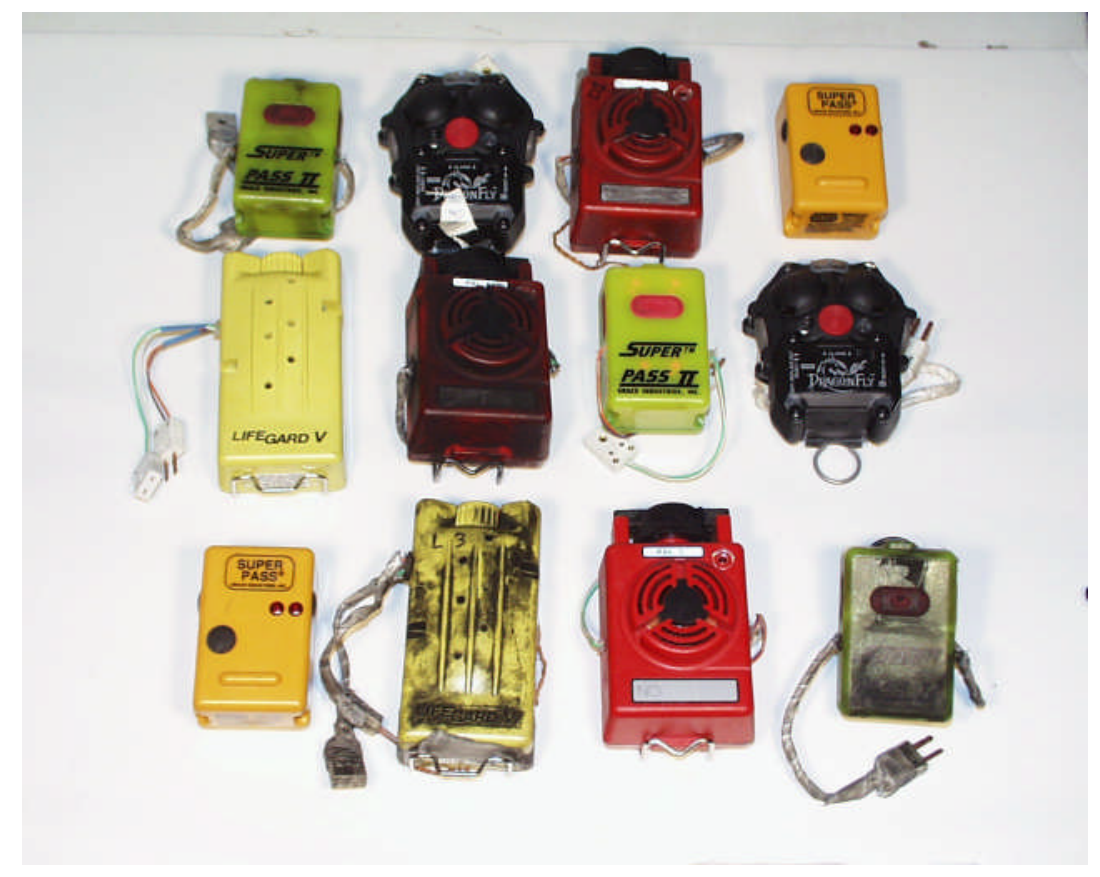

Figure 1. Personal Alert Safety System (PASS) devices from various manufacturers.

Thermal sensing PASS devices use a temperature response curve to determine which thermal exposures will activate an alarm. Two examples of temperature response curves are shown in Figure 2. Once the thermal sensor temperature has exceeded the temperature response value (above the temperature versus time curve) for a period of time that corresponds to that temperature, the thermal sensor will activate an alarm. For example, a sensor designed to follow the lower curve (Curve A in Figure 2) would alarm in less than 1 minute to a temperature above $320{ }^{\circ} \mathrm{C}\left(600{ }^{\circ} \mathrm{F}\right)$. A sensor that is configured to the upper response curve (Curve $\mathrm{B}$ in Figure 2) would require significantly longer time to respond, 3 minutes at a temperature of $320{ }^{\circ} \mathrm{C}\left(600{ }^{\circ} \mathrm{F}\right)$. For lower temperatures at around $66^{\circ} \mathrm{C}\left(150{ }^{\circ} \mathrm{F}\right)$, the lower and upper curves indicate a response time of 20 minutes and 25 minutes, respectively. If the thermal sensor equipped PASS device is designed to monitor exposure to lower temperatures for longer periods of time, either of the response curves would activate an alarm at 25 minutes of exposure to $66{ }^{\circ} \mathrm{C}$ $\left(150{ }^{\circ} \mathrm{F}\right)$. But, if the PASS device was designed to warn a fire fighter of an exposure to higher temperatures for designed to Curve B. However, even a thermal sensor that alarms 


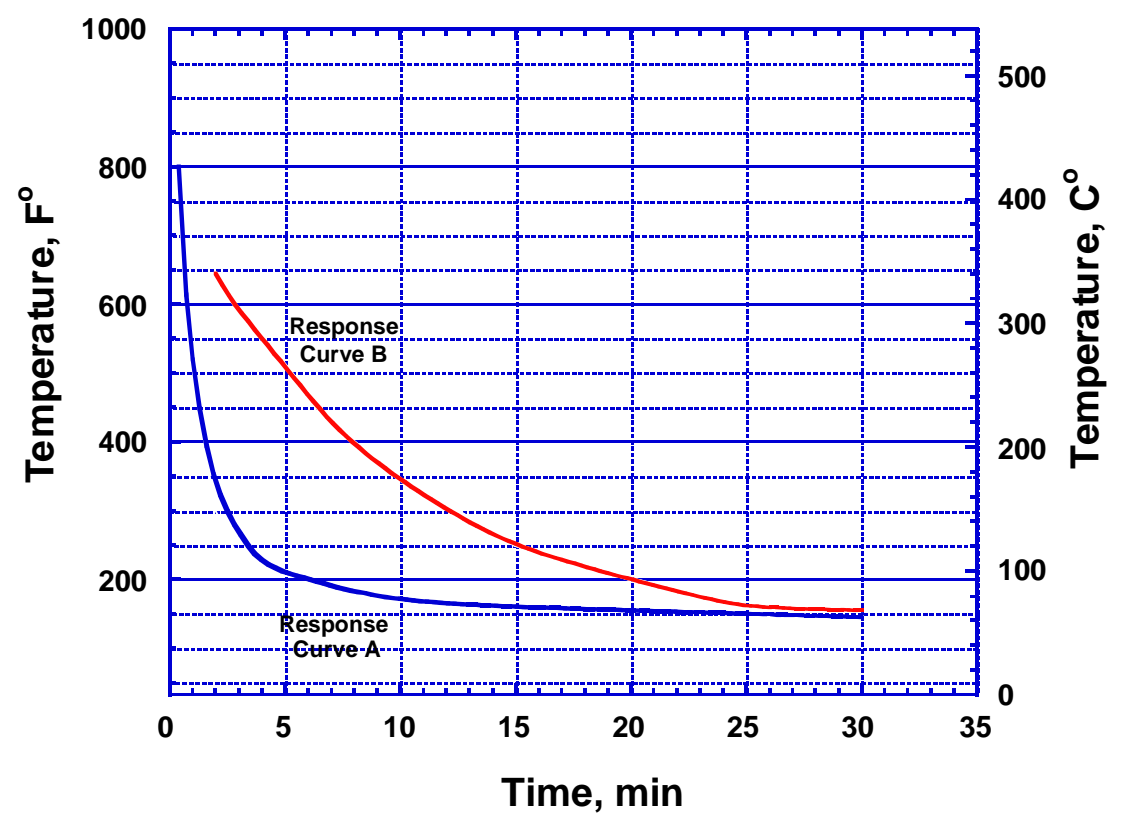

Figure 2. Temperature response curves.

after a 1 min exposure to $320{ }^{\circ} \mathrm{C}\left(600{ }^{\circ} \mathrm{F}\right)$, may not provide adequate time for a fire fighter to escape a serious thermal threat.

A standard testing protocol would allow the fire service and manufacturers a method to evaluate or characterize the performance of thermal sensors in PASS devices. The performance characteristics can vary from manufacturer to manufacturer due to different sensing elements, multiple sensing locations, e.g. inside PASS case or outside a case, and different temperature averaging algorithms. A standard testing protocol would help ensure that every PASS device responds to a basic set of fire conditions or thermal environments that may be encountered by a fire fighter wearing a thermal sensing PASS device. It is important that the performance characterized by the testing protocol be representative of the conditions a fire fighter may experience.

But, the thermal environment that a fire fighter encounters can be complex. Fire fighters may find themselves standing or crouching in a room full of hot combustion products and smoke. In this scenario, the fire fighter is enveloped in a relatively static layer of hot gases. If suppression has been initiated, water droplets and steam may also be present. Fire fighters may also be moving through a smoke filled room or experience a situation where the smoke is moving past them. In these circumstances, a fire fighter is immersed in a flowing smoke layer. Fire fighters may also need to enter a room in which a fire is burning. Under these conditions, a fire fighter is exposed to the intense thermal radiation that is produced by a hot fire. During each of these scenarios, the fire fighter and PASS devices that they are wearing experience the transfer of heat from the hot smoke or fire via conduction, convection, and/or radiation. To understand the performance of the thermal exposure sensors, it is necessary to examine the response of the thermal sensor and PASS device to these various conditions that may be experienced by fire fighters.

The performance of thermal exposure sensors was documented for three different PASS models from three different manufacturers. Through a series of lab- and full-scale experiments, 
the overall performance of a PASS device to alarm in response to a specific thermal insult or condition was evaluated. This limited set of experiments was designed to provide a better understanding of the response characteristics of PASS devices equipped with thermal sensors in order to help develop a standard test protocol.

These experimental series was not intended to be "product testing" and is too limited to be used to rank the individual PASS devices. Since the focus of this work is to develop a standard test protocol which does not favor any one specific thermal sensor technology, PASS devices will only be identified as Model A, Model B, and Model C. Multiple PASS devices of the same model from the same manufacturer will be identified as A-1, A-2, and A-3.

\section{Experimental Apparatus}

The performance of different PASS models from various manufacturers was examined during experiments in a static oven, in a heated flow loop, and on a mannequin in field tests. Four different models of PASS devices were exposed to static hot gases, flowing hot gases, or real scale combustion gases. Three of the models had thermal sensors and one model did not. This study will focus on the temperature versus alarm activation data for the three models that incorporated thermal sensors. While not the focus of this study, the impact of repeated thermal exposures on the motion repeated thermal exposures did not appear to impact the motion sensing capability of the PASS devices, with or without the thermal sensor. The performance of thermal sensor equipped PASS devices were examined in 60 tests in a static oven, 48 runs in a heated flow loop, and four mannequin tests in townhouse fires.

The laboratory experiments involved exposing each thermal sensor equipped PASS device to a series of different temperature environments in a static oven as well as a flow loop that allowed hot air to flow past each device. Both the static oven and flow loop experiments were designed to allow careful monitoring of the temperature around each PASS device and when each PASS device alarmed. In each laboratory experiment, the temperature could be increased gradually and in a controlled fashion. For each case, static or flowing, the temperature of the hot gases was increased until the thermal sensor alarmed.

Field experiments were designed to expose each PASS device to realistic fire conditions in which the temperatures may increase more quickly (and realistically) than in the laboratory experiments. Six PASS devices were mounted on a mannequin that was also instrumented with thermocouples on the front, rear, inside, and top of the protective gear. This instrumented and PASS equipped mannequin was then exposed to a series of townhouse burns when the temperature and time history were monitored until the thermal sensors alarmed.

\section{A. Laboratory Experiment - Static Oven}

For each of the static oven tests, either a single or a pair of PASS devices was suspended inside a small electric resistance oven (Figures 3 and 4) with internal dimensions of $0.44 \mathrm{~m}$ (17.3 in) wide $\times 0.29 \mathrm{~m}$ (11.6 in) deep x $0.39 \mathrm{~m}$ (15.5 in) height. This oven temperature was continuously variable between $18{ }^{\circ} \mathrm{C}\left(64{ }^{\circ} \mathrm{F}\right)$ and $250{ }^{\circ} \mathrm{C}\left(480{ }^{\circ} \mathrm{F}\right)$ and thermostatically controlled. 


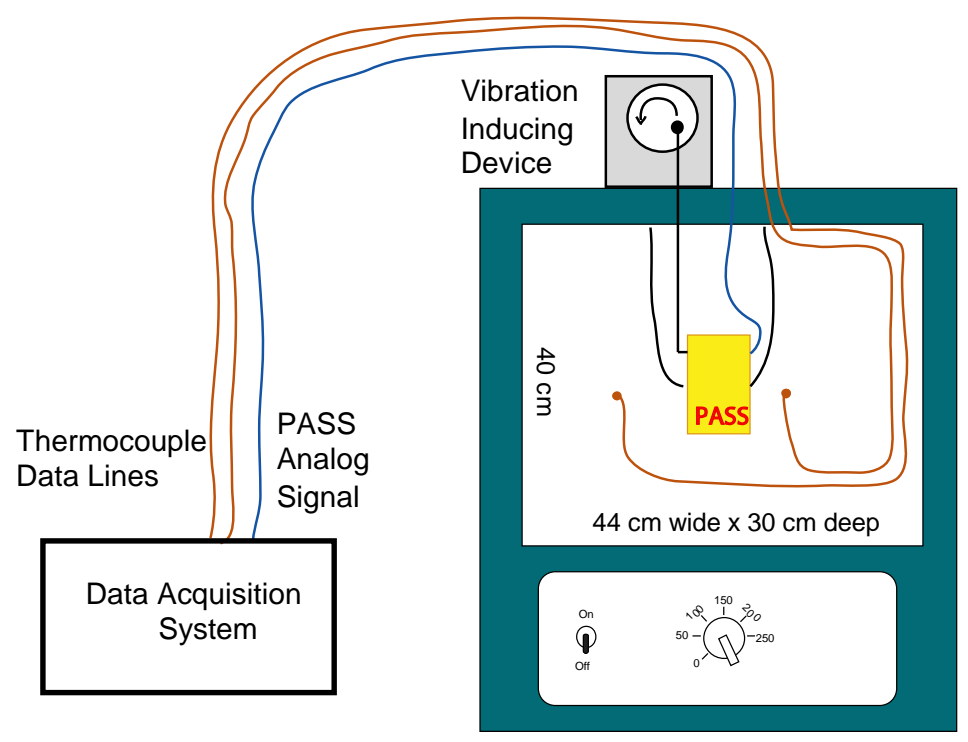

Electrical Resistance Oven

Figure 3. Schematic of static oven apparatus.

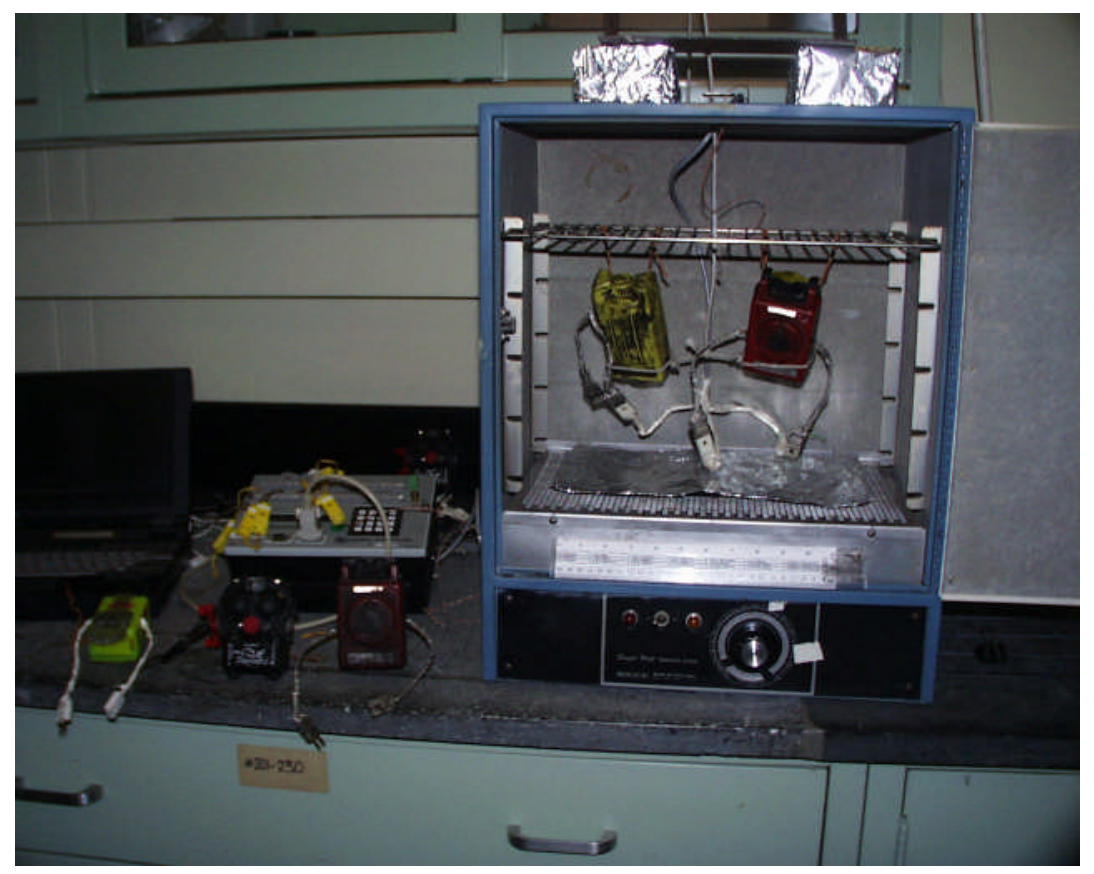

Figure 4. Photograph of static oven apparatus. 
Each device was suspended approximately in the center of the oven and connected to the data acquisition system. Each PASS device was instrumented front and rear with Chromel-Alumel thermocouples with bead diameters of $2 \mathrm{~mm}(0.08 \mathrm{in})$ diameter. Additional thermocouples were placed in the center of the oven and outside the oven to monitor the gas temperature and ambient temperature, respectively. These thermocouples allowed the PASS device, gas, and ambient temperatures to be monitored continuously. Prior to inserting the PASS devices into the static oven, each device received a new 9 Volt battery.

For each oven test, the initial oven temperature was recorded, typically being between $18{ }^{\circ} \mathrm{C}\left(64{ }^{\circ} \mathrm{F}\right)$ to $28{ }^{\circ} \mathrm{C}\left(82{ }^{\circ} \mathrm{F}\right)$. Each PASS device or pair of PASS devices was mounted along the centerline of the oven. Once mounted inside the oven, each PASS devices was connected to the data acquisition system and to a vibration-inducing device. The vibration or shaker device induced a slight movement (vertical direction) in each PASS devices in order to prevent false alarms due to the motion sensor. The oven door was closed and the oven temperature was reset to $40{ }^{\circ} \mathrm{C}\left(105^{\circ} \mathrm{F}\right)$. The temperature of the gas as indicated by a thermocouple in the center of the oven was allowed to reach the initial temperature set point. After ten minutes if the PASS device had not alarmed, the temperature set point was increased by $5{ }^{\circ} \mathrm{C}\left(9^{\circ} \mathrm{F}\right)$. This process of increasing the temperature and exposing the PASS device to that temperature for 10 minutes was continued until the PASS alarmed or the oven temperature exceeded $120{ }^{\circ} \mathrm{C}\left(250{ }^{\circ} \mathrm{F}\right)$.

If two PASS devices had been mounted in the oven, then the device that had alarmed was removed from the oven and the test continued with the other PASS device alarm. After each PASS device had alarmed, the PASS devices were removed and the oven was allowed to cool down and then the procedure was initiated with the next two PASS devices. Each set of experiments for a given PASS device included at least three runs in the oven and at least two PASS devices from each manufacturer were exposed.

\section{B. Laboratory Experiment - Flow Loop}

For each of the flow loop tests, a single PASS device was suspended inside a section of a larger flow loop (Figures 5 and 6). The flow loop was originally designed as part of a test apparatus used to conduct water sprinkler plunge tests [8]. The internal dimensions of the test section were $0.2 \mathrm{~m}$ ( 8 in) deep x $0.2 \mathrm{~m}$ ( 8 in) height $\times 0.36 \mathrm{~m}$ (14.25 in) wide. The blower necessary to move the air flow and the electrical resistance heaters required to maintain the gases at a specific temperature are located in other sections of the apparatus. The gas temperature of the flow loop was continuously variable between $18{ }^{\circ} \mathrm{C}\left(64{ }^{\circ} \mathrm{F}\right)$ and $150{ }^{\circ} \mathrm{C}\left(300{ }^{\circ} \mathrm{F}\right)$ and thermostatically controlled. The flow velocity of the flow loop was variable from $0.25 \mathrm{~m} / \mathrm{s}$ $(0.6 \mathrm{mph})$ to $5 \mathrm{~m} / \mathrm{s}(11.2 \mathrm{mph})$ and was continuously monitored via a bi-directional probe.

The flow loop featured a hinged access door that formed the top wall or roof of the test section. This access door could be opened and moved out of the way to allow a second top wall or removable section to be quickly positioned into the opening. Each PASS device was mounted on the removable section for quick insertion and removal. Each instrument was mounted on a horizontal metal rod that was suspended via thin wires from the removable section. 


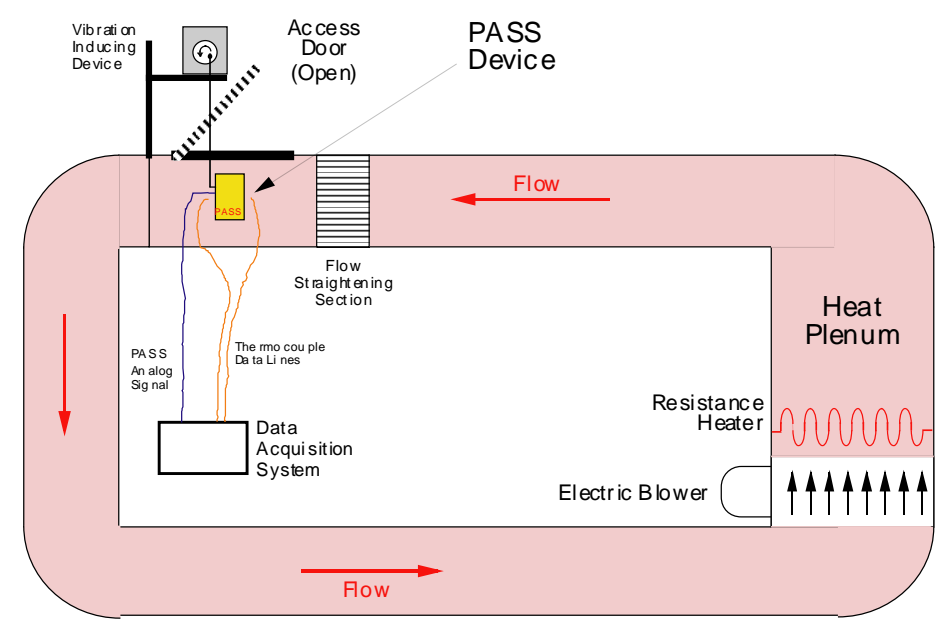

Figure 5. Schematic of flow loop experimental apparatus.

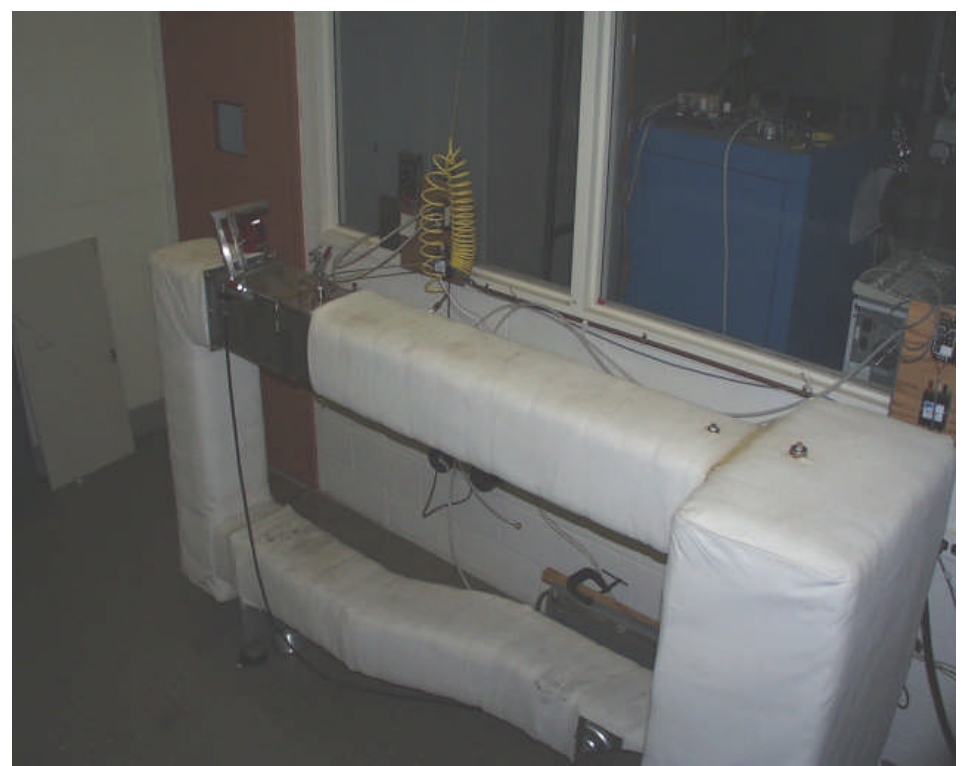

Figure 6. Photograph of flow loop experimental apparatus.

When the removable section was inserted into the flow loop, the PASS device was positioned so that the front of the device faced into the flow of the hot air. The PASS device did not have a backer board or support plate behind the device case. Each PASS device was instrumented front and rear with Chromel-Alumel thermocouples with bead diameters of $2 \mathrm{~mm}(0.08 \mathrm{in})$ diameter.

Additional thermocouples were placed in the center of the flow and outside the loop to monitor the gas temperature and ambient temperature, respectively. These thermocouples 
allowed the PASS device, gas, and ambient temperatures to be monitored continuously. Prior to inserting the PASS devices into the flow loop, each device received a new 9 Volt battery. Each PASS was then mounted on a removable section, connected to the data acquisition system and the vibration-inducing device.

After the flow loop had reached a velocity of $1.3 \mathrm{~m} / \mathrm{s}(3 \mathrm{mph})$, and maintained that velocity for several minutes, the temperature of the flow was recorded, typically being between $24{ }^{\circ} \mathrm{C}\left(75^{\circ} \mathrm{F}\right)$ to $28{ }^{\circ} \mathrm{C}\left(82^{\circ} \mathrm{F}\right)$. The PASS device was turned on, the shaker device was activated, and the device equipped removable section was placed into the flow section. After checking to insure that each PASS device was not alarming due to lack of motion, the removable section and PASS device were lifted out of the flow section. The hinged access door was closed and the flow loop temperature was reset to $40{ }^{\circ} \mathrm{C}\left(105^{\circ} \mathrm{F}\right)$.

For each of the flow loop tests, a PASS device was quickly inserted into a flow of heated air. If the device did not alarm after ten minutes of exposure, the PASS device was removed. The temperature of the air was increased by $10^{\circ} \mathrm{C}\left(18^{\circ} \mathrm{F}\right)$. This process of increasing the temperature and exposing the PASS device to that temperature for 10 minutes was continued until the PASS alarmed or the flow loop air temperature exceeded $120^{\circ} \mathrm{C}\left(250{ }^{\circ} \mathrm{F}\right)$. These experiments were repeated at least three times with each of the different PASS devices.

\section{Full Scale Experiments- Mannequin Tests}

Full-scale experiments were conducted to examine the performance of thermal exposure sensors under more realistic conditions than the static or flow loop tests provided. For each fullscale experiment, a mannequin that was instrumented with six PASS devices (Figures 7 - 10) was inserted into a series of townhouse burns (Figure 11). During a series of burns in identical townhouse units, an instrumented mannequin was positioned inside and exposed to different fuel packages. The mannequin was located between the dining room and living room initially and could be retracted to the kitchen (Figure 12). Townhouse Unit 1 (Figure 12) was only furnished with carpeting while townhouse Unit 2 (Figure 12) and Unit 3 (not shown) were furnished with sofa, chair, lamp, end table and carpeting. For Unit land Unit 2, $1.0 \mathrm{~L}(0.26$ gal $)$ of gasoline was poured on the center of the carpet and ignited. Unit 3 was ignited using an electric match in crumpled up newspaper in the corner of the sofa. Fuel package in Unit 1 was not sufficient to allow the fire to approach flashover so active suppression was unnecessary. Since the fuel package was sufficient to achieve flashover in Unit 2 and 3, each fire was allowed to approach flashover, but water from a $3.8 \mathrm{~cm}$ (1.5 in) hose line was used to suppress each fire as flashover began. The response of the PASS devices was continuously monitored throughout each exposure. The mannequin was also instrumented with thermocouples to track the temperatures on the front, rear, and top of the mannequin. Additional thermocouples and total heat flux gauges were also positioned next to the mannequin.

A full-size, kneeling mannequin was clothed in protective pants and jacket, boots, gloves and helmet. Three PASS devices were positioned on the chest of the mannequin as shown in Figure 7, 8, and 9. The centerline of each PASS device, front and rear, was $0.95 \mathrm{~m}$ (37.4 in) above the floor. Three devices were also mounted on the back or rear side of the mannequin (Figure 10) at an elevation of $0.95 \mathrm{~m}$ (37.4 in) above the floor. The mannequin was also instrumented with thermocouples on the outside of the protective gear jacket near where the six PASS devices were mounted, the top of both shoulders, and on the top of the helmet. Two 


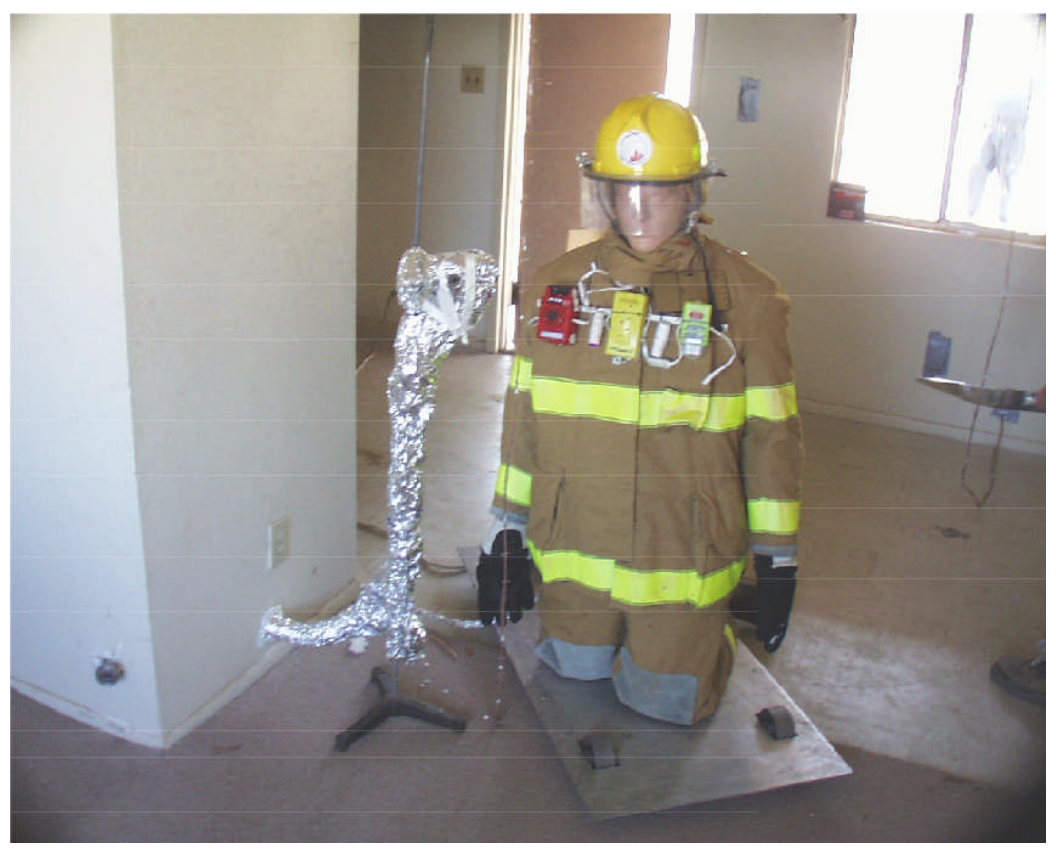

Figure 7. Instrumented mannequin for full-scale field experiments.

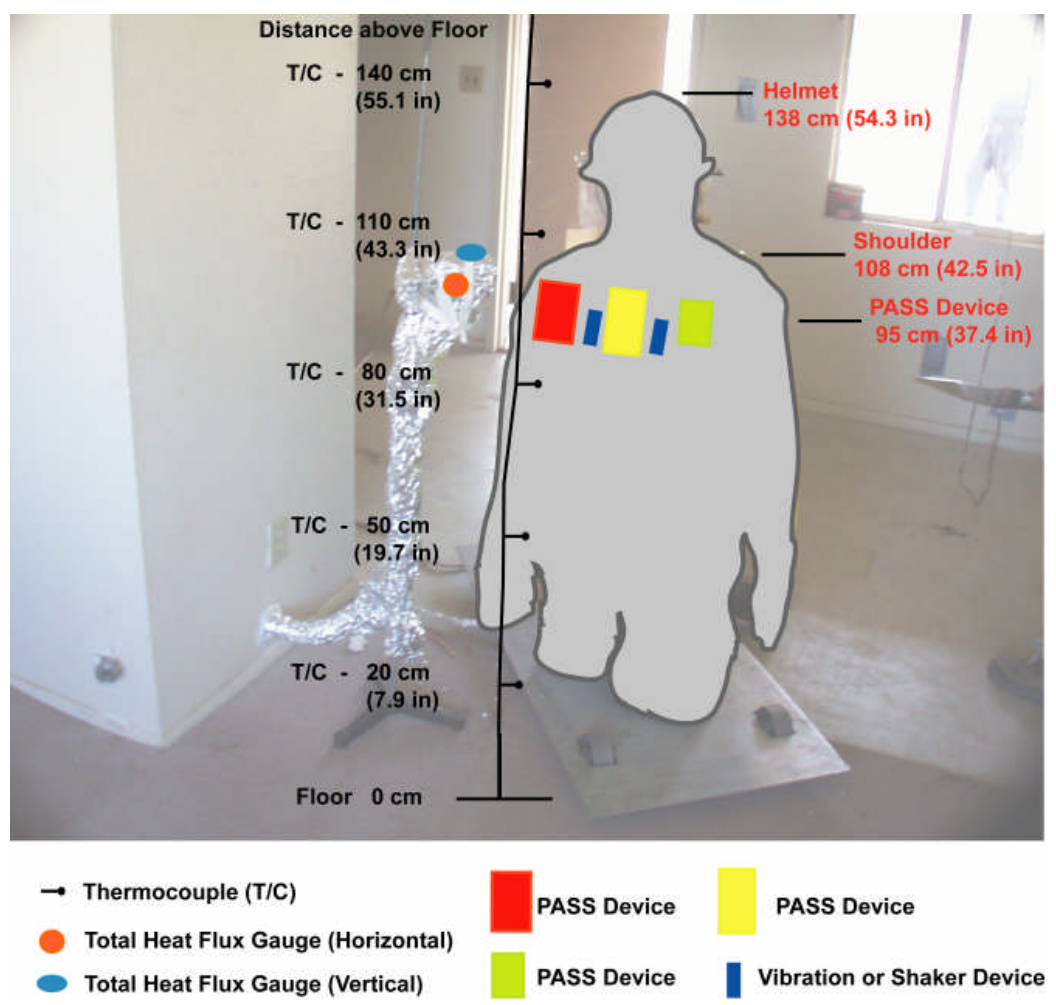

Figure 8. Thermocouple and mannequin elevations. 


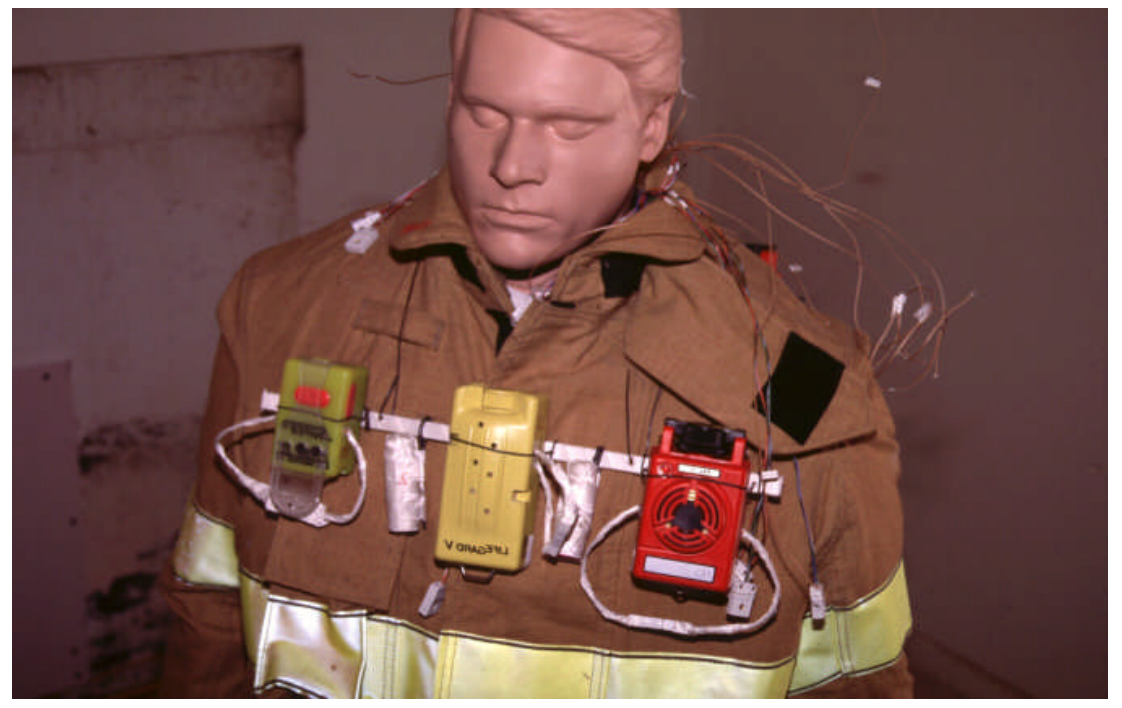

Figure 9. PASS devices positioned on front of mannequin.

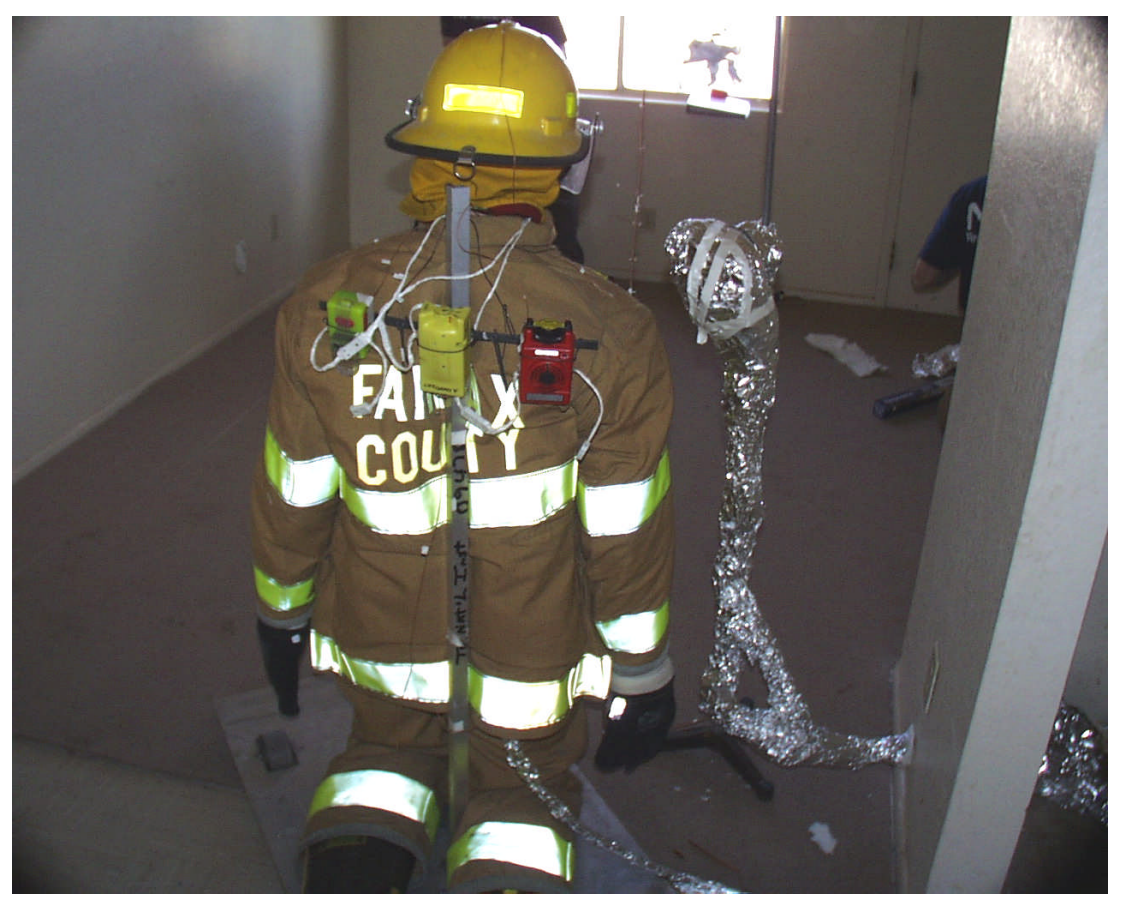

Figure 10. PASS devices positioned on rear of mannequin. 


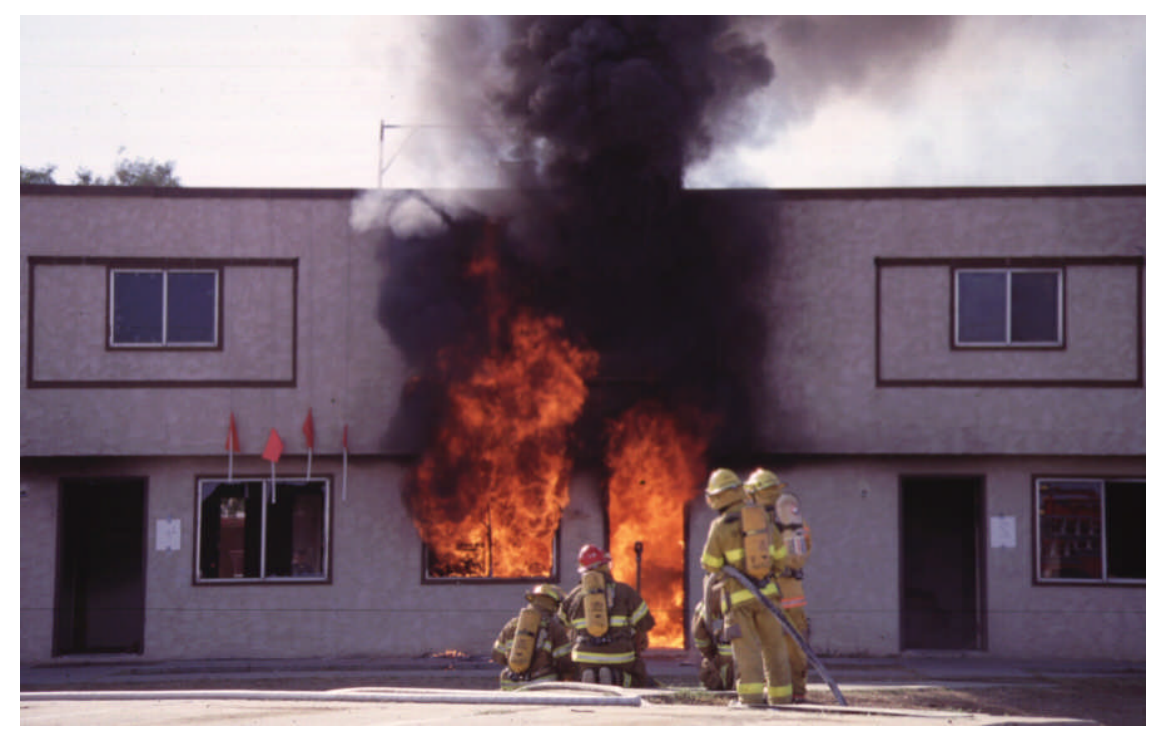

Figure 11. Full-scale townhouse fire test used to expose instrumented mannequin.

total heat flux gauges, one oriented parallel to the floor and one positioned perpendicular to the floor, were mounted next to the mannequin to monitor horizontal and vertical components of thermal radiation and heat flux. A vertical array of thermocouples was located next to the mannequin. Thermocouple beads with diameters of $2 \mathrm{~mm}(0.08 \mathrm{in})$ were spaced at $0.31 \mathrm{~m}$ (12 in) intervals from ceiling to floor. The thermocouple elevations are shown on Figure 8. The mannequin was positioned so that it faced the fuel package that was to be ignited. The kneeling mannequin was mounted on a platform $0.05 \mathrm{~m}$ ( 2 in) above the floor. The platform incorporated wheels that allowed the mannequin to be withdrawn into the kitchen area. If the specific fuel/ventilation/suppression configuration required the room to extend to flashover then the mannequin was pulled back or retreated into the kitchen area (Figure 12). Once the mannequin had been retreated into the kitchen, a fire resistant curtain was dropped in front of the mannequin to shield it from additional thermal radiation and hot gases.

\section{Analog Signal from PASS Devices}

Each PASS device was modified so that the alarm/no alarm status of each individual device could be continuously monitored by a data acquisition system. Two different techniques were used to extract an analog signal from each PASS device as it alarmed. The first method was to monitor the voltage signal at the piezo-electric disk while the second method was to track the battery voltage. PASS devices typically incorporate a piezo-electic disc to generate a 95 decibel alarm signal. When a voltage is applied across a piezo-electric material, such as quartz or barium titanate, the electrical energy is converted to mechanical energy. The mechanical motion of a disc creates the alarm signal. Monitoring the piezo-electric voltage provided a relatively stable signal that typically was near zero until the device began to alarm. When the alarm was activated the amplitude increased dramatically and exhibited high frequency 


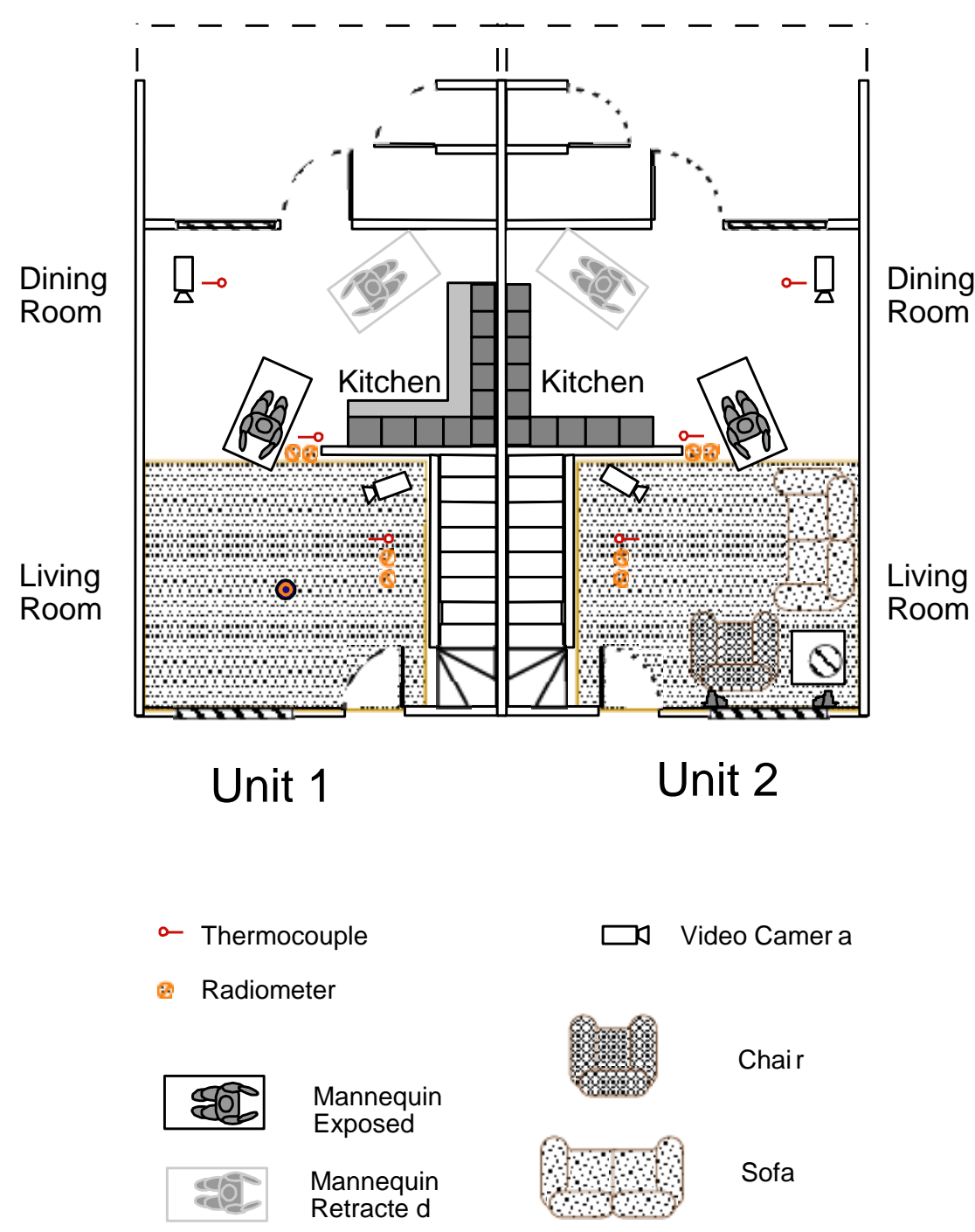

Figure 12. Diagram of townhouse floor plan.

fluctuations. The voltage to the piezo-electric disk could also be interrupted to disable the 95 decibel alarm signal. The second method of monitoring did not disable the alarm signal, but simply tracked the battery voltage. Tracking the battery voltage resulted in signal that steadily declined as the device functioned normally. This steady decline was expected as the electronics used electrical energy stored in the battery. As the alarm was activated, a dramatic decrease in the voltage occurred as the device began to draw more and more electrical energy out of the battery.

Both techniques worked equally well at marking the activation of the alarm. In either situation, there was a dramatic change in the voltage signal when the PASS device alarmed. A simple extension of monitoring the voltage to the piezo-electric disc was to interrupt the voltage and this disabled the alarm signal. Temporarily deactivating the alarm signal allowed personnel 
to conduct the test series without additional ear protection and caused less disturbance to nearby laboratories and offices. In the field experiments, having all six of the PASS device on the mannequin in alarm simultaneously would have required the operator to wear ear protection, earplugs or ear muffs. Monitoring the piezo-electric signal in the field again allowed for the experiments to be conducted without ear protection.

\section{E. Vibration or Shaker Device}

As each thermal sensor was being exposed to a different thermal environment, whether it was a static oven, flow loop, or full-scale fire test, it was necessary to prevent the PASS device from alarming due to lack of motion. The lack of motion detector and thermal exposure sensor shared the same piezo-electric disks to generate the 95 decibel alarm signal. An alarm from the lack of motion could have been confused with the alarm from the thermal sensor. To prevent this confusion, each PASS device was connected to a shaker or vibration inducing device. The shaker cause a relatively small movement, typically less than $0.013 \mathrm{~m}(0.5 \mathrm{in})$, and this was sufficient motion to prevent the motion detector from activating the alarm. For the lab-scale tests in the static oven and flow loop the shaker device was attached to each PASS device via high temperature wire and periodically lifted the device and allowed the PASS to drop back down approximately 4 to 5 times a minute.

For the field experiments, it was impractical to use the lab-scale device to shake the PASS devices mounted on the mannequin. The lab-scale shaker was relatively large and was powered via 120 volt AC house electricity. For the field work, smaller battery powered shakers, each $2.54 \mathrm{~cm}$ ( 1 in) diameter and $8.9 \mathrm{~cm}(3.5 \mathrm{in})$ long, were attached to the harness that held the three PASS devices on the front and three devices on the rear of the mannequin. Two of the battery powered vibration devices appear as white cylindrical shaped objects in between the PASS devices in Figure 9 and blue rectangles in Figure 8. Each of the small shakers incorporated a small direct current (DC) motor that moved a small weight that resulted in a slight movement of the shaker. Since each of the vibration inducing devices was attached to the same harness the secured the PASS devices, the vibrations were transmitted to the PASS devices. Multiple shakers were necessary to obtain sufficient movement or vibrations to prevent the PASS devices from alarming due to lack of motion.

\section{F. Data Acquisition System}

The analog voltage signal from each PASS device as well as the electrical signal from each of the thermocouples were connected to a 12 channel (Model CRX-23) or 70 channel (Model CR-7) portable data acquisition system from Campbell Scientific Instruments. The 12 channel system was used for the static oven and flow loop experiments while the 70 channel system was utilized in the field experiments. Both of these battery powered data collection boxes recorded the PASS and thermocouple data at $2 \mathrm{~s}$ intervals. The software available with the data acquisition system also allowed the temperatures and alarm status of the PASS devices to be continuously monitored via a laptop computer. 


\section{Results}

For each of the tests, the response of a PASS device and the temperature were monitored as a function of time. Five different models from four different manufacturers were included in this study. The focus of this study was to help develop a standard test protocol for testing thermal sensors, not to specifically evaluate the performance of any single PASS device. Each model of PASS device was assigned an alphabetic letter as an identifier, such A, B, C, D, or E. Since there were multiple devices of each model, the first device was assigned the number B-1 and the second B-2, and the third, B-3. Devices A through C included thermal sensors and devices $\mathrm{D}$ and $\mathrm{E}$ did not include thermal sensors. The response and temperature data for the laboratory tests are plotted versus time in Figures 13 - 15, and 16 - 18 for the static oven and flow loop tests, respectively. For the full-scale tests, each PASS device response, temperature and total heat flux are plotted in Figures $19-22$.

\section{A. Static Oven Tests}

As shown in Figure 13 - 15, the each test was started with the temperature at less than $25^{\circ} \mathrm{C}\left(77^{\circ} \mathrm{F}\right)$. Over a period of time, ranging from 25 minutes to 60 minutes, the oven temperature was gradually increased to $120{ }^{\circ} \mathrm{C}\left(250{ }^{\circ} \mathrm{F}\right)$. At temperatures above $120^{\circ} \mathrm{C}(250$ $\left.{ }^{\circ} \mathrm{F}\right)$, all the PASS devices began to emit odors that were suggestive of thermal decomposition and since these PASS devices were also needed for flow tests and full scale tests, the static oven tests were limited to $120{ }^{\circ} \mathrm{C}\left(250{ }^{\circ} \mathrm{F}\right)$ exposures. As the temperature inside the oven increased, the PASS device would activate its alarm. For each test, alarm activation caused a change in the analog signal from the PASS device. The corresponding gas or air temperature at the time of this alarm activation was recorded as the alarm temperature. Each alarm activation was confirmed visually by the test operator who examined the LEDs on the front of each PASS device.

For PASS Device Model A, the average temperature (for each unit) at which the thermal exposure sensor alarmed for three different units was $98{ }^{\circ} \mathrm{C}\left(210{ }^{\circ} \mathrm{F}\right)$ to $100{ }^{\circ} \mathrm{C}\left(212{ }^{\circ} \mathrm{F}\right)$. Individual test alarm activations occurred between $88^{\circ} \mathrm{C}\left(190{ }^{\circ} \mathrm{F}\right)$ and $105^{\circ} \mathrm{C}\left(220^{\circ} \mathrm{F}\right)$. As shown in Figure 13, Model A-2 alarmed at $103{ }^{\circ} \mathrm{C}\left(217{ }^{\circ} \mathrm{F}\right)$ at $2170 \mathrm{~s}$ into the test. For PASS Device Model B, the average temperature at which the thermal exposure sensor alarmed for three different units was $82{ }^{\circ} \mathrm{C}\left(190{ }^{\circ} \mathrm{F}\right)$ to $98{ }^{\circ} \mathrm{C}\left(208{ }^{\circ} \mathrm{F}\right)$ which is slightly lower temperatures than for Model A. Individual test alarm activations occurred between $81{ }^{\circ} \mathrm{C}\left(178{ }^{\circ} \mathrm{F}\right)$ and $98{ }^{\circ} \mathrm{C}\left(208{ }^{\circ} \mathrm{F}\right)$. As shown in Figure 14, Model B-3 alarmed at $94{ }^{\circ} \mathrm{C}\left(201{ }^{\circ} \mathrm{F}\right)$ at $1880 \mathrm{~s}$ into the test. For PASS Device Model $\mathrm{C}$, the average temperature at which the thermal exposure sensor alarmed for three different units was $93{ }^{\circ} \mathrm{C}\left(199{ }^{\circ} \mathrm{F}\right)$ to $110{ }^{\circ} \mathrm{C}\left(230^{\circ} \mathrm{F}\right)$ which is slightly higher temperatures than for Model A. Individual test alarm activations occurred between $80{ }^{\circ} \mathrm{C}\left(176{ }^{\circ} \mathrm{F}\right)$ and $122{ }^{\circ} \mathrm{C}$ $\left(252{ }^{\circ} \mathrm{F}\right)$. As shown in Figure 15, Model C-2 alarmed at $90{ }^{\circ} \mathrm{C}\left(194{ }^{\circ} \mathrm{F}\right)$ at 2630 s into the test. The static oven temperature versus response data for each of the PASS devices is included in Table 1. Overall, the reproducibility between different PASS devices from the same manufacture was relatively good. The range of alarm temperatures for Model A and Model B was $17{ }^{\circ} \mathrm{C}\left(31^{\circ} \mathrm{F}\right)$ and for all tests and all units. Model $\mathrm{C}$ exhibited a much larger variation in temperatures with a range of $42{ }^{\circ} \mathrm{C}\left(76^{\circ} \mathrm{F}\right)$. The greatest variation in alarm temperatures was also exhibited by Model $\mathrm{C}$ devices. 


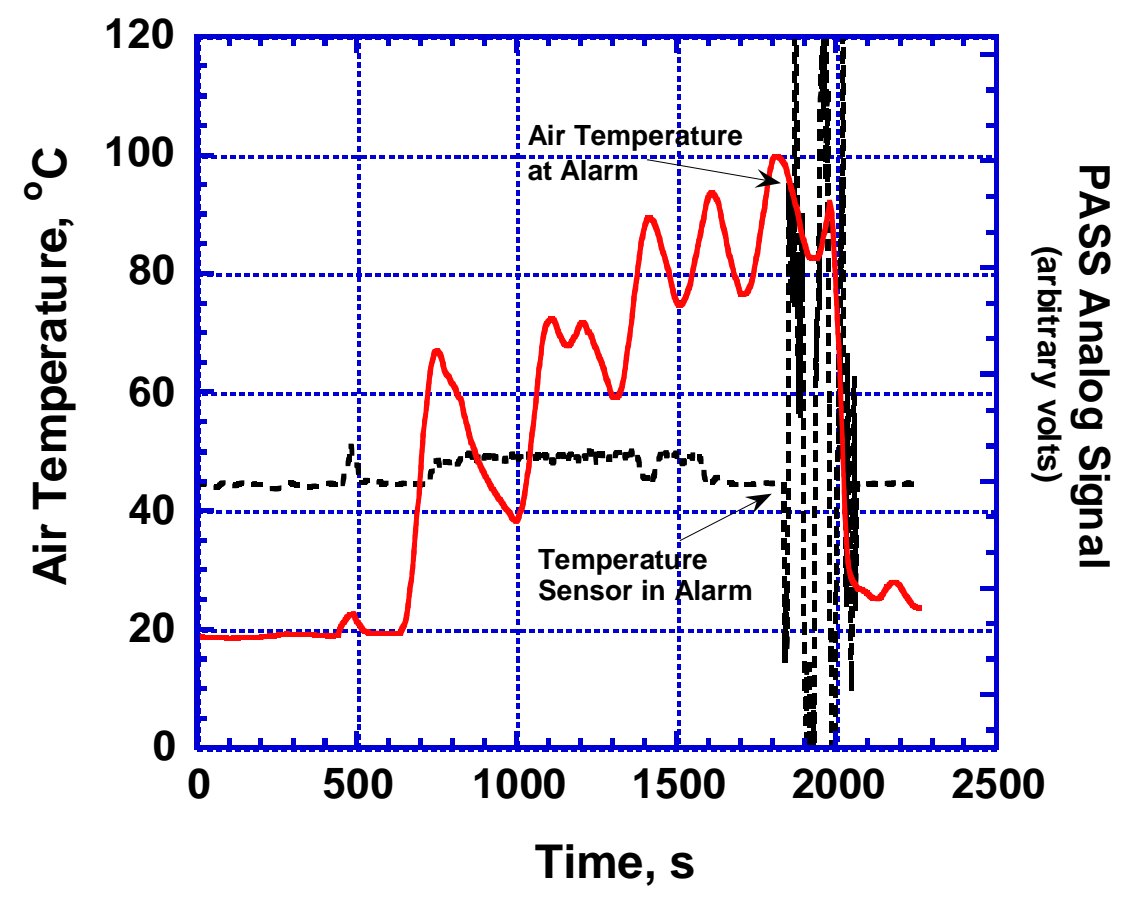

Figure 13. Static oven gas temperature versus PASS analog signal for device A-2.

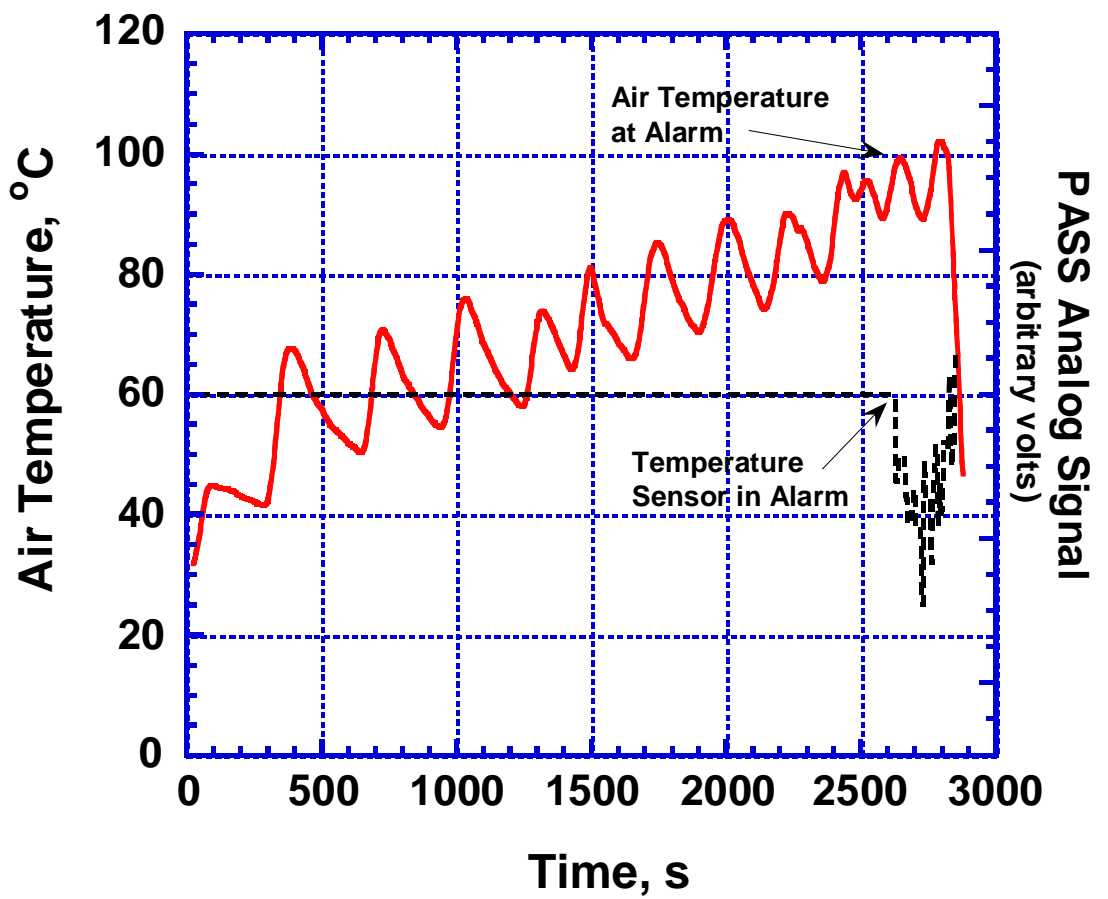

Figure 14. Static oven gas temperature versus PASS analog signal for device B-3. 


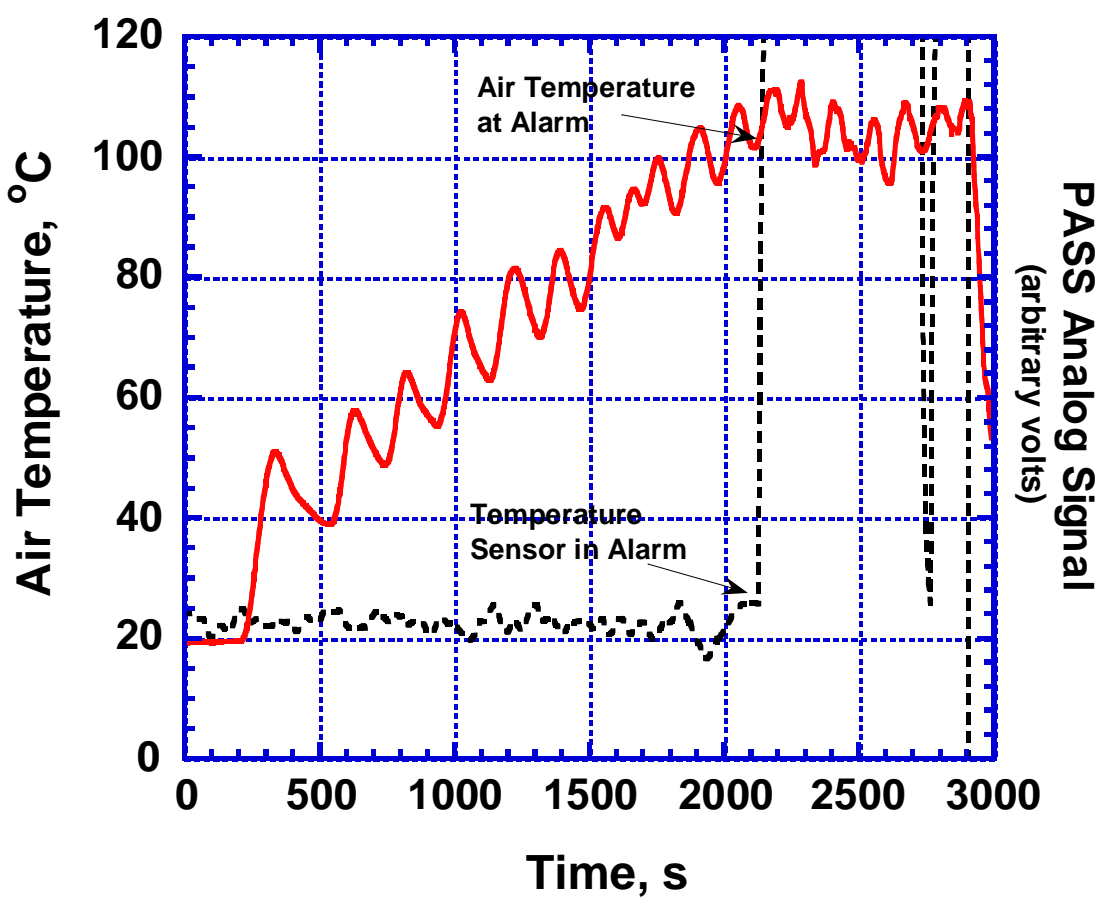

Figure 15. Static oven gas temperature versus PASS analog signal for device C-2.

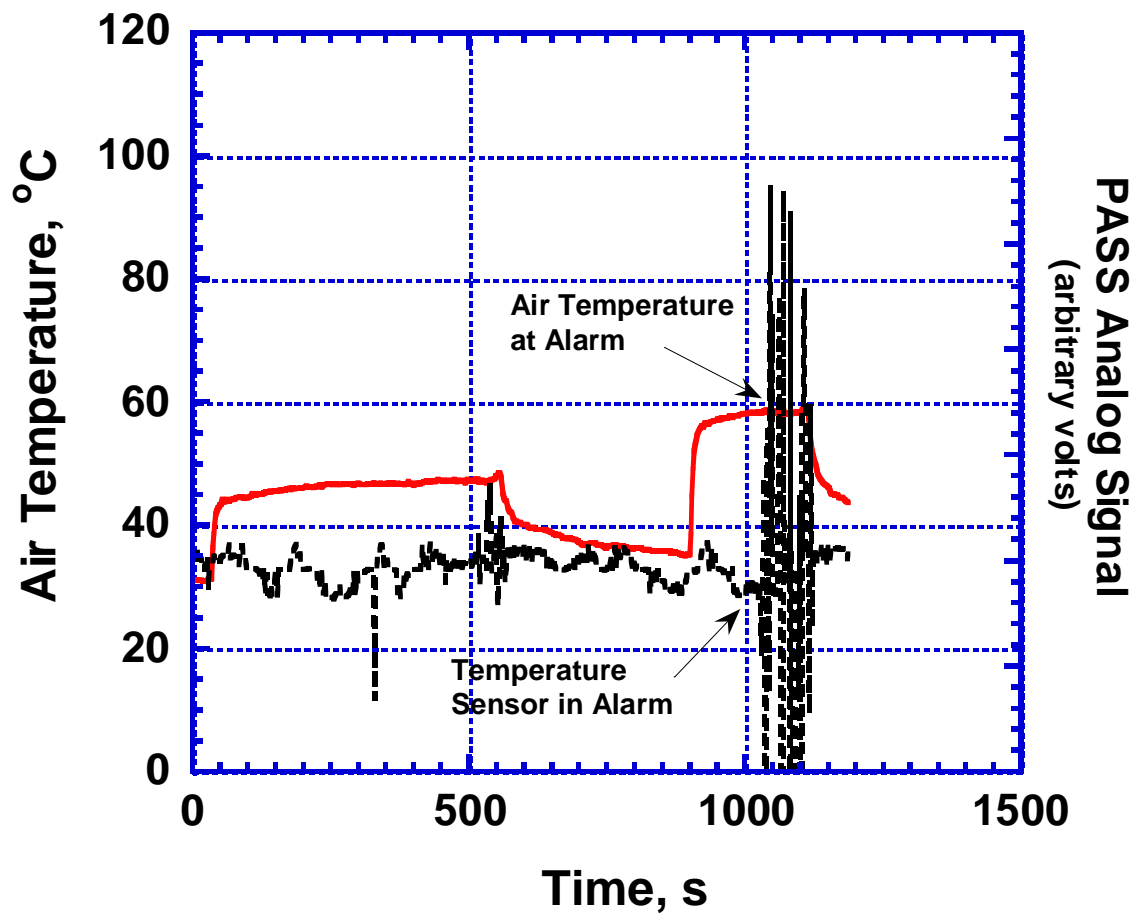

Figure 16. Flow loop gas temperature versus PASS analog signal for device A-1. 
Table 1. Static oven exposure tests for PASS devices.

\begin{tabular}{|c|c|c|c|}
\hline $\begin{array}{l}\text { PASS } \\
\text { Device }\end{array}$ & $\begin{array}{c}\text { Range of } \\
\text { Alarm } \\
\text { Temperature }\end{array}$ & $\begin{array}{c}\text { Average } \\
\text { Alarm } \\
\text { Temperature }\end{array}$ & $\begin{array}{c}\text { Number } \\
\text { of } \\
\text { Tests }\end{array}$ \\
\hline \multicolumn{4}{|l|}{ Model A } \\
\hline A-1 & $\begin{array}{c}89{ }^{\circ} \mathrm{C}-105{ }^{\circ} \mathrm{C} \\
\left(192{ }^{\circ} \mathrm{F}-221{ }^{\circ} \mathrm{F}\right)\end{array}$ & $\begin{array}{c}99^{\circ} \mathrm{C} \\
\left(210^{\circ} \mathrm{F}\right)\end{array}$ & 4 \\
\hline A-2 & $\begin{array}{c}93{ }^{\circ} \mathrm{C}-105^{\circ} \mathrm{C} \\
\left(199{ }^{\circ} \mathrm{F}-221^{\circ} \mathrm{F}\right)\end{array}$ & $\begin{array}{l}100{ }^{\circ} \mathrm{C} \\
\left(212{ }^{\circ} \mathrm{F}\right)\end{array}$ & 3 \\
\hline A-3 & $\begin{array}{l}88{ }^{\circ} \mathrm{C}-105{ }^{\circ} \mathrm{C} \\
\left(190{ }^{\circ} \mathrm{F}-221{ }^{\circ} \mathrm{F}\right)\end{array}$ & $\begin{array}{c}98{ }^{\circ} \mathrm{C} \\
\left(208^{\circ} \mathrm{F}\right)\end{array}$ & 4 \\
\hline \multicolumn{4}{|l|}{ Model B } \\
\hline B-1 & $\begin{array}{c}81{ }^{\circ} \mathrm{C}-98{ }^{\circ} \mathrm{C} \\
\left(178{ }^{\circ} \mathrm{F}-208{ }^{\mathrm{o}} \mathrm{F}\right)\end{array}$ & $\begin{array}{c}87{ }^{\circ} \mathrm{C} \\
\left(189^{\circ} \mathrm{F}\right)\end{array}$ & 4 \\
\hline B-2 & $\begin{array}{c}82{ }^{\circ} \mathrm{C}-93{ }^{\circ} \mathrm{C} \\
\left(187{ }^{\circ} \mathrm{F}-199{ }^{\circ} \mathrm{F}\right)\end{array}$ & $\begin{array}{c}88^{\circ} \mathrm{C} \\
\left(190^{\circ} \mathrm{F}\right)\end{array}$ & 5 \\
\hline B-3 & $\begin{array}{c}86{ }^{\circ} \mathrm{C}-97{ }^{\circ} \mathrm{C} \\
\left(187{ }^{\circ} \mathrm{F}-207{ }^{\circ} \mathrm{F}\right)\end{array}$ & $\begin{array}{c}92{ }^{\circ} \mathrm{C} \\
\left(198{ }^{\circ} \mathrm{F}\right)\end{array}$ & 4 \\
\hline \multicolumn{4}{|l|}{ Model C } \\
\hline C-1 & $\begin{array}{l}109{ }^{\circ} \mathrm{C}-114^{\circ} \mathrm{C} \\
\left(228{ }^{\circ} \mathrm{F}-237{ }^{\mathrm{o}} \mathrm{F}\right)\end{array}$ & $\begin{array}{c}110^{\circ} \mathrm{C} \\
\left(230^{\circ} \mathrm{F}\right) \\
\end{array}$ & 3 \\
\hline $\mathrm{C}-2$ & $\begin{array}{c}87^{\circ} \mathrm{C}-98{ }^{\circ} \mathrm{C} \\
\left(189^{\circ} \mathrm{F}-208{ }^{\circ} \mathrm{F}\right)\end{array}$ & $\begin{array}{c}93{ }^{\circ} \mathrm{C} \\
\left(199^{\circ} \mathrm{F}\right)\end{array}$ & 2 \\
\hline $\mathrm{C}-3$ & $\begin{array}{c}80{ }^{\circ} \mathrm{C}-122{ }^{\circ} \mathrm{C} \\
\left(176{ }^{\circ} \mathrm{F}-252{ }^{\circ} \mathrm{F}\right)\end{array}$ & $\begin{array}{c}98^{\circ} \mathrm{C} \\
\left(208^{\circ} \mathrm{F}\right)\end{array}$ & 5 \\
\hline
\end{tabular}

\section{B. Flow Loop Tests}

As shown in Figure 16 - 18, the each test was started with the temperature at less than $25^{\circ} \mathrm{C}\left(77^{\circ} \mathrm{F}\right)$. Over a period of time, ranging from 30 minutes to 150 minutes, the loop air temperature was gradually increased to $120^{\circ} \mathrm{C}\left(250{ }^{\circ} \mathrm{F}\right)$. Because additional time was necessary for the flow loop air temperature to stabilize after a step change, the duration of the flow loop tests were significantly longer than for the static oven tests. As the temperature 


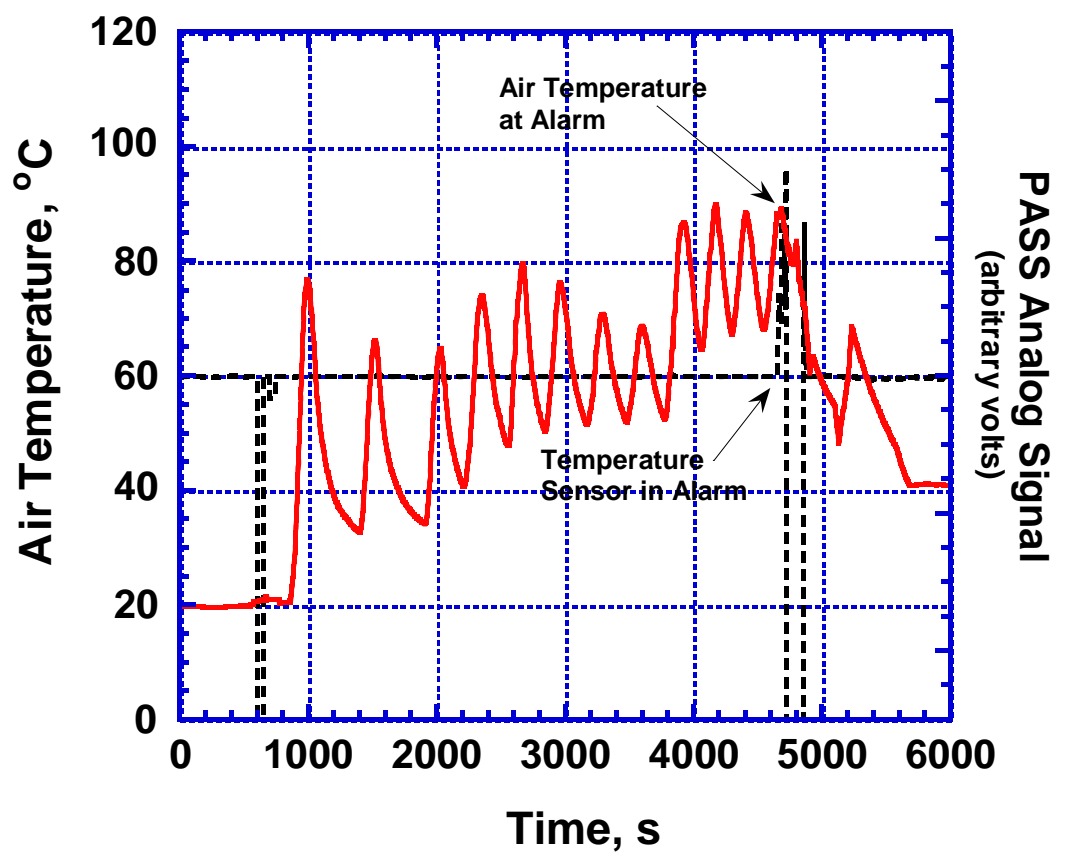

Figure 17. Flow loop gas temperature versus PASS analog signal for device B-4.

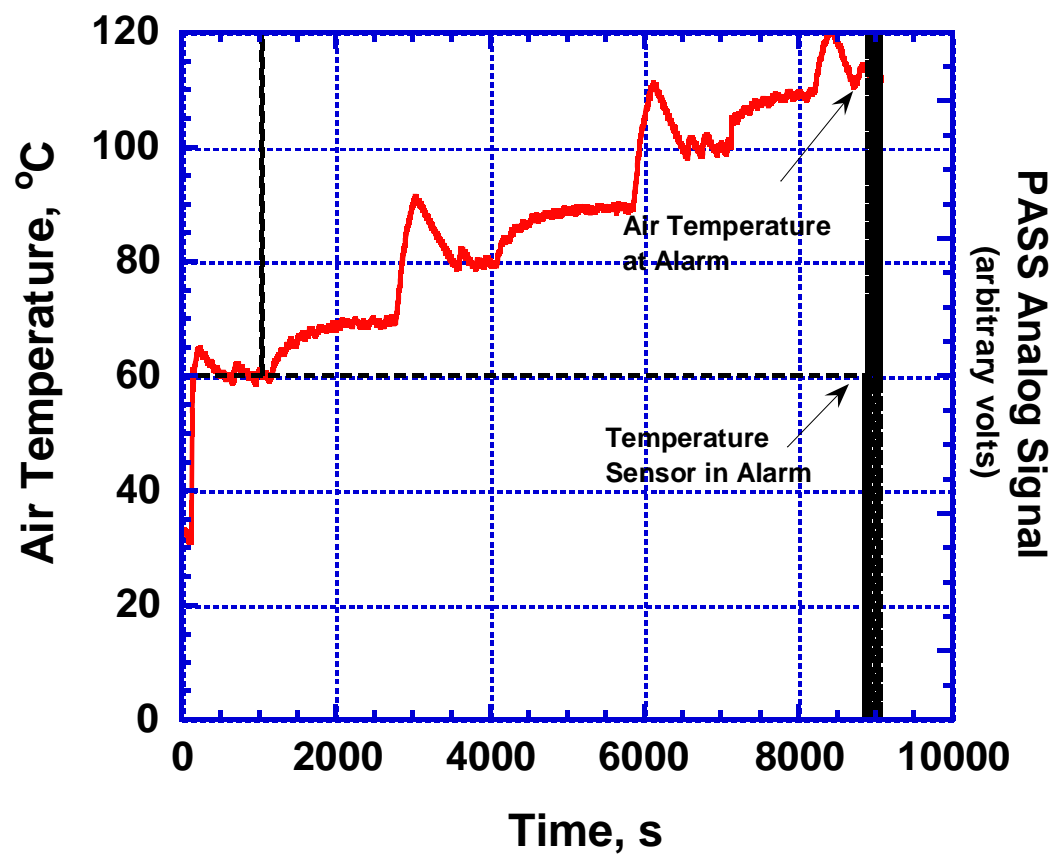

Figure 18. Flow loop gas temperature versus PASS analog signal for device C-3. 
inside the loop increased, the PASS device would activate its alarm. For each test, alarm activation caused a change in the analog signal from the PASS device. The corresponding gas or air temperature at the time of this alarm activation was recorded as the alarm temperature. Each alarm activation was confirmed visually by the test operator by examining the LEDs on the front of the device.

For PASS Device Model A, the average temperature (for each device) at which the thermal exposure sensor alarmed for three different units was $47{ }^{\circ} \mathrm{C}\left(117{ }^{\circ} \mathrm{F}\right)$ to $58{ }^{\circ} \mathrm{C}\left(136{ }^{\circ} \mathrm{F}\right)$. Individual test alarm activations occurred between $41{ }^{\circ} \mathrm{C}\left(106{ }^{\circ} \mathrm{F}\right)$ and $61{ }^{\circ} \mathrm{C}\left(142{ }^{\circ} \mathrm{F}\right)$. As shown in Figure 16, Model A-1 alarmed at $59{ }^{\circ} \mathrm{C}\left(138^{\circ} \mathrm{F}\right)$ at $1030 \mathrm{~s}$ into the test. For PASS Device Model $\mathrm{B}$, the average temperature at which the thermal exposure sensor alarmed for two different units was $70{ }^{\circ} \mathrm{C}\left(158{ }^{\circ} \mathrm{F}\right)$ to $73{ }^{\circ} \mathrm{C}\left(163{ }^{\circ} \mathrm{F}\right)$ which is slightly higher temperatures than for Model A. Individual test alarm activations occurred between $55^{\circ} \mathrm{C}\left(131{ }^{\circ} \mathrm{F}\right)$ and $90{ }^{\circ} \mathrm{C}$ $\left(194{ }^{\circ} \mathrm{F}\right)$. As shown in Figure 17, Model B-4 alarmed at $90{ }^{\circ} \mathrm{C}\left(194{ }^{\circ} \mathrm{F}\right)$ at 4650 s into the test.

Table 2. Flow loop exposure tests for PASS devices.

\begin{tabular}{|c|c|c|c|}
\hline PASS Device & $\begin{array}{c}\text { Range of } \\
\text { Alarm } \\
\text { Temperatures }\end{array}$ & $\begin{array}{c}\text { Average } \\
\text { Alarm } \\
\text { Temperature }\end{array}$ & $\begin{array}{c}\text { Number of } \\
\text { Tests }\end{array}$ \\
\hline \multicolumn{4}{|l|}{ Model A } \\
\hline A-1 & $\begin{array}{c}50{ }^{\circ} \mathrm{C}-61{ }^{\circ} \mathrm{C} \\
\left(122{ }^{\circ} \mathrm{F}-142{ }^{\circ} \mathrm{F}\right)\end{array}$ & $\begin{array}{c}56{ }^{\circ} \mathrm{C} \\
\left(133{ }^{\circ} \mathrm{F}\right)\end{array}$ & 4 \\
\hline A-2 & $\begin{array}{c}58{ }^{\circ} \mathrm{C} \\
\left(136{ }^{\circ} \mathrm{F}\right) \\
\end{array}$ & $\begin{array}{c}58{ }^{\circ} \mathrm{C} \\
\left(136^{\circ} \mathrm{F}\right)\end{array}$ & 1 \\
\hline A-3 & $\begin{array}{c}41{ }^{\circ} \mathrm{C}-50^{\circ} \mathrm{C} \\
\left(106{ }^{\circ} \mathrm{F}-122^{\circ} \mathrm{F}\right)\end{array}$ & $\begin{array}{c}47^{\circ} \mathrm{C} \\
\left(117^{\circ} \mathrm{F}\right)\end{array}$ & 3 \\
\hline \multicolumn{4}{|l|}{ Model B } \\
\hline B-2 & $\begin{array}{c}70^{\circ} \mathrm{C} \\
\left(158^{\circ} \mathrm{F}\right)\end{array}$ & $\begin{array}{c}70{ }^{\circ} \mathrm{C} \\
\left(158{ }^{\circ} \mathrm{F}\right)\end{array}$ & 1 \\
\hline B-4 & $\begin{array}{c}55^{\circ} \mathrm{C}-90^{\circ} \mathrm{C} \\
\left(131^{\circ} \mathrm{F}-194^{\circ} \mathrm{F}\right) \\
\end{array}$ & $\begin{array}{c}73{ }^{\circ} \mathrm{C} \\
\left(163{ }^{\circ} \mathrm{F}\right) \\
\end{array}$ & 2 \\
\hline \multicolumn{4}{|l|}{ Model C } \\
\hline $\mathrm{C}-2$ & $\begin{array}{c}90^{\circ} \mathrm{C}-113{ }^{\circ} \mathrm{C} \\
\left(194{ }^{\circ} \mathrm{F}-235^{\circ} \mathrm{F}\right)\end{array}$ & $\begin{array}{c}102{ }^{\circ} \mathrm{C} \\
\left(216^{\circ} \mathrm{F}\right) \\
\end{array}$ & 4 \\
\hline
\end{tabular}


For PASS Device Model C, the average temperature at which the thermal exposure sensor alarmed for a single unit was $102{ }^{\circ} \mathrm{C}\left(216^{\circ} \mathrm{F}\right)$ which is slightly higher temperatures than for Model A or B. Individual test alarm activations occurred between $90{ }^{\circ} \mathrm{C}\left(194{ }^{\circ} \mathrm{F}\right)$ and $113{ }^{\circ} \mathrm{C}$ $\left(235^{\circ} \mathrm{F}\right)$. As shown in Figure 18, Model C-3 alarmed at $113{ }^{\circ} \mathrm{C}\left(235^{\circ} \mathrm{F}\right)$ at 8900 s into the test. The flow loop temperature versus response data for each of the PASS devices is included in Table 2. Overall, the reproducibility between different PASS devices from the same manufacturer was not as good as for the static oven tests. The range of alarm temperatures for Model A was $17{ }^{\circ} \mathrm{C}\left(31^{\circ} \mathrm{F}\right)$ for all tests and all units. Model B demonstrated a wider range of $35^{\circ} \mathrm{C}\left(63{ }^{\circ} \mathrm{F}\right)$ for the flow tests Model $\mathrm{C}$ exhibited a somewhat lower variation in temperatures with a range of $23{ }^{\circ} \mathrm{C}\left(41^{\circ} \mathrm{F}\right)$, but all four tests exposed the same PASS device, C-2. Model B-4 also exhibited the widest range alarm temperatures.

\section{Full-Scale Mannequin Experiments}

Data was collected from an instrumented mannequin that was exposed to realistic thermal conditions during a series of townhouse field burns. The mannequin was positioned between the kitchen and living room (Figure 12). An array of thermocouples was positioned next to the mannequin to monitor gas temperatures from floor to ceiling. Two total heat flux gauges were located next to the thermocouple array (Figures 8 and 12). One flux gauge was positioned vertically (looking at the ceiling) in order to track the thermal radiation from the upper layer. The other flux gauge was positioned horizontally (looking at the fire) to allow it to monitor the thermal radiation from the initial fuel package. The flux gauge viewing the upper layer would monitor the thermal flux that the shoulders and helmet might experience from the upper layer as he/she knelt in a room containing an active fire. The flux gauge viewing the fuel package would monitor the thermal flux that the front side of the fire fighter might experience as he/she faces the fire. For Unit 1 and Unit 2, $1 \mathrm{~L}(0.26 \mathrm{gal})$ of gasoline was poured on the center of the carpet and ignited. Unit 3 was ignited using crumpled up newspaper in the corner of the sofa.

Gas temperatures, thermal sensor activation, and thermal heat fluxes for the full-scale test in Unit 1 are plotted in Figures 19 - 24. For Unit 1, a thermocouple array from floor to ceiling was $10 \mathrm{~cm}$ to the left of the mannequin's left shoulder and had thermocouples located at approximately $30 \mathrm{~cm}(12 \mathrm{in})$ intervals. The left shoulder of the turn-out gear on the mannequin was $108 \mathrm{~cm}$ (42.5 in) above the floor and the centerline of the PASS devices was $95 \mathrm{~cm}$ (37.4 in) above the floor. Peak temperature (room) for the gasoline fire in Unit 1 was approximately $181{ }^{\circ} \mathrm{C}\left(358{ }^{\circ} \mathrm{F}\right)$ at $200 \mathrm{~cm}(78.7 \mathrm{in})$ above the floor and was recorded at $260 \mathrm{~s}$ (Figure 19). The total heat flux peaked at $30 \mathrm{~kW} / \mathrm{m}^{2}$ and $21 \mathrm{~kW} / \mathrm{m}^{2}$ for the horizontal and vertical gauges, respectively (Figure 20). The horizontal or fuel package flux gauge reported higher values of thermal flux earlier in the burn than the vertical flux gauge. This would be consistent with the fire fighter experiencing most of the thermal radiation directly from the fire initially because the upper layer requires additional time to form a hot layer of gases.

The analog signal from the thermal sensor and the temperatures for $200 \mathrm{~cm}(78.7 \mathrm{in})$, $110 \mathrm{~cm}$ (43.3 in), and $80 \mathrm{~cm}$ (31.5 in) above the floor are plotted in both Figures 21 and 22. The $200 \mathrm{~cm}$ thermocouple tracked gas temperatures $30 \mathrm{~cm}$ (12 in) below the ceiling. 


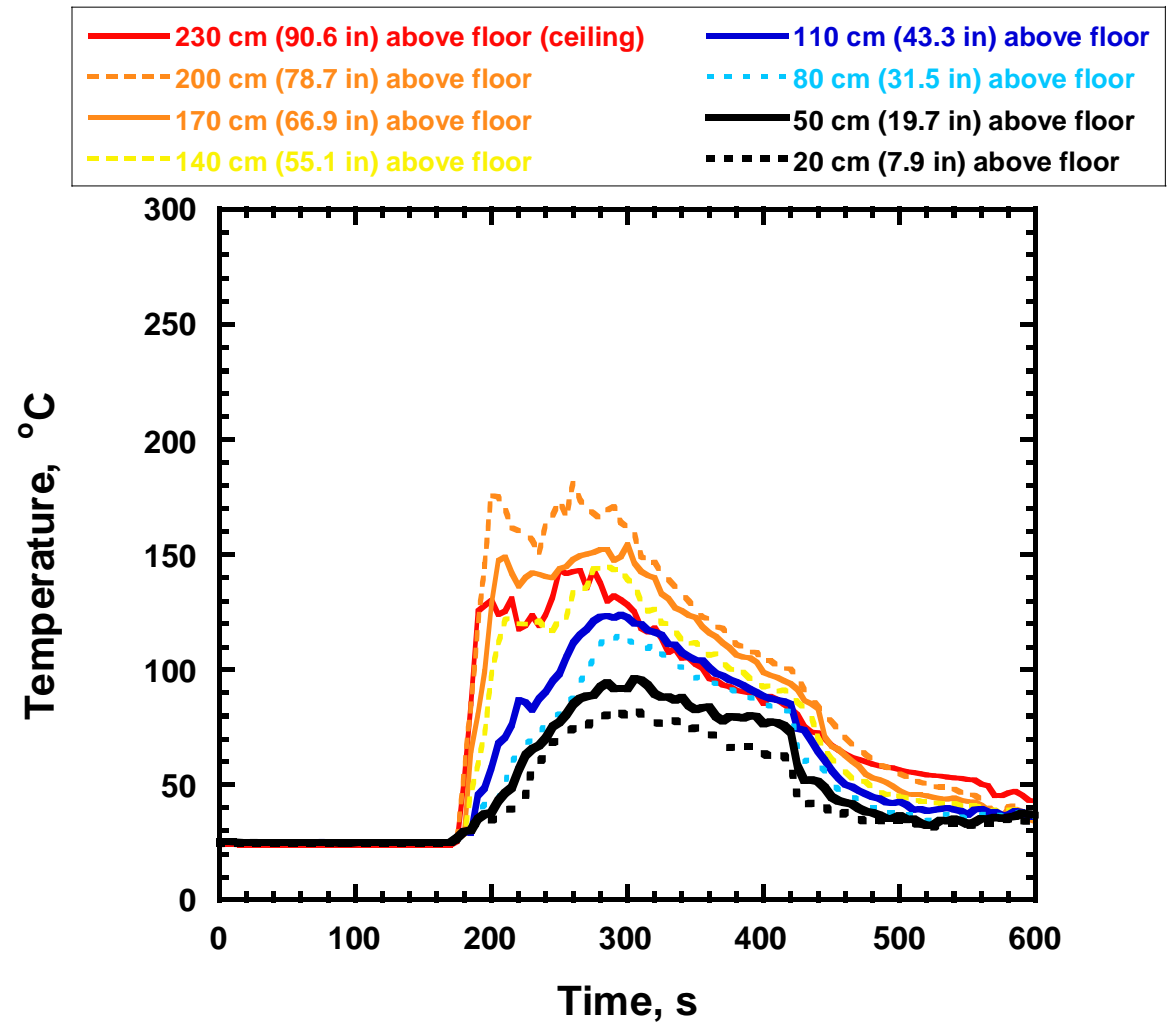

Figure 19. Gas temperatures versus time for full-scale townhouse burn in Unit 1.

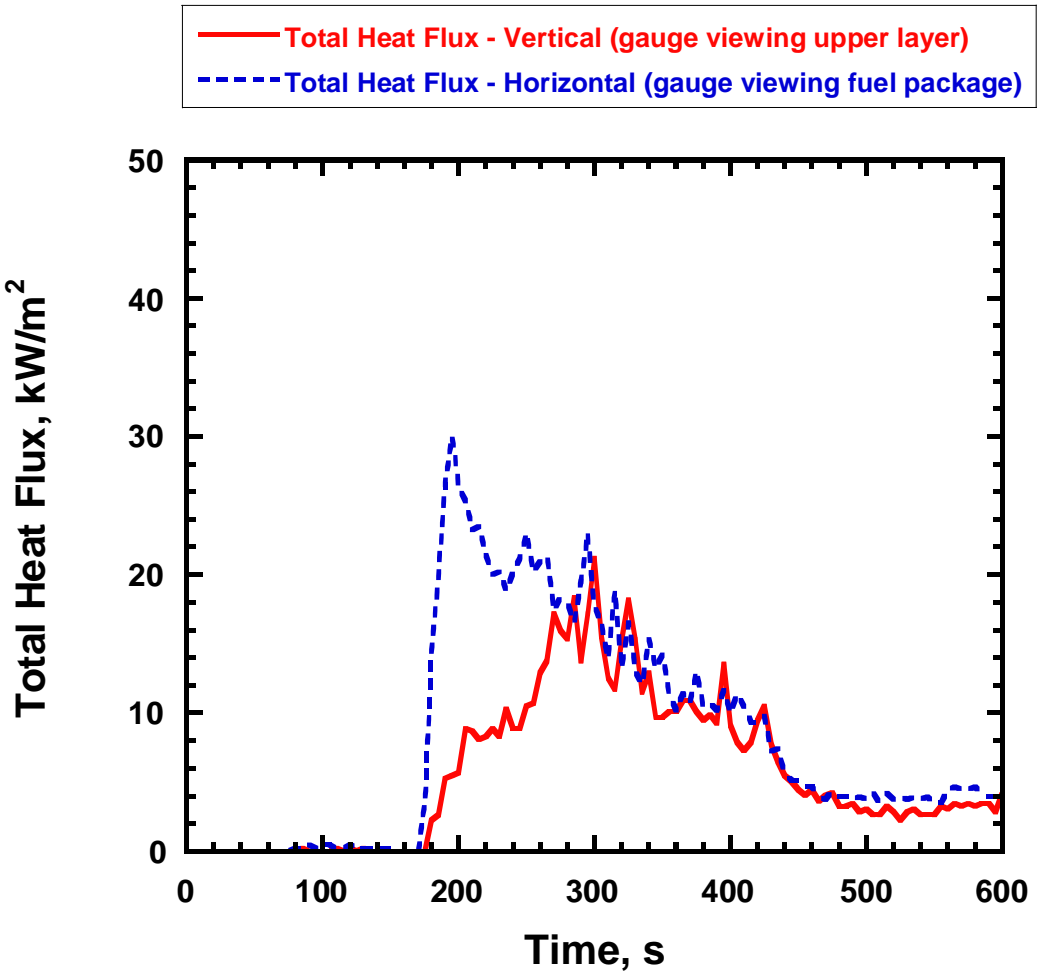

Figure 20. Thermal heat flux versus time for full-scale townhouse burn in Unit 1 . 


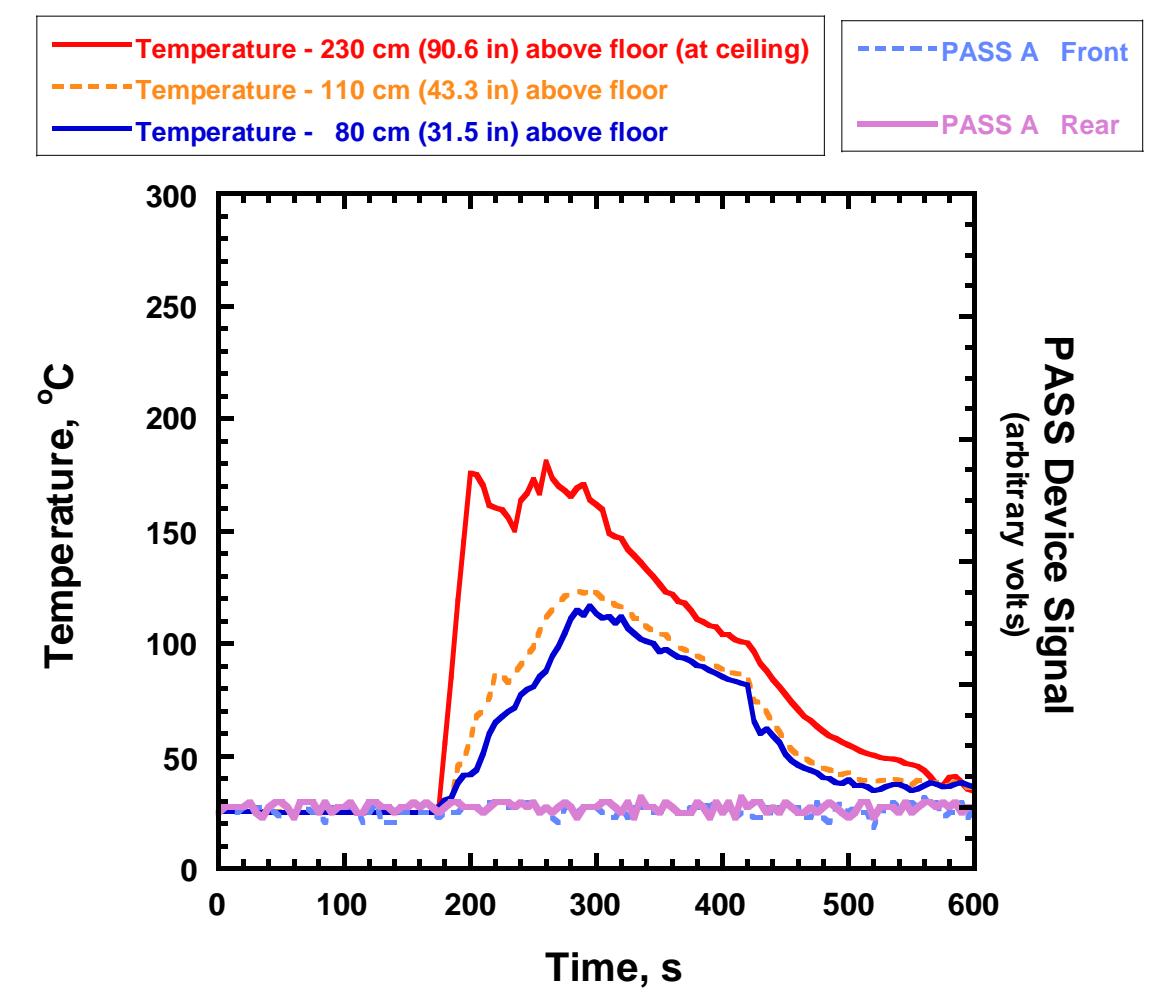

Figure 21. Gas temperature (room) versus thermal sensor activation for A model PASS devices on front and rear of mannequin in Unit 1.

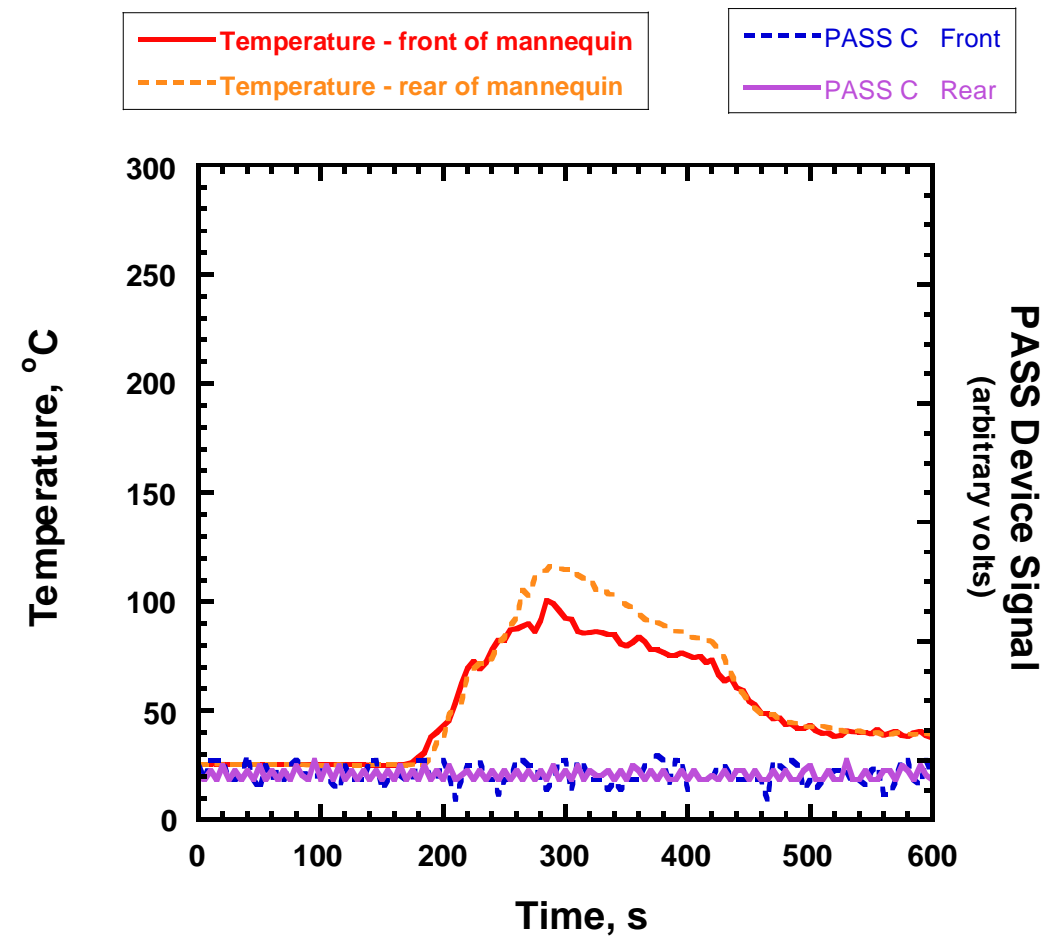

Figure 22. Gas temperature (room) versus thermal sensor activation for C model PASS devices on front and rear of mannequin in Unit 1. 


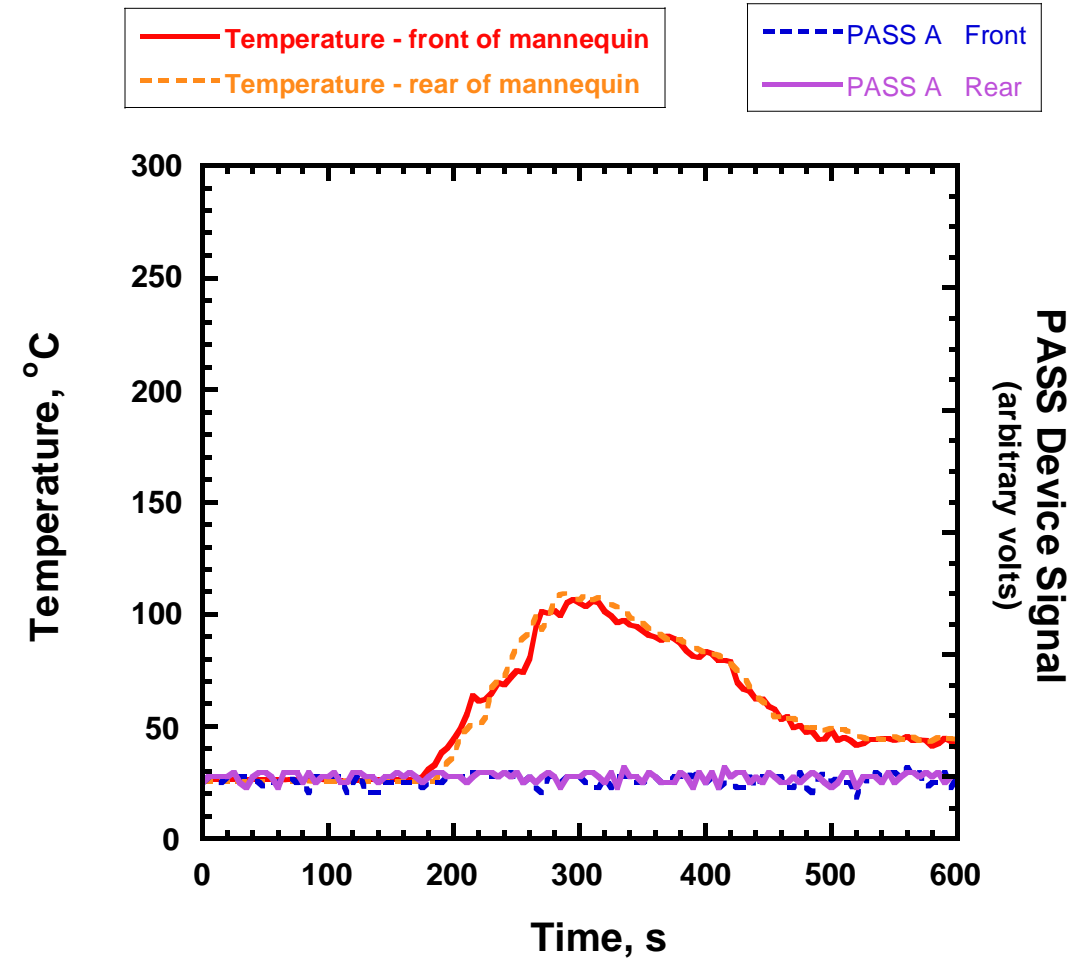

Figure 23. Gas temperature (mannequin front and rear) and thermal sensor activation for model A PASS devices in Unit 1.

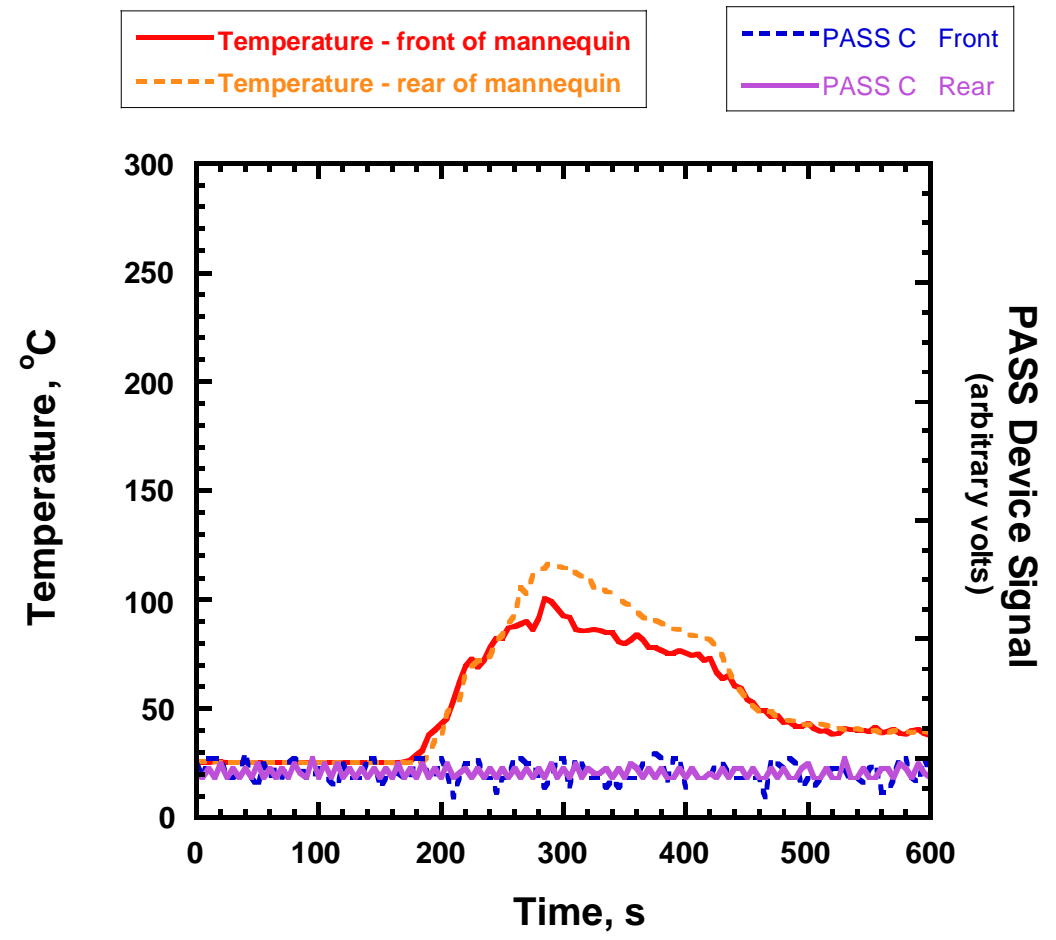

Figure 24. Gas temperature (mannequin front and rear) and thermal sensor activation for model C PASS devices in Unit 1. 
The $110 \mathrm{~cm}$ thermocouple was $2 \mathrm{~cm}$ (1 in) above the left shoulder and the thermocouple at $80 \mathrm{~cm}$ was $15 \mathrm{~cm}$ (6 in) below the PASS devices. PASS devices were positioned on the front and rear of the mannequin. The thermal environment of this burn did not cause any of the four PASS devices, front or rear to activate during this test (Figure 21 and 22). The peak temperature (room), time of peak at which the peak temperature (room) occurred, and the alarm activation time are tabulated in Table 3. In a similar manner the analog signal from the thermal sensor and the temperatures for front and rear of the mannequin near each PASS device are plotted in both Figures 23 and 24. The peak temperature (mannequin front and rear), time of peak at which the peak temperature (front and rear) occurred, and the alarm activation time are tabulated in Table 4.

Gas temperatures, thermal sensor activation, and thermal heat fluxes for the full-scale test in Unit 2 are plotted in Figures 25 - 30. For Unit 2, a thermocouple array from floor to ceiling was $10 \mathrm{~cm}$ to the left of the mannequin's left shoulder and had thermocouples located at approximately $30 \mathrm{~cm}$ (12 in) intervals. The left shoulder of the turn-out gear on the mannequin was $108 \mathrm{~cm}$ (42.5 in) above the floor and the centerline of the PASS devices was $95 \mathrm{~cm}$ (37.4 in) above the floor. Peak temperature (room) for the fire in Unit 2 was $306{ }^{\circ} \mathrm{C}\left(583{ }^{\circ} \mathrm{F}\right)$ at $200 \mathrm{~cm}$ (78.7 in) above the floor and was recorded at approximately $410 \mathrm{~s}$ (Figure 25). The total heat flux peaked at $97 \mathrm{~kW} / \mathrm{m}^{2}$ and $70 \mathrm{~kW} / \mathrm{m}^{2}$ for the horizontal and vertical gauges, respectively (Figure 26). The peak heat flux was much greater in Unit 2 than for Unit 1, however, the peak in Unit 2 is observed later as the additional fuel, including the sofa and chair, become involved in the fire. Early in the burn at about $210 \mathrm{~s}$, the vertical heat flux reaches a level of $40 \mathrm{~kW} / \mathrm{m}^{2}$ which is similar in magnitude to the peak heat flux in Unit 1 . This would be consistent with each of the fires in Unit 1 and 2 being initiated with $1 \mathrm{~L}(0.26 \mathrm{gal})$ of gasoline. However, it should be noted that in Unit 1, the horizontal heat flux reached about $30 \mathrm{~kW} / \mathrm{m}^{2}$ while in Unit 2 it was the vertical component of heat flux which reached $40 \mathrm{~kW} / \mathrm{m}^{2}$.

The analog signal from the thermal sensor and the temperatures for $200 \mathrm{~cm}(78.7 \mathrm{in})$, $110 \mathrm{~cm}$ (43.3 in), and $80 \mathrm{~cm}$ (31.5 in) above the floor are plotted in both Figures 27 and 28. The $200 \mathrm{~cm}$ thermocouple tracked gas temperatures $30 \mathrm{~cm}$ (12 in) below the ceiling. The $110 \mathrm{~cm}$ thermocouple was $2 \mathrm{~cm}(1 \mathrm{in})$ above the left shoulder and the thermocouple at $80 \mathrm{~cm}$ was $15 \mathrm{~cm}$ (6 in) below the PASS devices. PASS devices were positioned on the front and rear of the mannequin. The peak temperature (room) of $306{ }^{\circ} \mathrm{C}\left(583{ }^{\circ} \mathrm{F}\right)$ was reached at $410 \mathrm{~s}$ and only the rear mounted PASS devices activated during the fire in Unit 2. Model A-1 activated at $530 \mathrm{~s}$ (Figure 27) and Model C-3 alarmed at $485 \mathrm{~s}$ (Figure 28). The time between peak exposure (room) and thermal sensor activation was $120 \mathrm{~s}$ and $75 \mathrm{~s}$ for A-1 and C-3, respectively. In a similar manner the analog signal from the thermal sensor and the temperatures for front and rear of the mannequin near each PASS device are plotted in both Figures 29 and 30. The peak temperature (mannequin front and rear), time of peak at which the peak temperature (front and rear) occurred, and the alarm activation time are tabulated in Table 4.

Gas temperatures, thermal sensor activation, and thermal heat fluxes for the full-scale test in Unit 3 are plotted in Figures 31 - 36. For Unit 3, a thermocouple array from floor to ceiling was $10 \mathrm{~cm}$ to the left of the mannequin's left shoulder and had thermocouples located at approximately $30 \mathrm{~cm}$ (12 in) intervals. The left shoulder of the turn-out gear on the mannequin was $108 \mathrm{~cm}$ (42.5 in) above the floor and the centerline of the PASS devices was $95 \mathrm{~cm}$ (37.4 in) above the floor. Peak temperature for the fire in Unit 3 was $631{ }^{\circ} \mathrm{C}\left(1168{ }^{\circ} \mathrm{F}\right)$ at $200 \mathrm{~cm}$ (78.7 in) above the floor and was recorded at approximately $305 \mathrm{~s}$ (Figure 31). The total heat 
flux peaked at $150 \mathrm{~kW} / \mathrm{m}^{2}$ and $130 \mathrm{~kW} / \mathrm{m}^{2}$ for the horizontal and vertical gauges, respectively (Figure 32). The peak heat flux was much greater in Unit 3 than for Unit 1 or 2. The early rapid rise in heat flux that was observed in Unit 1 and 2 is missing in Unit 3, but Unit 3 was initiated by igniting a crumpled newspaper, not the gasoline as in Unit 1 and 2.

The analog signal from the thermal sensor and the temperatures for $200 \mathrm{~cm}(78.7 \mathrm{in})$, $110 \mathrm{~cm}$ (43.3 in), and $80 \mathrm{~cm}$ (31.5 in) above the floor are plotted in both Figures 33 and 34. The $200 \mathrm{~cm}$ thermocouple tracked gas temperatures $30 \mathrm{~cm}$ (12 in) below the ceiling. The $110 \mathrm{~cm}$ thermocouple was $2 \mathrm{~cm}$ ( 1 in) above the left shoulder and the thermocouple at $80 \mathrm{~cm}$ was $15 \mathrm{~cm}$ ( 6 in) below the PASS devices. PASS devices were positioned on the front and rear of the mannequin. The peak temperature (room) of $631{ }^{\circ} \mathrm{C}\left(1168{ }^{\circ} \mathrm{F}\right)$ was reached at $305 \mathrm{~s}$ and the thermal sensors for all four of the PASS devices activated. Two Model A PASS devices were mounted on the mannequin, A-3 on the front and A-1 on the rear. The thermal sensors activated at $330 \mathrm{~s}$ and $385 \mathrm{~s}$ for the front and rear, respectively (Figure 33). Two Model C PASS devices were also mounted on the mannequin, one on the front and one on the rear. While the front mounted C-4 PASS activated at $340 \mathrm{~s}$, the C-3 device on the rear of the mannequin activated at $365 \mathrm{~s}$ (Figure 34). The times between peak exposure (room) and thermal sensor activation for the front of the mannequin were $25 \mathrm{~s}$ and $35 \mathrm{~s}$ for A-3 and C-4, respectively. The times between peak exposure (room) to activation for the rear of the mannequin were significantly longer at $80 \mathrm{~s}$ and $60 \mathrm{~s}$ for A-1 and C-3, respectively. In a similar manner the analog signal from the thermal sensor and the temperatures for front and rear of the mannequin near each PASS device are plotted in both Figures 35 and 36. The peak temperature (mannequin front and rear), time of peak at which the peak temperature (front and rear) occurred, and the alarm activation time are tabulated in Table 4.

\section{Uncertainty Analysis}

There are different components of uncertainty in the temperatures, total heat flux, and time to activate data reported here. Uncertainties are grouped into two categories according to the method used to estimate them. Type A uncertainties are evaluated by statistical methods, and Type B are evaluated by other means [9]. Type B analysis of systematic uncertainties involves estimating the upper $(+a)$ and lower $(-a)$ limits for the quantity in question such that the probability that the value would be in the interval $( \pm \mathrm{a})$ is essentially 100 percent. After estimating uncertainties by either Type A or B analysis, the uncertainties are combined in quadrature to yield the combined standard uncertainty. Multiplying the combined standard uncertainty by a coverage factor of two results in the total expanded uncertainty that corresponds to a 95 percent confidence interval $(2 F)$.

Components of uncertainty are tabulated in Tables 5 and 6. Some of these components, such as the zero and calibration elements, are derived from instrument specifications. Other components, such as soot deposition or radiative cooling/heating include past experience with thermophoretic deposition on cool surfaces and thermocouples in high temperature fuel rich environments. The uncertainty in the air temperature measurements includes radiative cooling in the each of the tests series, but also includes radiative heating for thermocouple located in the lower layer of the full-scale tests. This resulted in an estimate of $-23 \%$ to $+12 \%$ total expanded uncertainty for the lab tests and a slightly larger estimate of $-32 \%$ to $+15 \%$ for the 
Table 3. Full-scale townhouse exposure tests for PASS devices (room peak temperatures).

\begin{tabular}{|c|c|c|c|c|c|c|}
\hline $\begin{array}{l}\text { Configuration \& } \\
\text { Fuel Package }\end{array}$ & $\begin{array}{c}\text { Peak } \\
\text { Temperature } \\
\text { (room) }\end{array}$ & $\begin{array}{c}\text { Time of } \\
\text { Peak } \\
\text { Temperature } \\
\text { (room) }\end{array}$ & $\begin{array}{c}\text { PASS } \\
\text { Device } \\
\text { ID }\end{array}$ & $\begin{array}{c}\text { PASS } \\
\text { Location }\end{array}$ & $\begin{array}{l}\text { Time of } \\
\text { Activation }\end{array}$ & $\begin{array}{c}\text { Peak } \\
\text { Exposure to } \\
\text { Activation }\end{array}$ \\
\hline \multirow{2}{*}{$\begin{array}{l}\text { Unit } 1 \\
\text { Unfurnished } \\
\text { Living Room }\end{array}$} & \multirow{4}{*}{$\begin{array}{c}181^{\circ} \mathrm{C} \\
\left(358^{\circ} \mathrm{F}\right)\end{array}$} & \multirow{4}{*}{$182 \mathrm{~s}$} & A-3 & Front & $\begin{array}{l}\text { Did not } \\
\text { Activate }\end{array}$ & $\begin{array}{l}\text { Did Not } \\
\text { Activate }\end{array}$ \\
\hline & & & A-1 & Rear & $\begin{array}{l}\text { Did not } \\
\text { Activate }\end{array}$ & $\begin{array}{l}\text { Did Not } \\
\text { Activate }\end{array}$ \\
\hline \multirow{2}{*}{$\begin{array}{l}\text { Gasoline } \\
\text { Ignition }\end{array}$} & & & C-4 & Front & $\begin{array}{l}\text { Did not } \\
\text { Activate }\end{array}$ & $\begin{array}{l}\text { Did Not } \\
\text { Activate }\end{array}$ \\
\hline & & & C-3 & Rear & $\begin{array}{l}\text { Did not } \\
\text { Activate }\end{array}$ & $\begin{array}{l}\text { Did Not } \\
\text { Activate }\end{array}$ \\
\hline \multirow{2}{*}{$\begin{array}{l}\text { Unit } 2 \\
\text { Furnished Living } \\
\text { Room }\end{array}$} & \multirow{4}{*}{$\begin{array}{c}306^{\circ} \mathrm{C} \\
\left(583^{\circ} \mathrm{F}\right)\end{array}$} & \multirow{4}{*}{$410 \mathrm{~s}$} & A-3 & Front & $\begin{array}{l}\text { Did not } \\
\text { Activate }\end{array}$ & $\begin{array}{l}\text { Did Not } \\
\text { Activate }\end{array}$ \\
\hline & & & A-1 & Rear & $530 \mathrm{~s}$ & $120 \mathrm{~s}$ \\
\hline \multirow{2}{*}{$\begin{array}{l}\text { Gasoline } \\
\text { Ignition }\end{array}$} & & & C-4 & Front & $\begin{array}{l}\text { Did not } \\
\text { Activate }\end{array}$ & $\begin{array}{l}\text { Did Not } \\
\text { Activate }\end{array}$ \\
\hline & & & C-3 & Rear & $485 \mathrm{~s}$ & $75 \mathrm{~s}$ \\
\hline \multirow{4}{*}{$\begin{array}{l}\text { Unit } 3 \\
\text { Furnished Living } \\
\text { Room } \\
\text { Carpeting, Sofa, } \\
\text { Chair, End table }\end{array}$} & \multirow{4}{*}{$\begin{array}{c}631^{\circ} \mathrm{C} \\
\left(1168^{\circ} \mathrm{F}\right)\end{array}$} & \multirow{4}{*}{$305 s$} & A-3 & Front & $330 \mathrm{~s}$ & $25 \mathrm{~s}$ \\
\hline & & & A-1 & Rear & $385 \mathrm{~s}$ & $80 \mathrm{~s}$ \\
\hline & & & C-4 & Front & $340 \mathrm{~s}$ & $35 \mathrm{~s}$ \\
\hline & & & C-3 & Rear & $365 \mathrm{~s}$ & $60 \mathrm{~s}$ \\
\hline
\end{tabular}


Table 4. Full-scale townhouse exposure tests for PASS devices (mannequin peak temperatures).

\begin{tabular}{|c|c|c|c|c|c|c|}
\hline $\begin{array}{l}\text { Configuration \& } \\
\text { Fuel Package }\end{array}$ & $\begin{array}{l}\text { PASS } \\
\text { Device } \\
\text { ID }\end{array}$ & $\begin{array}{c}\text { PASS } \\
\text { Location }\end{array}$ & $\begin{array}{c}\text { Peak } \\
\text { Temperature } \\
\text { (mannequin) }\end{array}$ & $\begin{array}{l}\text { Time of Peak } \\
\text { Temperature } \\
\text { (mannequin) }\end{array}$ & $\begin{array}{l}\text { Time of } \\
\text { Activation }\end{array}$ & $\begin{array}{c}\text { Peak } \\
\text { Exposure to } \\
\text { Activation }\end{array}$ \\
\hline \multirow{2}{*}{$\begin{array}{l}\text { Unit } 1 \\
\text { Unfurnished } \\
\text { Living Room } \\
\text { Carpeting }\end{array}$} & A-3 & Front & $\begin{array}{c}107^{\circ} \mathrm{C} \\
\left(225^{\circ} \mathrm{F}\right)\end{array}$ & $295 \mathrm{~s}$ & $\begin{array}{l}\text { Did not } \\
\text { Activate }\end{array}$ & $\begin{array}{l}\text { Did Not } \\
\text { Activate }\end{array}$ \\
\hline & A-1 & Rear & $\begin{array}{r}109^{\circ} \mathrm{C} \\
\left(228^{\circ} \mathrm{F}\right) \\
\end{array}$ & $290 \mathrm{~s}$ & $\begin{array}{l}\text { Did not } \\
\text { Activate }\end{array}$ & $\begin{array}{l}\text { Did Not } \\
\text { Activate }\end{array}$ \\
\hline \multirow{2}{*}{$\begin{array}{l}\text { Gasoline } \\
\text { Ignition }\end{array}$} & C-4 & Front & $\begin{array}{c}101^{\circ} \mathrm{C} \\
\left(214^{\circ} \mathrm{F}\right)\end{array}$ & $285 s$ & $\begin{array}{l}\text { Did not } \\
\text { Activate }\end{array}$ & $\begin{array}{l}\text { Did Not } \\
\text { Activate }\end{array}$ \\
\hline & C-3 & Rear & $\begin{array}{c}118^{\circ} \mathrm{C} \\
\left(244^{\circ} \mathrm{F}\right)\end{array}$ & $290 \mathrm{~s}$ & $\begin{array}{l}\text { Did not } \\
\text { Activate }\end{array}$ & $\begin{array}{l}\text { Did Not } \\
\text { Activate }\end{array}$ \\
\hline \multirow{4}{*}{$\begin{array}{l}\text { Unit } 2 \\
\text { Furnished Living } \\
\text { Room } \\
\text { Carpeting, Sofa, } \\
\text { Chair, End table } \\
\text { Gasoline } \\
\text { Ignition }\end{array}$} & A-3 & Front & $\begin{array}{c}154^{\circ} \mathrm{C} \\
\left(309^{\circ} \mathrm{F}\right)\end{array}$ & $420 \mathrm{~s}$ & $\begin{array}{l}\text { Did not } \\
\text { Activate }\end{array}$ & $\begin{array}{l}\text { Did Not } \\
\text { Activate }\end{array}$ \\
\hline & A-1 & Rear & $\begin{array}{c}158{ }^{\circ} \mathrm{C} \\
\left(316^{\circ} \mathrm{F}\right)\end{array}$ & $420 \mathrm{~s}$ & $530 \mathrm{~s}$ & $110 \mathrm{~s}$ \\
\hline & C-4 & Front & $\begin{array}{c}169^{\circ} \mathrm{C} \\
\left(336^{\circ} \mathrm{F}\right)\end{array}$ & $420 \mathrm{~s}$ & $\begin{array}{l}\text { Did not } \\
\text { Activate }\end{array}$ & $\begin{array}{l}\text { Did Not } \\
\text { Activate }\end{array}$ \\
\hline & C-3 & Rear & $\begin{array}{r}182{ }^{\circ} \mathrm{C} \\
\left(360^{\circ} \mathrm{F}\right) \\
\end{array}$ & $420 \mathrm{~s}$ & $485 \mathrm{~s}$ & $65 s$ \\
\hline \multirow{4}{*}{$\begin{array}{l}\text { Unit } 3 \\
\text { Furnished Living } \\
\text { Room } \\
\text { Carpeting, Sofa, } \\
\text { Chair, End table }\end{array}$} & A-3 & Front & $\begin{array}{c}261^{\circ} \mathrm{C} \\
\left(502^{\circ} \mathrm{F}\right)\end{array}$ & $305 s$ & $330 \mathrm{~s}$ & $25 s$ \\
\hline & A-1 & Rear & $\begin{array}{r}245^{\circ} \mathrm{C} \\
\left(489^{\circ} \mathrm{F}\right)\end{array}$ & $310 \mathrm{~s}$ & $385 \mathrm{~s}$ & $75 s$ \\
\hline & C-4 & Front & $\begin{array}{c}266^{\circ} \mathrm{C} \\
\left(511^{\circ} \mathrm{F}\right)\end{array}$ & $305 s$ & $340 \mathrm{~s}$ & $35 \mathrm{~s}$ \\
\hline & $\mathrm{C}-3$ & Rear & $\begin{array}{c}265^{\circ} \mathrm{C} \\
\left(509^{\circ} \mathrm{F}\right)\end{array}$ & $310 \mathrm{~s}$ & $365 \mathrm{~s}$ & $55 s$ \\
\hline
\end{tabular}




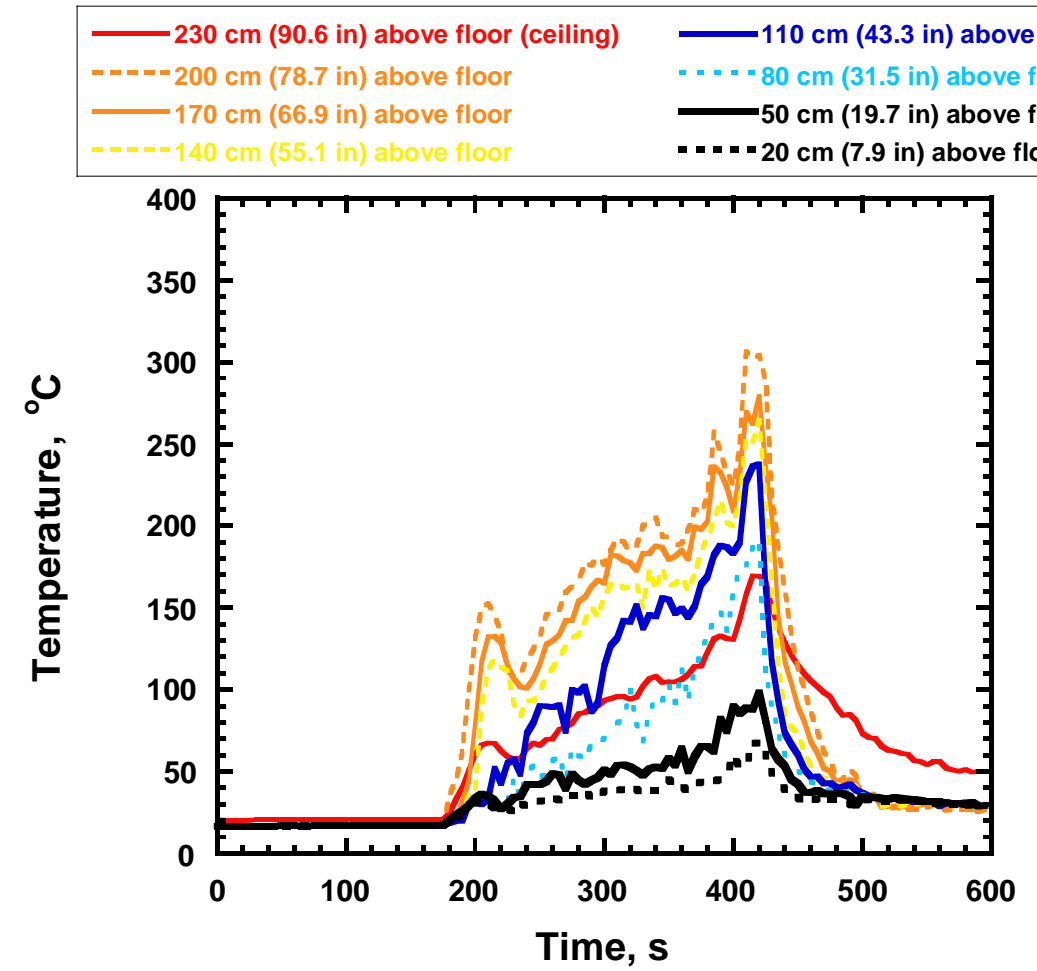

Figure 25. Gas temperatures versus time for full-scale townhouse burn in Unit 2.

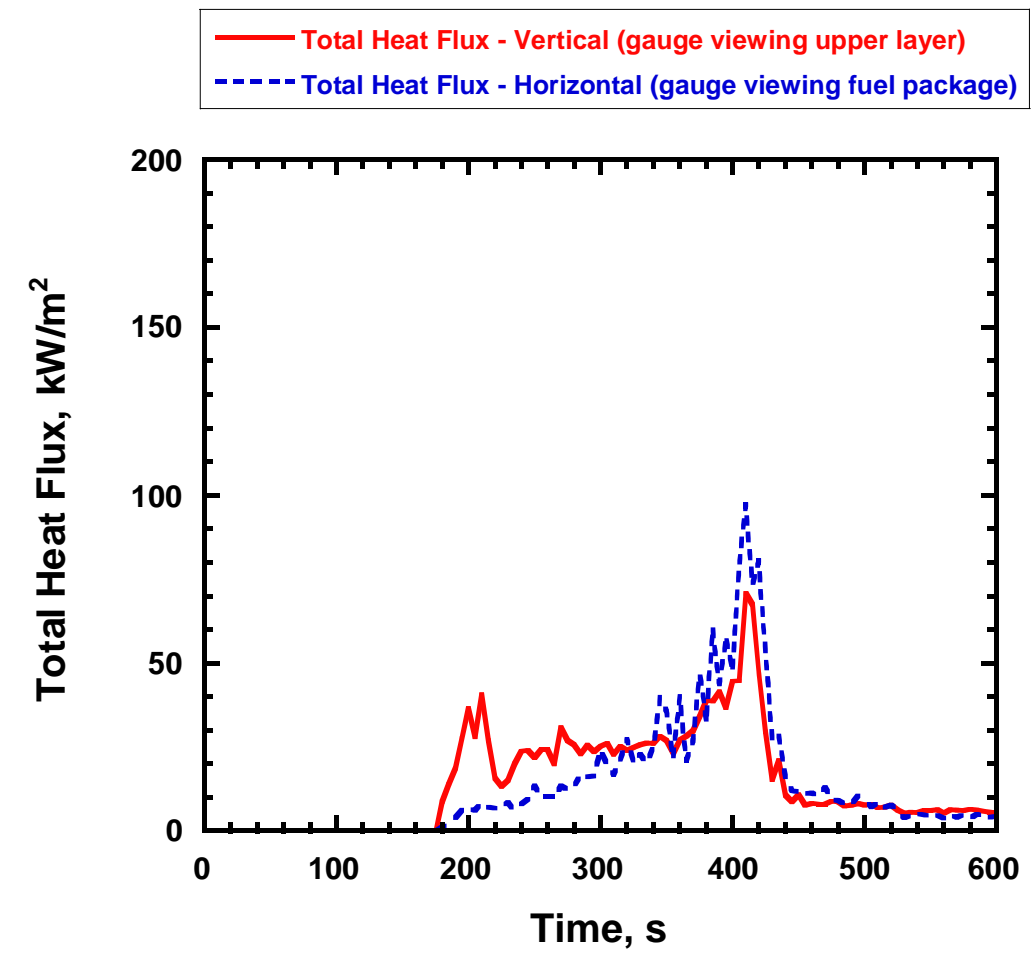

Figure 26. Thermal heat flux versus time for full-scale townhouse burn in Unit 2. 


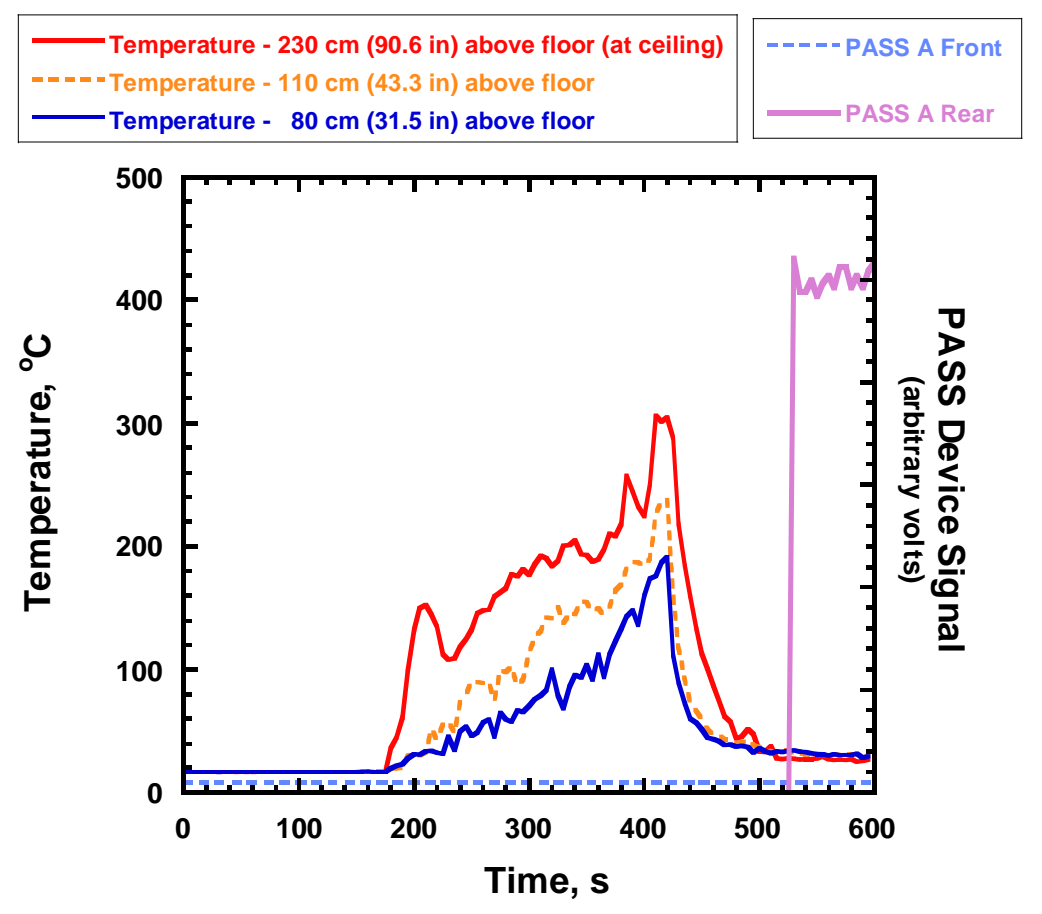

Figure 27. Temperature (room) and thermal sensor activation for PASS device A in Unit 2.

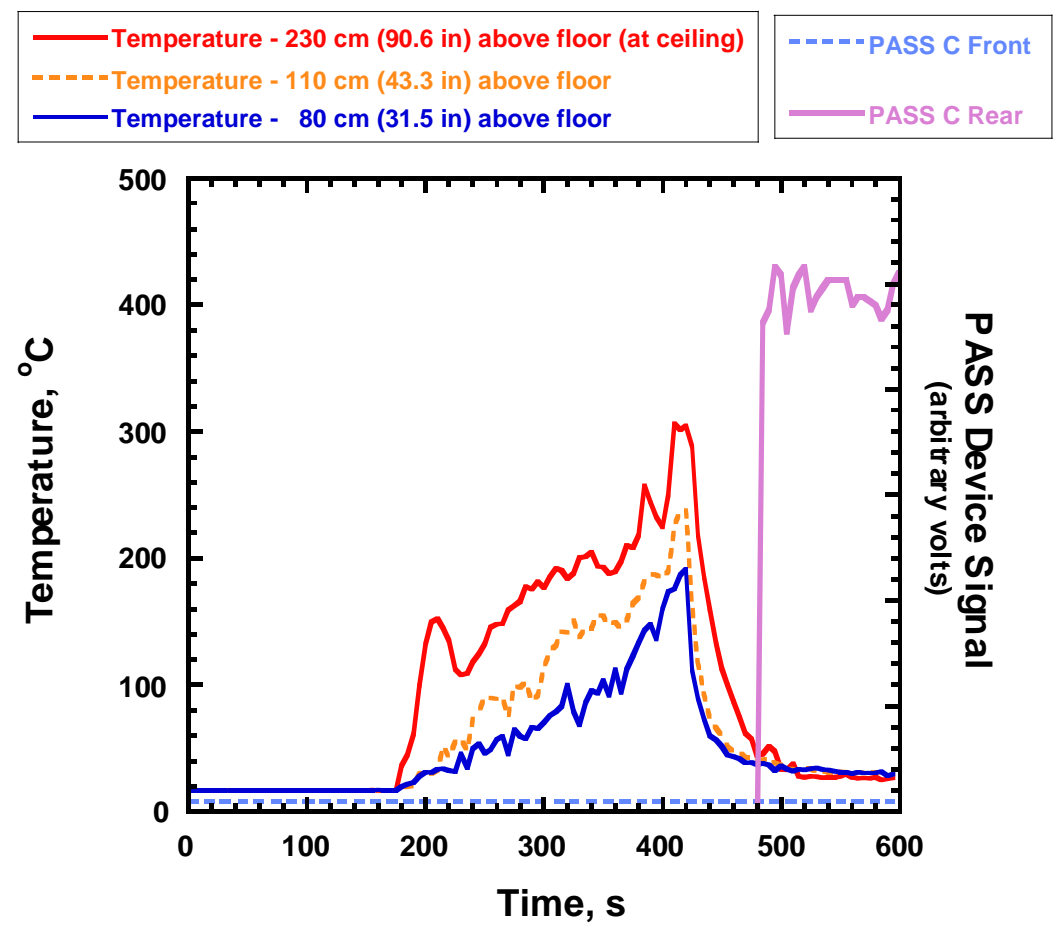

Figure 28. Temperature (room) and thermal sensor activation for PASS device C in Unit 2 


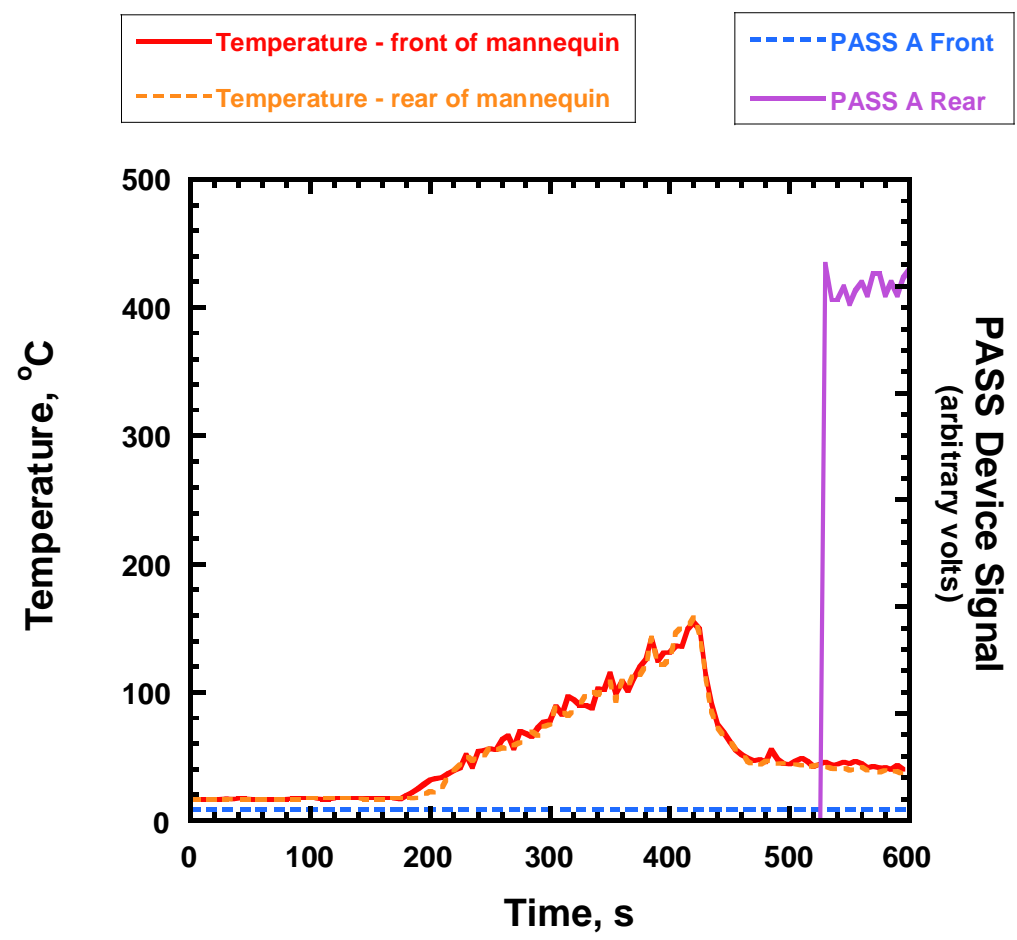

Figure 29. Temperature (mannequin front and rear) and thermal sensor activation for PASS device A in Unit 2
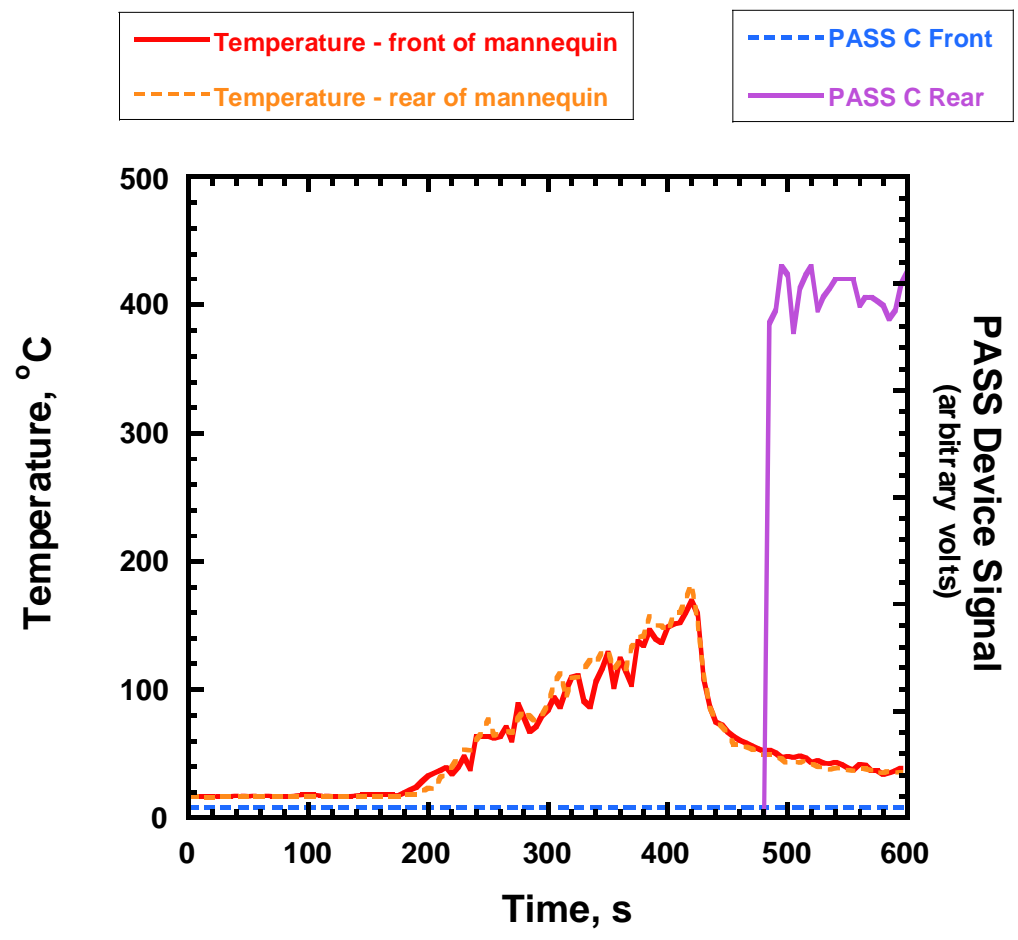

Figure 30. Temperature (mannequin front and rear) and thermal sensor activation for PASS device $\mathrm{C}$ in Unit 2 


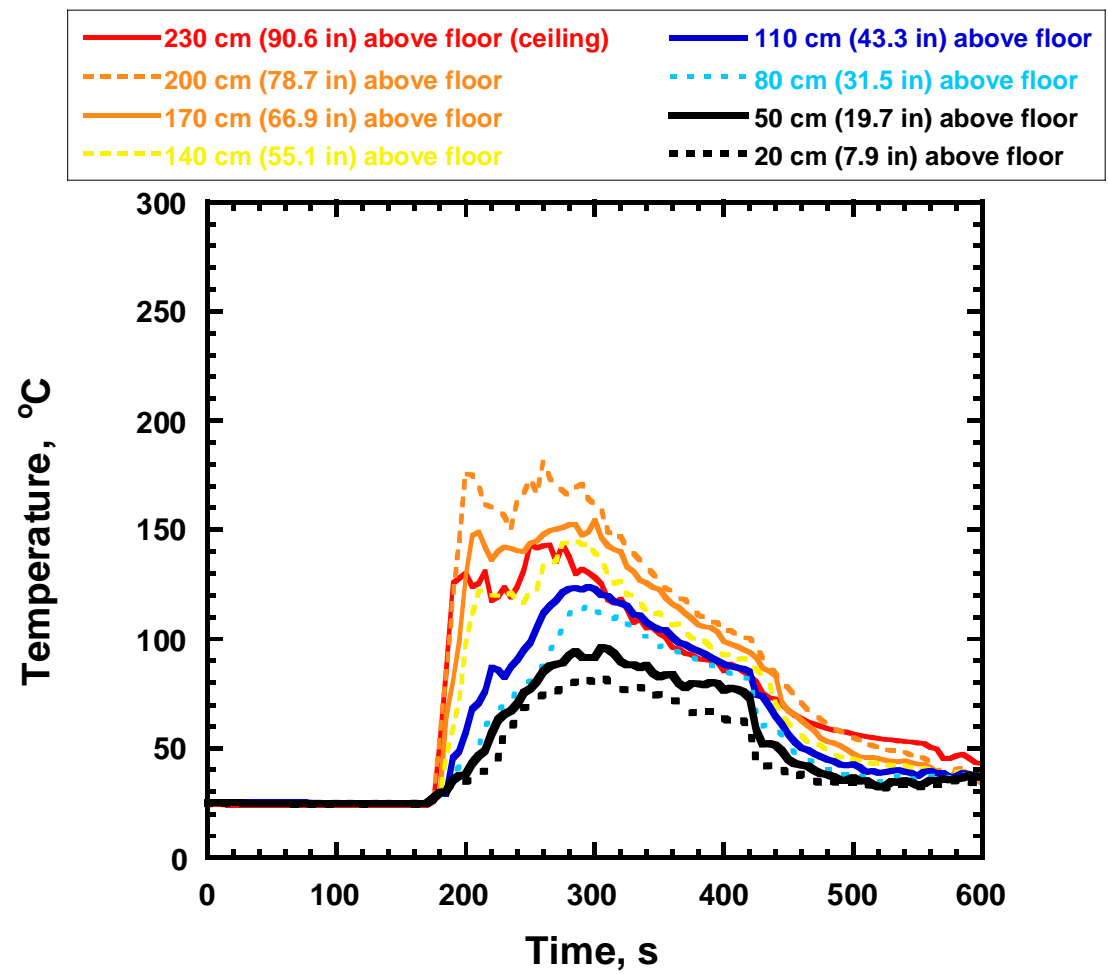

Figure 31. Gas temperatures versus time for full-scale townhouse burn in Unit 3.

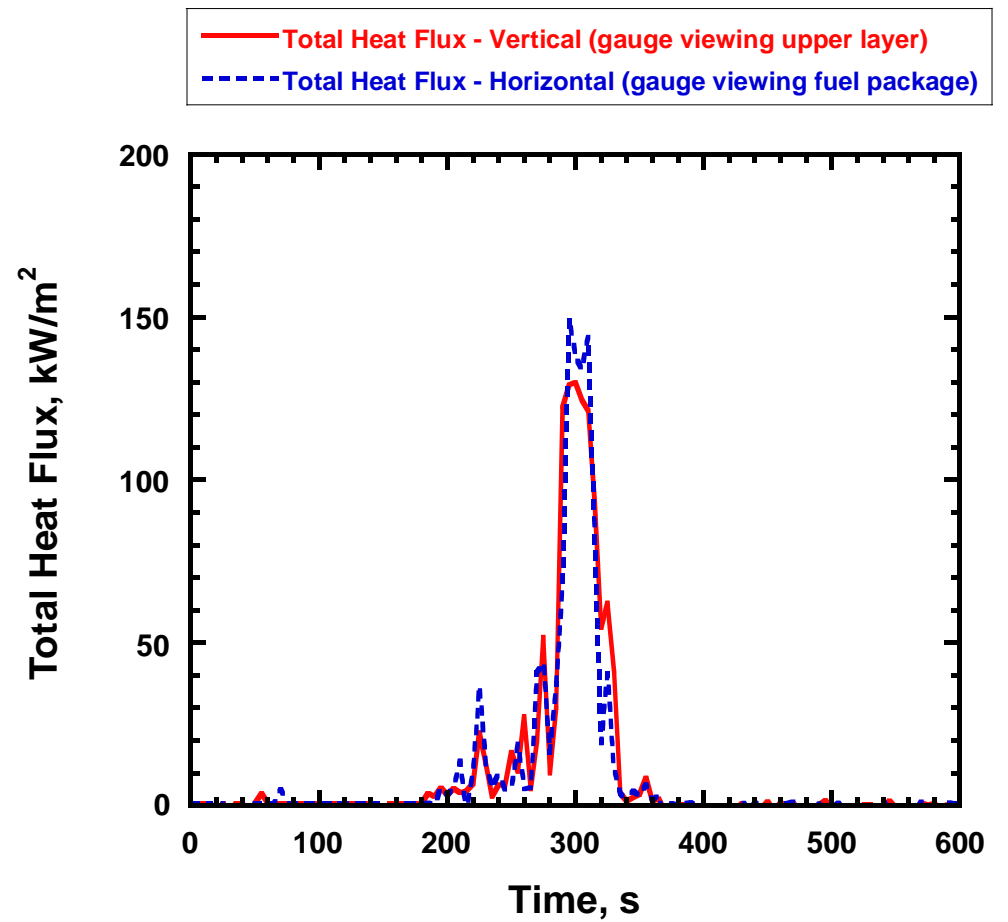

Figure 32. Thermal heat flux versus time for full-scale townhouse burn in Unit 3. 


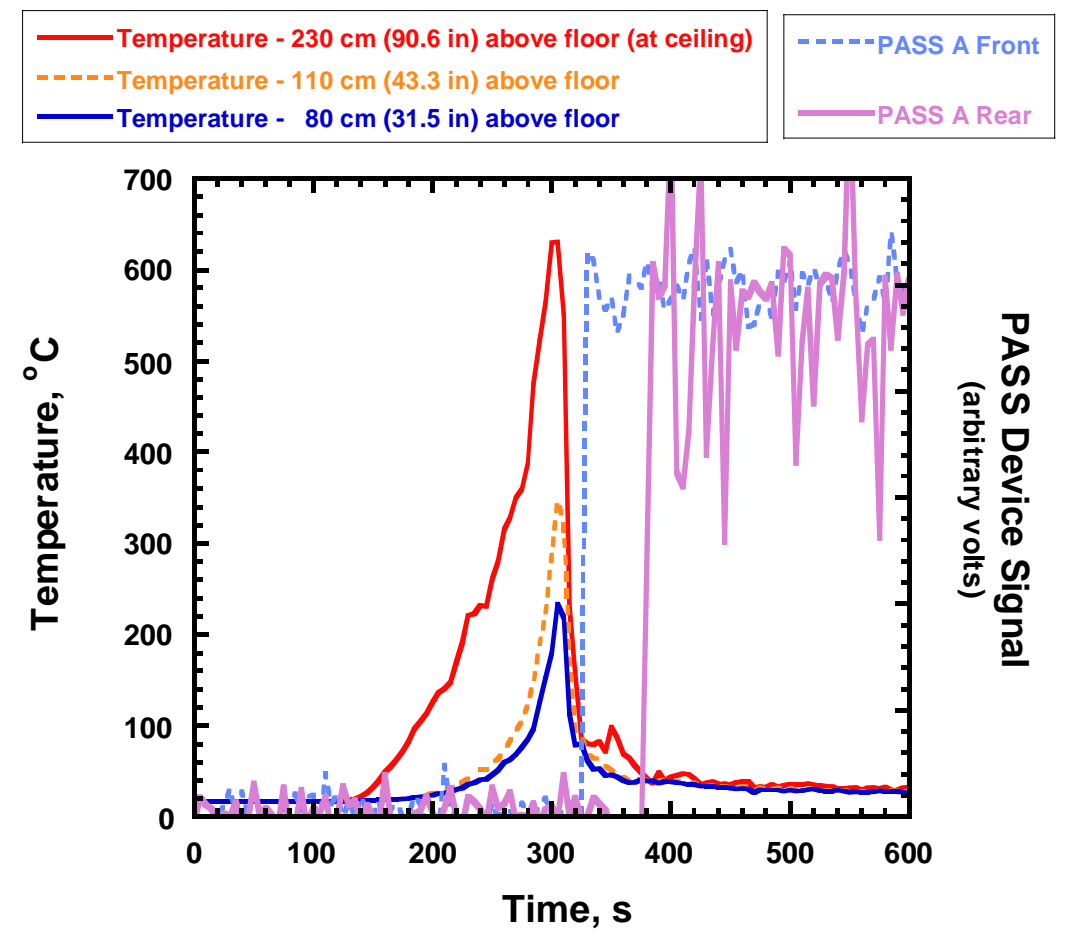

Figure 33. Temperature (room) and thermal sensor activation for PASS device A in Unit 3.

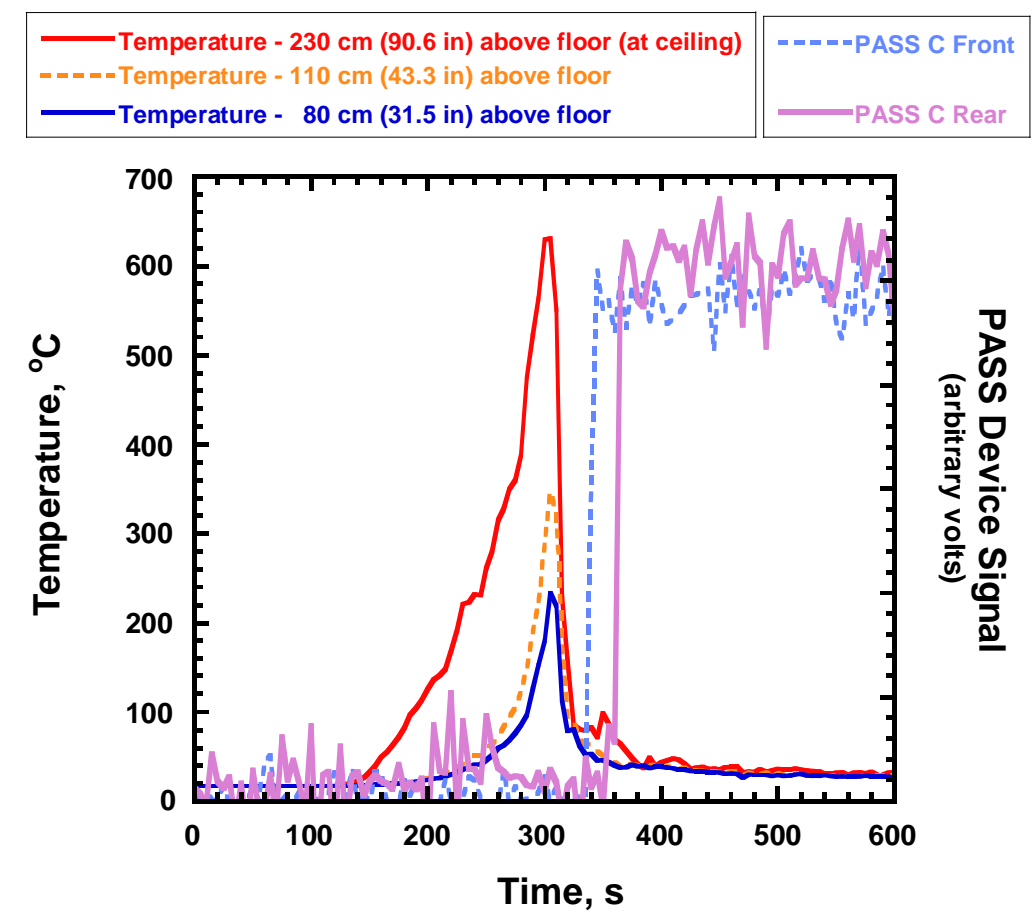

Figure 34. Temperature (room) and thermal sensor activation for PASS device C in Unit 3. 


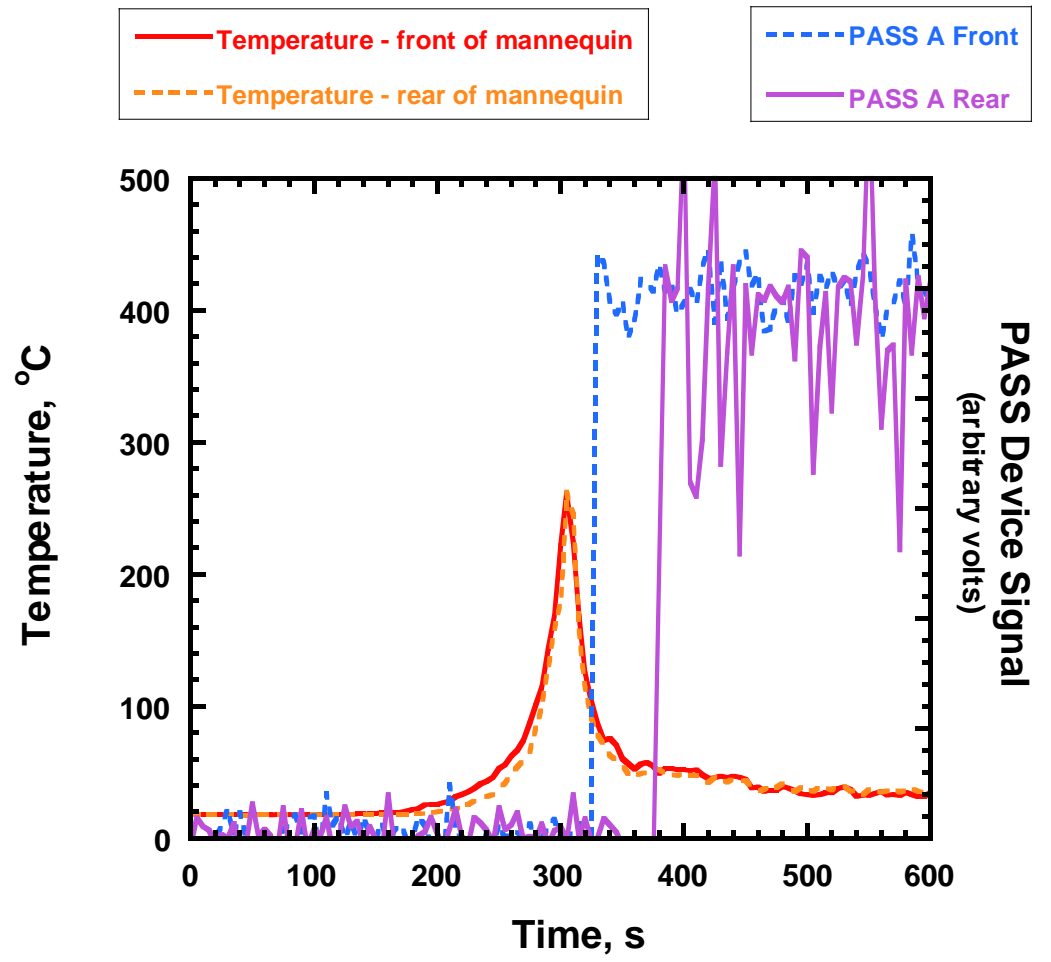

Figure 35. Temperature (mannequin front and rear) and thermal sensor activation for PASS device A in Unit 3.
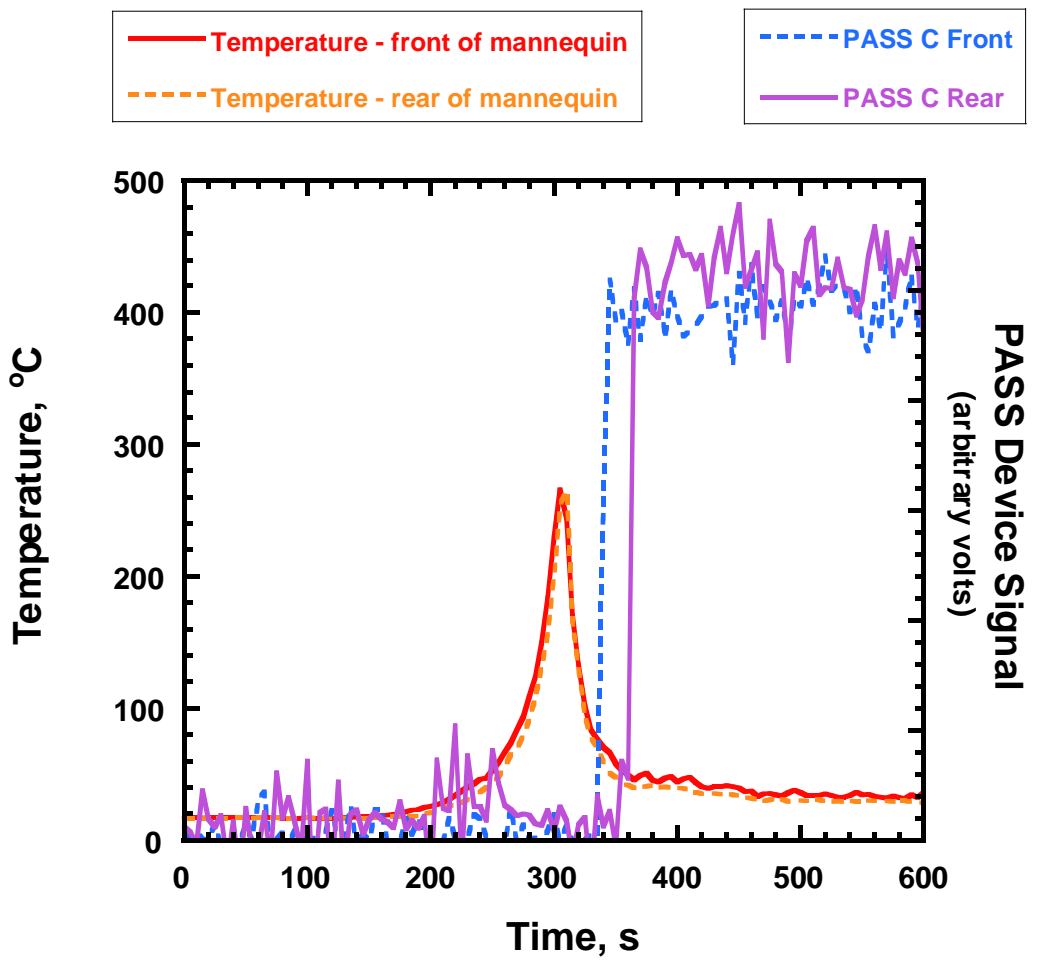

Figure 36. Temperature (mannequin front and rear) and thermal sensor activation for PASS device $\mathrm{C}$ in Unit 3. 
full scale tests. Soot deposition on the face of the water-cooled total heat flux gauges contributed significant uncertainty to the heat flux measurements. Calibration of heat flux gauges was completed at lower fluxes and then extrapolated to higher values and this resulted in a higher uncertainty in the flux measurement. Combining all of component uncertainties for total heat flux resulted in a total expanded uncertainty of $-31 \%$ to $+23 \%$ for the flux measurements. Estimating the uncertainty in the activation temperature for the static oven and flow loop experiments required the uncertainties in air temperature, alarm activation, and repeatability to generate a total expanded uncertainty range of $-32 \%$ to $+26 \%$. For the full-scale experiments, the total expanded uncertainty in peak exposure to alarm activation time measurements was estimated to range between $-15 \%$ and $+18 \%$. In all the experimental test series, positioning or locating instrumentation such as thermocouples or heat flux gauges was estimated to have the lowest total expanded uncertainty of $\pm 11 \%$.

Table 5. Uncertainty in static oven and flow loop experimental data.

\begin{tabular}{|c|c|c|c|}
\hline & $\begin{array}{l}\text { Component } \\
\text { Standard } \\
\text { Uncertainty }\end{array}$ & $\begin{array}{l}\text { Combined } \\
\text { Standard } \\
\text { Uncertainty }\end{array}$ & $\begin{array}{c}\text { Total } \\
\text { Expanded } \\
\text { Uncertainty }\end{array}$ \\
\hline $\begin{array}{l}\text { Air Temperature } \\
\text { Calibration } \\
\text { Radiative Cooling } \\
\text { Repeatability }^{1} \\
\text { Random }^{1}\end{array}$ & $\begin{array}{c} \pm 1 \% \\
-10 \% \text { to }+0 \% \\
\pm 5 \% \\
\pm 3 \%\end{array}$ & $-12 \%$ to $+6 \%$ & $-23 \%$ to $+12 \%$ \\
\hline $\begin{array}{c}\text { Activation Temperature } \\
\text { Air Temperature } \\
\text { Alarm Activation } \\
\text { Repeatability }^{1} \\
\text { Random }^{1}\end{array}$ & $\begin{array}{c}-12 \% \text { to }+6 \% \\
-0 \% \text { to }+5 \% \\
\pm 10 \% \\
\pm 3 \%\end{array}$ & $-16 \%$ to $+13 \%$ & $-32 \%$ to $+26 \%$ \\
\hline $\begin{array}{l}\text { Instrument Location } \\
\text { Zero } \\
\text { Repeatability }^{1} \\
\text { Random }^{1}\end{array}$ & $\begin{array}{l} \pm 1 \% \\
\pm 5 \% \\
\pm 2 \%\end{array}$ & $\pm 5 \%$ & $\pm 11 \%$ \\
\hline \multicolumn{4}{|c|}{$\begin{array}{l}\text { Notes: 1. Random and repeatability evaluated as Type A, other components as Type B. } \\
\text { 2. Determined from intersection of oven temperature and PASS alarm signal data when plotted } \\
\text { versus time on a single graph. }\end{array}$} \\
\hline
\end{tabular}


Table 6. Uncertainty in full scale experimental data.

\begin{tabular}{|c|c|c|c|}
\hline & $\begin{array}{l}\text { Component } \\
\text { Standard } \\
\text { Uncertainty }\end{array}$ & $\begin{array}{l}\text { Combined } \\
\text { Standard } \\
\text { Uncertainty }\end{array}$ & $\begin{array}{c}\text { Total } \\
\text { Expanded } \\
\text { Uncertainty }\end{array}$ \\
\hline $\begin{array}{l}\text { Air Temperature } \\
\text { Calibration } \\
\text { Radiative Cooling } \\
\text { Radiative Heating } \\
\text { Repeatability }^{1} \\
\text { Random }^{1}\end{array}$ & $\begin{array}{c} \pm 1 \% \\
-15 \% \text { to }+0 \% \\
-0 \% \text { to }+5 \% \\
\pm 5 \% \\
\pm 3 \%\end{array}$ & $-16 \%$ to $+8 \%$ & $-32 \%$ to $+15 \%$ \\
\hline $\begin{array}{l}\text { Total Heat Flux } \\
\text { Calibration } \\
\text { Zero } \\
\text { Soot Deposition } \\
\text { Repeatability }^{1} \\
\text { Random }^{1}\end{array}$ & $\begin{array}{c} \pm 10 \% \\
-2 \% \text { to }+2 \% \\
-10 \% \text { to }+0 \% \\
\pm 5 \% \\
\pm 3 \%\end{array}$ & $-15 \%$ to $+12 \%$ & $-31 \%$ to $+23 \%$ \\
\hline $\begin{array}{l}\text { Peak Exposure to } \\
\text { Activation Time } \\
\text { Time of Peak } \\
\text { Alarm Activation } \\
\text { Repeatability }^{1} \\
\text { Random }^{1}\end{array}$ & $\begin{array}{c} \pm 5 \% \\
-0 \% \text { to }+5 \% \\
\pm 5 \% \\
\pm 3 \%\end{array}$ & $-8 \%$ to $+9 \%$ & $-15 \%$ to $+18 \%$ \\
\hline $\begin{array}{l}\text { Instrument Location } \\
\text { Zero } \\
\text { Repeatability }^{1} \\
\text { Random }^{1}\end{array}$ & $\begin{array}{l} \pm 1 \% \\
\pm 5 \% \\
\pm 2 \%\end{array}$ & $\pm 5 \%$ & $\pm 11 \%$ \\
\hline \multicolumn{4}{|c|}{$\begin{array}{l}\text { Notes: 1. Random and repeatability evaluated as Type A, other components as Type B. } \\
\text { 2. Peak Exposure to Activation Time - time between exposure to peak temperature near } \\
\text { PASS device and time of thermal sensor activation. }\end{array}$} \\
\hline
\end{tabular}




\section{Discussion}

\section{A. Thermal Exposure Sensor Activation}

This study has examined the performance of thermal exposure sensor equipped PASS devices to the different thermal environments that fire fighters experience on the fire ground. The static oven tests were designed to simulate fire fighter activity is a layer of stagnant hot gases. The flow loop exposures were intended to reproduce a fire fighter's motion through hot gases or the movement of hot combustion gases around a stationary fire fighter. And, the fullscale fire tests exposed the PASS instrumented mannequin to typical fire conditions. For each of these scenarios, the gas temperature and alarm activation was observed for each PASS device.

\section{Static Oven and Flow Loop Test Series}

This limited set of temperature versus alarm activation data demonstrates average alarm temperatures of between $87{ }^{\circ} \mathrm{C}\left(189{ }^{\circ} \mathrm{F}\right)$ and $110{ }^{\circ} \mathrm{C}\left(230{ }^{\circ} \mathrm{F}\right)$ for all the PASS devices (Table 1). This series of tests reveals that different models can respond differently to static smoke conditions. Model B PASS devices displayed the lowest average activation temperatures while Model $\mathrm{C}$ revealed the highest average activation temperatures. Alarm activation repeatability appears good for Model A and B. Model C unit C-3 exhibited a wider range of alarm activation temperatures than any other PASS tested. Activation temperature is influenced by many factors including, but not limited to sensor type, sensor position, and how the temperature is processed by the circuitry of the PASS device. This limited data set does not demonstrate which factor or factors are responsible for generating the range of activation temperatures. There are significant uncertainties (Table 5) associated with the measurements and the range of total expanded uncertainties is larger than the range of temperatures measured.

The smaller series of flow loop tests produced much lower activation temperatures than observed in the static oven tests. This would be consistent with the heated air flow being able to transfer thermal energy to the PASS device more effectively than the static oven. The flow loop experiments generated wider range of activation temperatures than for the static oven tests. The thermal exposure sensors exhibited average alarm temperatures from $54{ }^{\circ} \mathrm{C}\left(129{ }^{\circ} \mathrm{F}\right), 72{ }^{\circ} \mathrm{C}$ $\left(162{ }^{\circ} \mathrm{F}\right)$, to $102{ }^{\circ} \mathrm{C}\left(216{ }^{\circ} \mathrm{F}\right)$ for Models $\mathrm{A}, \mathrm{B}$, and $\mathrm{C}$, respectively. Model A activated over a narrower range than Models B and C. On average, Model A alarmed at a much lower temperature than Model B or C. Even though this is a limited data set, the activation temperatures indicate that the thermal sensors respond differently to moving or flowing smoke than to static or quiescent smoke. Would the lower response temperatures display by Model A provide additional warning to fire fighters or would the lower activation temperatures generate unwanted false alarms?

Comparing the static oven and the flow loop alarm temperatures suggests that the thermal sensor utilized by Model A is more sensitive to the convective component of heat transfer associated with the flow loop. Model B also appears to respond to the convective component of heat transfer, but to a lesser degree than Model A. Model C activated at similar temperatures for both the static oven and the flow loop tests.

While each PASS device experienced similar exposures to the thermal environment of the static oven or flow loop series, additional experiments would be necessary to map out the entire temperature versus alarm response curve as a function of time. For example, this 
experimental data set would not have captured an alarm activation resulting from a 60 minute exposure to $50{ }^{\circ} \mathrm{C}\left(122{ }^{\circ} \mathrm{F}\right)$ environment. In a similar fashion, it might be useful to expose each PASS device to much higher temperatures, such as $400{ }^{\circ} \mathrm{C}\left(752{ }^{\circ} \mathrm{F}\right)$ for short durations. However, the high temperature/short durations would probably cause irreversible damage to the PASS device. The high temperature endurance of the thermal exposure sensors, in terms of the total duration or number of trips into high temperature conditions, would also be useful information in determining when PASS devices should be replaced.

\section{Full-Scale Mannequin Experimental Series}

The response of the PASS devices during the townhouse burns initially appears to be inconsistent. In the Unit 1 fire test, none of the thermal sensors activated during the burn. In Unit 2, the rear PASS devices, A-1 and C3, both alarmed but the front PASS devices, A-3 and C-4, did not alarm. In the Unit 3, both front PASS devices alarm before the rear PASS devices alarm. However, with more detailed examination of the gas temperatures and total heat fluxes, the thermal sensor activations are relatively consistent. Each of the fires in Unit 1 and Unit 2 was initiated by igniting gasoline, so both fire developed quickly, but the fuel in Unit 1 was limited to carpeting, no furniture. The fire in Unit 1 started quickly, but after consuming the gasoline, the fire began to decrease in its intensity. Initially the gasoline fueled fire generated significant levels of thermal radiation to help pyrolyze additional fuel, but as the gasoline was expended, the carpeting continued to burn, but the line of flames was distributed over a wider flame front and this would have reduced the radiation feedback to the fuel. The reduced feedback would have caused the fire to decrease in it intensity. The fire in Unit 2 also started quickly, but there was additional furniture in the living room. Consequently, the temperature data show the same initial development and actually begin to decline. But as the fire spreads to additional items, the intensity of the fire increases until the fire begins to approach flashover and suppression was initiated. The fire in Unit 3 was slower to develop initially because it was ignited with crumpled newspaper rather than gasoline. The crumpled newspaper was positioned on the sofa and may have caused the fire to spread more quickly across the sofa and chair. The gasoline was spilled in the center of the carpet and the fire at least in the initial stages, was a greater distance from the additional fuel items. The higher temperatures and heat fluxes observed in Unit 3 suggest that more of the fuel package became involved in the early stages of the fire than in Unit 2. As a result of more of the furnishings becoming involved, the intensity of the fire in Unit 3 fire increased until the fire approached flashover and water suppression was initiated.

As one would expect, the intensity of the fire in Unit 3 produced the highest gas temperatures and the highest thermal heat fluxes while Unit 1 reported the lowest temperatures and heat fluxes. It would be consistent to find that the fire in Unit 3 activated all of the thermal sensors, front and rear of the mannequin, while none of the thermal sensors activated in Unit 1. This indicates that the temperatures/fluxes were sufficient in Unit 3, and not sufficient to cause activation in Unit 1. In Unit 2, the fire produced temperatures and fluxes in between those observed in Unit 1 (lower than Unit 2) and Unit 3 (higher than Unit 2). Consequently, it should not be a surprise that only two out of the four thermal sensor equipped PASS devices alarmed in Unit 2. It is curious that it was not the two PASS devices on the front of the mannequin which faced the burning fuel package. It was the two PASS devices on the rear of the mannequin that activated. Since the PASS devices on the front and rear of the mannequin would experience the 
radiation from the hot upper layer, one might expect that the additional thermal flux from the burning fuel package that only the PASS devices facing the fire would experience would cause the front PASS devices to activate first. However, the rear-mounted devices activated first and those PASS devices would have been shielded by the body of the mannequin from the radiation of the burning fuel. But, the activation of the rear thermal sensors demonstrates that the rear of the mannequin may have experienced some additional energy that did not impact the PASS devices on the front. One possibility is that as the hot layer moved across the ceiling and struck the rear wall of the townhouse, some portions of the hot layer may have recirculated or moved down the wall and towards the rear of the mannequin. If this "reflected jet" of hot upper layer gases was sufficiently strong, it may have convected additional thermal energy to the rear of the mannequin. The mannequin would have shielded the front mounted devices from this reflected stream of hot gases. This would suggest that the energy convected by the reflected stream to the rear devices was greater than the radiative energy received by the front PASS devices. Modeling this set of experiments using computer fire models such as fire Dynamic Simulator [10] could provide additional insight about the recirculation the hot combustion gases around the mannequin.

While the activation of the rear mounted PASS devices in Unit 2 may suggest that the radiation from the burning fuel package was not sufficient to activate the thermal sensors on the front of the mannequin, the heat flux reached much higher levels in Unit 3 and the combination of gas temperatures did activate all four of the thermal sensor equipped PASS devices in Unit 3. But, the two front mounted devices activated much more quickly than the rear mounted devices and this would be consistent with radiative heat flux playing a role in the activation. There were also significant delays between the activation of the front PASS devices and the rear PASS devices. The time between peak temperature and thermal sensor activation was tabulated for both peak room temperature and peak temperature near each PASS device. It did not appear to make much difference whether the time was calculated from the peak room temperature or the peak mannequin temperature. The peak exposure to alarm activation time was significantly longer, $65 \mathrm{~s}$ to $120 \mathrm{~s}$, for the mannequin in Unit 2 as compared to Unit 3 which had a range of $25 \mathrm{~s}$ to $80 \mathrm{~s}$. The longer exposure to activation time in Unit 2 would be consistent with a less intense fire development while the shorter times in Unit 3 would reflect the more intense temperature and heat flux environment. The full-scale townhouse burns demonstrate that thermal radiation can significantly affect the activation of the thermal exposure sensor, but clearly illustrate that conduction, convection and radiation can work in different combinations to cause a thermal sensor to alarm.

Since a fire fighter may be exposed to relatively low temperature environments such as the fire in Unit 1, it is important that a standard testing protocol include a component that simulates the exposure of the thermal sensor to a relative low temperature, less than $70{ }^{\circ} \mathrm{C}$ $\left(158{ }^{\circ} \mathrm{F}\right)$, for a relatively long period of time, up 30 minutes. When the static oven activation temperatures are compared to the flow loop temperatures, it is clear that the testing protocol also needs to include a component with the hot gases moving across the fire fighter. The importance of moving or recirculating gases was also observed in the activation of the rear mounted PASS devices in Unit 2. The full-scale results illustrate the role that thermal radiation can play in thermal sensor activation and the standard protocol should also include exposure to thermal radiation. Although limited, the static oven, flow loop, and full-scale test data, all indicate that 
a thermal sensor must be characterized under conductive, convective, and radiative modes of heat transfer.

This limited data set also raises some additional issues associated with thermal sensors in PASS devices. Each thermal sensor is designed to activate according to a temperature response curve. The higher the temperature, the quicker the thermal sensor is designed to activate. But, in the full-scale townhouse tests, there was between $25 \mathrm{~s}$ and $120 \mathrm{~s}$ delay between peak exposure and sensor activation. If a fire fighter had delayed their retreat until the thermal sensor had activated, up to 2 minutes, serious injury could have occurred. If the thermal sensor in PASS devices is intended to warn the fire fighter of a possibly hazardous thermal environment, the PASS device must provide this warning quickly, not $60 \mathrm{~s}$ or $90 \mathrm{~s}$ later. A thermal sensor can be designed to activate in response to a range of parameters. Sensors can activate when a specific temperature is exceeded. This type of sensor might be set to alarm when a temperature greater than $100{ }^{\circ} \mathrm{C}\left(212{ }^{\circ} \mathrm{F}\right)$ is experienced. The sampling frequency of a sensor can also impact how quickly it alarms. If a sensor only looks at the temperature every $30 \mathrm{~s}$, the temperature may exceed the set point for up to $30 \mathrm{~s}$ before the alarm is activated. A temperature specific sensor might alarm at the sudden rise in temperature, but a prolonged exposure to temperatures just below the set point, say 2 hours at $98^{\circ} \mathrm{C}\left(209^{\circ} \mathrm{F}\right)$ might not trigger an alarm. A thermal sensor can also be designed to activate when the sensor has experienced a certain amount of energy. This type of sensor would accumulate or integrate the energy and when sufficient energy had been collected, it would alarm. An integrating type sensor would alarm whether that energy arrived in a few seconds or over an hour, but the process of accumulating the energy could slow how fast the alarm is activated. A sensor can also be designed to alarm at a certain rate of temperature increase. A rate of rise sensor would activate when the temperature is increasing faster than a specific rate. For instance, if alarm set point was $50{ }^{\circ} \mathrm{C}\left(90^{\circ} \mathrm{F}\right)$ per second, a temperature that increased from $100{ }^{\circ} \mathrm{C}\left(212{ }^{\circ} \mathrm{F}\right)$ to $200{ }^{\circ} \mathrm{C}\left(392{ }^{\circ} \mathrm{F}\right)$ in less than a second would trigger an alarm. Different fire conditions would cause each of these different sensor designs to alarm. A rate of rise sensor would not alarm under the thermal conditions, relatively low temperatures over a period of time, that occurred in Unit 1. A temperature specific or integrating sensor may not respond quickly enough to warn of the hazardous conditions, rapidly rising temperature, in Unit 2 or 3. A thermal sensor may have to incorporate the ability to alarm to multiple conditions, rapid temperature rise over a short period of time as well as lower temperatures over a prolonged period of time. The full-scale townhouse data clearly suggests that the thermal sensors mounted on the front and rear of the mannequin did not provide sufficient warning to allow safe retreat from the fire conditions. These PASS thermal sensors may provide information on the integrated or total exposure to thermal conditions which could be used by the incident commander to reassign the affected fire fighters to rehab. But, this limited data indicates that fire fighters should not rely on current thermal sensors to provide adequate warning of short-term exposures to the hazards of high thermal radiation or high temperature environments.

A second issue that the full-scale data highlights is the position or location of the thermal sensor on the fire fighter. In the Unit 3 tests, the body of the mannequin shielded the rearmounted PASS devices from the thermal radiation of the burning fuel package. In Unit 2, the body of mannequin may have shielded the front mounted PASS devices from the recirculation zone that may have occurred behind the mannequin. If a single thermal sensor is utilized, neither the front or rear location will adequately address the issue of the sensor being shielded by 
the body of the fire fighter. Either multiple point sensing, front and rear, or another location on the fire fighter may needed to be considered. Multiple point sensing would monitor the temperature at different locations and would alarm if the set point temperature is exceeded on either front or rear location. Mounting the thermal sensor on the shoulder or on the helmet may provide a compromise that minimizes the ability of the body to shield the thermal sensor. Front or rear mounted thermal sensors do not appear to provide optimum coverage and alternatives need to be investigated.

\section{B. Standard Test Protocol}

The thermal exposure sensor response data collected by this study demonstrates that current sensors respond differently to different fire conditions. Thermal exposures can be for short periods at high temperatures or for prolonged periods at lower temperatures. For both of these exposures, acute and prolonged, thermal exposure sensors are expected to provide adequate warning of hazardous thermal environments. A well-designed testing protocol must characterize the thermal sensor performance when immersed in stagnant hot gases, enveloped by moving combustion products, and experiencing intense thermal radiation. The testing protocol should at a minimum include components to collect response versus temperature data for thermal sensors encountering the following fire scenarios:

A) Quiescent hot gases for temperature ranging from $150{ }^{\circ} \mathrm{C}\left(300{ }^{\circ} \mathrm{F}\right)$ to $300{ }^{\circ} \mathrm{C}\left(572{ }^{\circ} \mathrm{F}\right)$, for prolonged and acute exposures respectively; recommend using static oven to evaluate this condition,

B) Flowing or moving hot gases for temperature ranging from $125^{\circ} \mathrm{C}\left(260{ }^{\circ} \mathrm{F}\right)$ to $250{ }^{\circ} \mathrm{C}$ $\left(482^{\circ} \mathrm{F}\right.$ ) for prolonged and acute exposures respectively; with gas velocity ranging from $0.22 \mathrm{~m} / \mathrm{s}(0.5 \mathrm{mph})$ to $2.24 \mathrm{~m} / \mathrm{s}(5 \mathrm{mph})$; recommend employing a flow loop that allows for variable temperature and velocity.

C) High thermal flux / pre-flashover conditions with total heat fluxes from $2.5 \mathrm{~kW} / \mathrm{m}^{2}$ to $30 \mathrm{~kW} / \mathrm{m}^{2}$ for prolonged and acute exposures respectively; recommend either electric resistance radiant panel or gas fired radiant panel.

While the test protocol needs to include these scenarios, the protocol should not be used to limit the characterization of thermal sensor performance to only these three scenarios. For example, it is important that a temperature response curve describe the thermal sensor performance over a wider range of temperatures from $25^{\circ} \mathrm{C}\left(77^{\circ} \mathrm{F}\right)$ to $600{ }^{\circ} \mathrm{C}\left(1112{ }^{\circ} \mathrm{F}\right)$.

As the standard testing protocol is developed, it must also address whether the thermal sensor is designed to provide warning of an imminent hazard, such as rapid increase in temperature just before flashover, or designed to alarm after a more prolonged exposure to relatively lower temperatures. If the alarm is intended to provide time to retreat safely from an imminent hazard, then the alarm activation must occur almost instantaneously when the sensor experiences either the imminent hazard or the conditions leading to an imminent hazard. The time delay must be on the order of seconds, not minutes. If the alarm is expected to warn of an 
exposure over an extended period of time, then the time between exposure and alarm can be substantially longer.

A draft protocol for Thermal Exposure Sensor is described in Appendix A. It includes sections that address A) Design Requirements, B) Performance Requirements, and C) Test Methods. The draft protocol incorporates

1) Exposure temperatures and durations for each of the above three scenarios,

2) Tests on fully assembled, ready for service, PASS devices,

3) Pre-test conditioning of specimens,

4) Testing of multiple units of the same model of PASS device,

5) Specific velocities for moving gases,

6) Non-destructive testing at low temperatures,

7) Destructive testing at high temperatures,

8) Data to be recorded during each test,

9) Interpretation of results.

It is critically important that input from the fire service, the PASS manufacturers, testing laboratories, and fire research institutions be included in the development of the standard testing protocol. The fire service will provide insight into the conditions and thermal environments that fire fighters experience. Manufacturers will continue to incorporate new technologies to provide improved instrumentation for fire fighter safety. Fire testing laboratories will make sure that the performance can be adequately characterized. Research institutions will help ensure a scientific foundation for the design and help identify new technology for future devices.

\section{Conclusions}

The limited set of temperature versus thermal sensor activation data indicates that sensors respond differently under static, flowing, and radiation intense conditions. The full-scale data demonstrate that current thermal sensing/PASS implementations are unlikely to provide a fire fighter with sufficient warning of an acute thermal hazard. Current PASS devices may provide information to fire fighters about their longer term exposure to thermal conditions, but there is a significant delay of $25 \mathrm{~s}$ to $120 \mathrm{~s}$ before the fire fighter receives this alarm or information.

This limited series of experiments demonstrates the need to develop a standard testing protocol to insure that all PASS devices provide adequate protection for fire fighters. This testing protocol must evaluate the performance of thermal sensors under a range of fire environments that fire fighters may realistically encounter on a routine basis. The fire service, equipment manufacturers, and fire research and fire testing laboratories must be included in the development of a standard testing protocol.

The overall goal of this work is to improve the safety and effectiveness of fire fighters. To accomplish this goal, the fire service must be able to incorporate state-of-the-art technology into all of its equipment. But, in order for the fire service to integrate new technology safely, it must be able to understand the performance and the limitations of this new technology. 


\section{Acknowledgements}

This project was funded by the US Fire Administration, Federal Emergency Management Agency with Mr. William Troup served as project officer. Mr. Jack Lee and Mr. Roy McLane expertly conducted both static oven and flow loop experiments. Mr. Robert Vettori and Mr. Jay McElroy did an excellent job of field instrumentation and mannequin setup.

\section{References}

1. Karter, M.J., Jr., "Patterns of Firefighter Fireground Injuries," Quincy, MA: National Fire Protection Association, Fire Analysis and Research Division, Nov. 2003.

2. Fahy, R. and Leblanc, P., "On-Duty Deaths Firefighter Fatalities 2002," National Fire Protection Association Journal, Vol. 97, No. 4, pp 56-63, July/August 2003.

3. "Provisional Report for On-Duty Firefighter Fatalities in the United States Date Range 01/01/2003 to 12/31/2003 ," Emittsburg, MD, US Fire Administation, updated Feb. 2004.

4. "Fire Fighter Deaths in Structural Collapses, 1979-1988." Quincy, MA: National Fire Protection Association, Fire Analysis and Research Division, Aug. 1989.

5. "Fire Ground Fatalities As A Result of Structural Collapse, 1983-1992." Quincy, MA: National Fire Protection Association, Fire Analysis and Research Division, Aug. 1993.

6. Brassell, L.D. and Evans, D.D., Trends in Firefighter Fatalities Due to Structural Collapse, 1979-2002. NISTIR 7069. Gaithersburg, MD: National Institute of Standards and Technology, Nov. 2003.

7. Standard on Personal Alert Safety Systems (PASS), 1998 Edition, Quincy, MA: National Fire Protection Association, August 1998.

8. Fleming, R. P., "Theory of Automatic Sprinkler Performance." Fire Protection Handbook, Eighteenth Edition, Section 6/Chapter 8, Quincy, MA: National Fire Protection Association, pp 6-113 - 6-123, 1997.

9. Taylor, B. N. and C. E. Kuyatt, Guidelines For Evaluating and Expressing the Uncertainty of NIST Measurement Results. National Institute of Standards and Technology (U.S.) NIST TN 1297; September, 20 p. 1994.

10. McGrattan, Kevin B.; Baum, Howard R.; Rehm, Ronald G.; Hamins, Anthony; Forney, Glenn P.; "Fire Dynamics Simulator - Technical Reference Guide," National Institute of Standards and Technology, Gaithersburg, MD, NISTIR 6467, January 2000. 


\section{Other Resources}

United States Fire Administration Website - http://www.usfa.fema.gov/

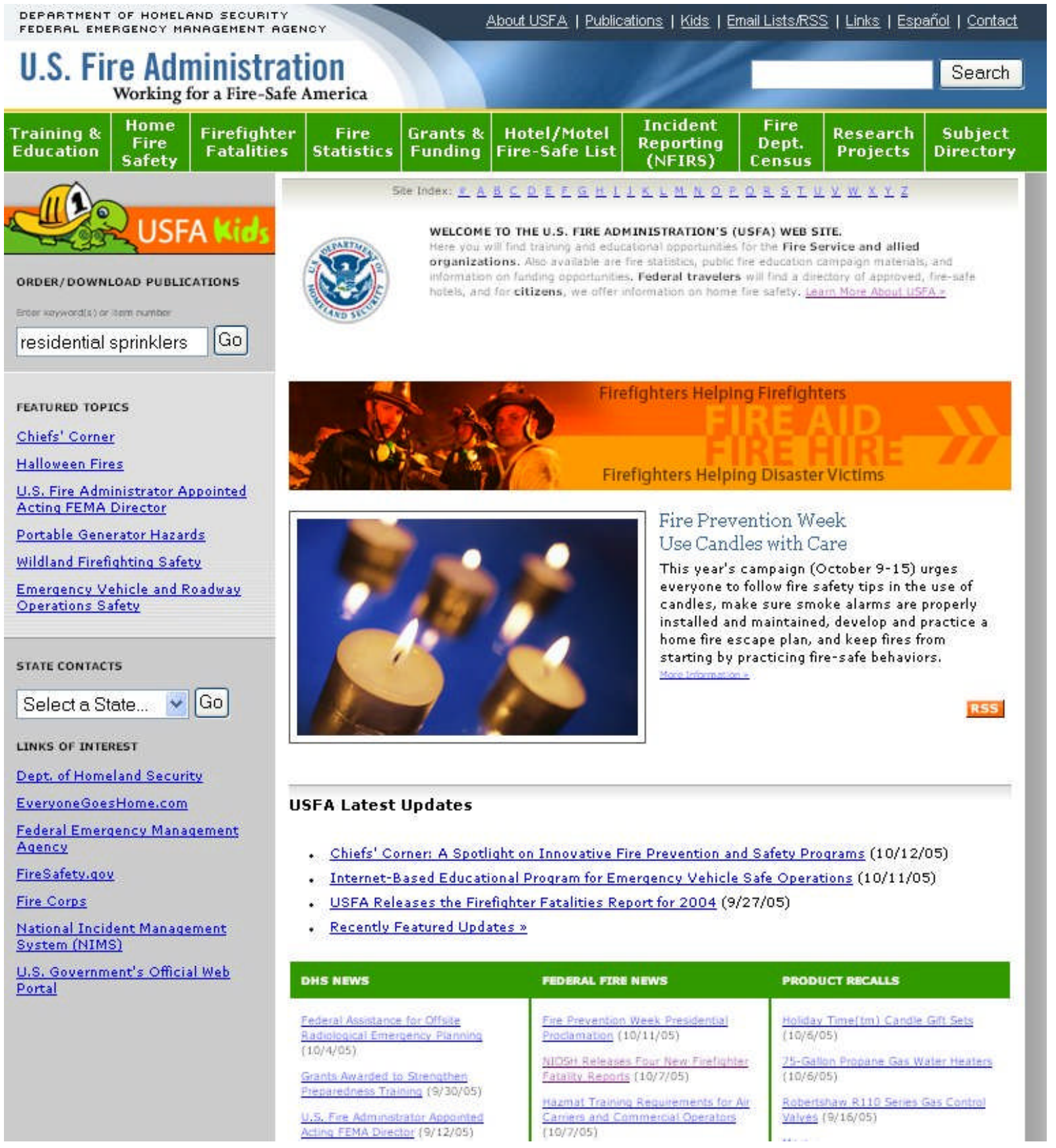


DEPARTMENT OF HOMELAND SECURITY
FEDERAL EMERGENOY MANAGEMENT AGENOY

Home | Ahout USFA | Publications | Kids | Email ListsRSS | Links | Español | Contact

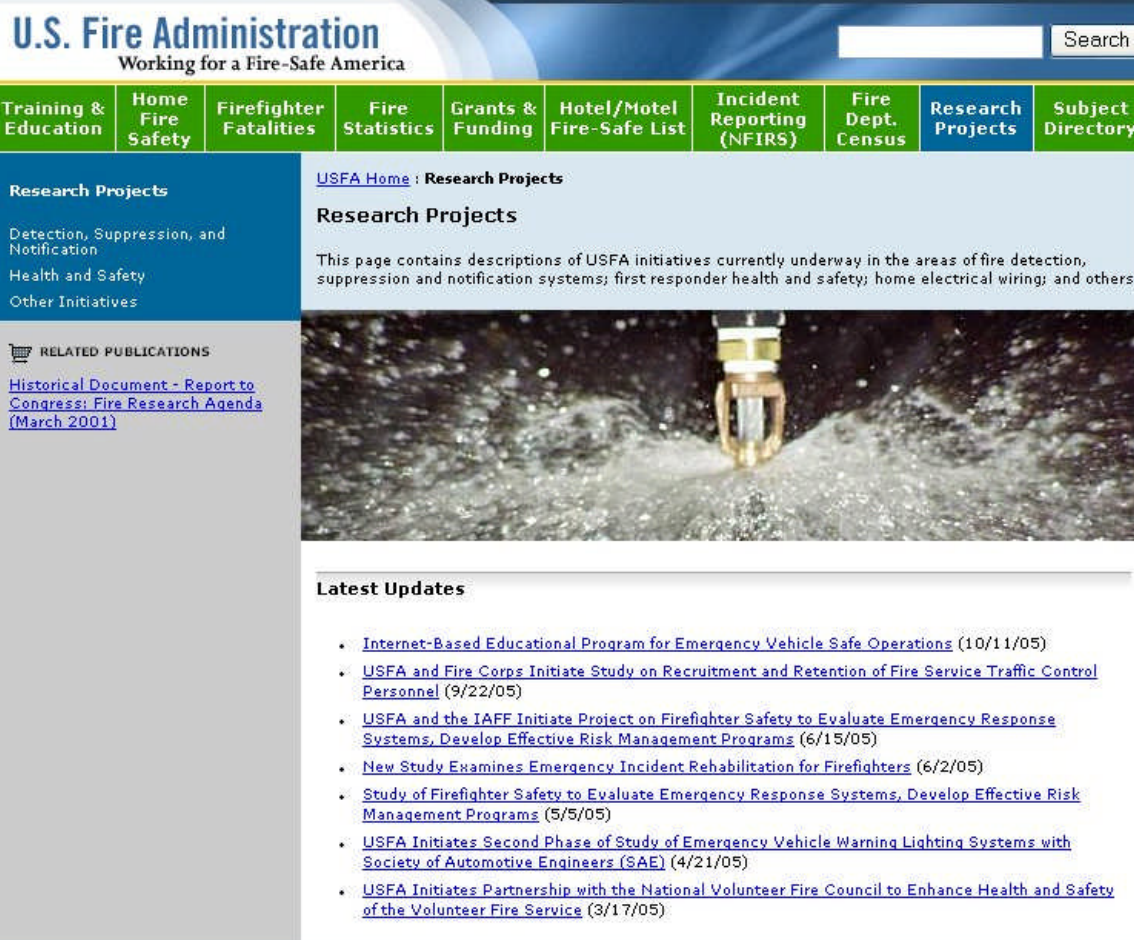

DEFARTMENT OF HOMELAND SECURITY
FEDEAL EMERGENOY MANAGEMENT AGENOY

U.S. Fire Administration

Working for a Fire-Safe America

Home | About USFA | Publications | Kids | Emeil Lists:RSS | Links | Español | Contact

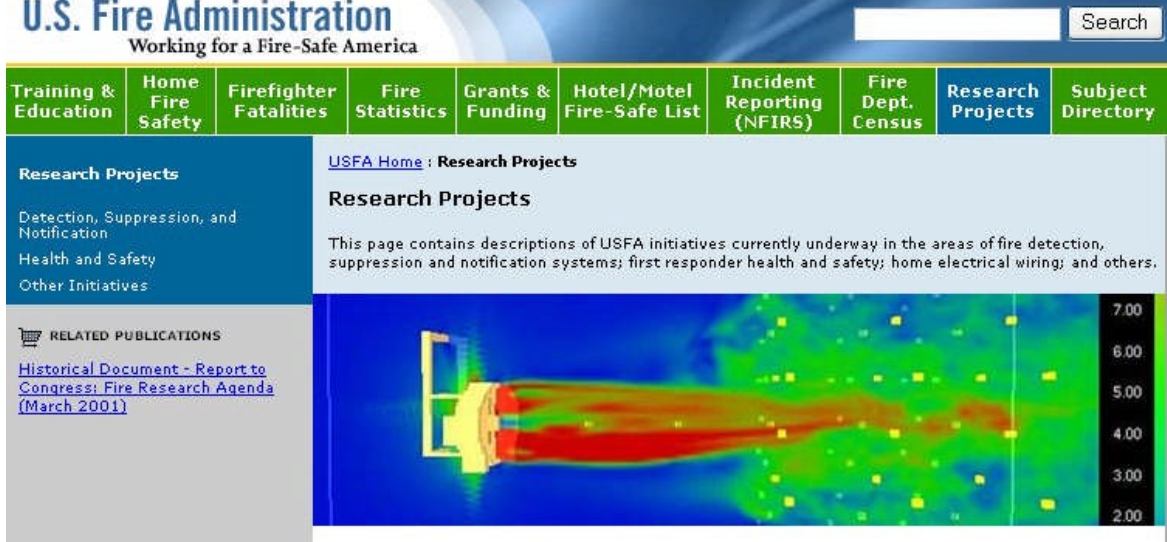

Latest Updates

- Internet-Based Educational Proaram for Emergency Vehicle Safe Operations (10/11/05)

- USFA and Fire Corps Initiate Study on Recruitment and Retention of Fire Service Traffic Control

USFA and the IAFF Initiate Project on Firefiahter Safety to Evaluate Emergency Response

- New Study Examines Emergency Incident Rehabilitation for Firefiahters $(6 / 2 / 05)$

- Study of Firefighter Safety to Evaluate Emergency Response Systems, Develop Effective Risk Management Programs $(5 / 5 / 05)$

- USFA Initiates Second Phase of Study of Emeraency Vehicle Warning Lighting Systems with Society of Automotive Engineers (SAE) ( $4 / 21 / 05)$

- USFA Initiates Partnership with the National Volunteer Fire Council to Enhance Health and Safety of the Volunteer Fire Service $(3 / 17 / 05)$ 
Building and Fire Research Laboratory Website - http://www.bfrl/nist.gov

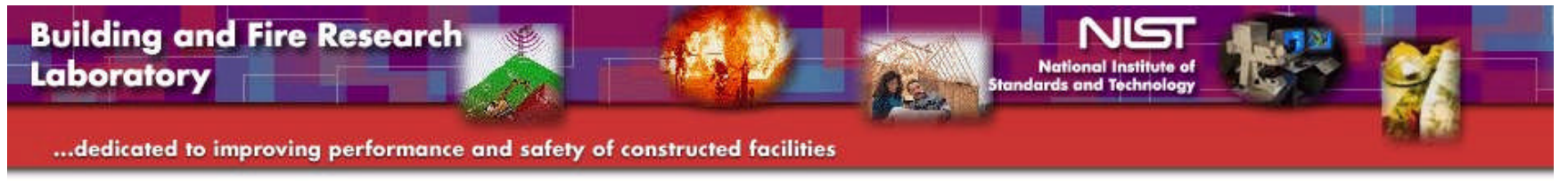

\section{About BFRL}

- What BFRL Does

- Research Areas

- Organization

- Staff

- Highlights

working with BFRL

- Director's Message

- Conferences

- Standards Activities

- Ask the Experts

Products and Services

- Publications

- Software

- Research Facilities

- Fire on the Web

- Fire Research Information Service (FRIS)

- Fire Research Grants

\section{Project Spotlight}

- Computer Integrated Construction

- Fire Dynamics Simulator (FDS) and Smokeview

- Virtual Cement and Concrete Testing Laboratory

a The Building Integrated Photovoltaic Program

- Fire.Gov Newsletter

- National Earthquake Hazards Reduction Program (NEHRP)

- Construction Safety Investigations (NCST)

\section{Research Areas}

- High Performance Construction Materials and Systems: Enable scientific and technology-based innovation to modernize and enhance the performance of construction materials and systems.

- Fire Loss Reduction: Enable engineered fire safety for people, products, facilities; and enhanced firefighter effectiveness with $50 \%$ reduction in fatalities.

m Enhanced Building Performance: Provide the means to assure buildings work better throughout their useful lives.

- Homeland Security: Use the lessons learned from the World Trade Center disaster to better protect people and property, enhance the safety of fire and emergency responders, and restore public confidence in the safety of tall buildings nationwide.
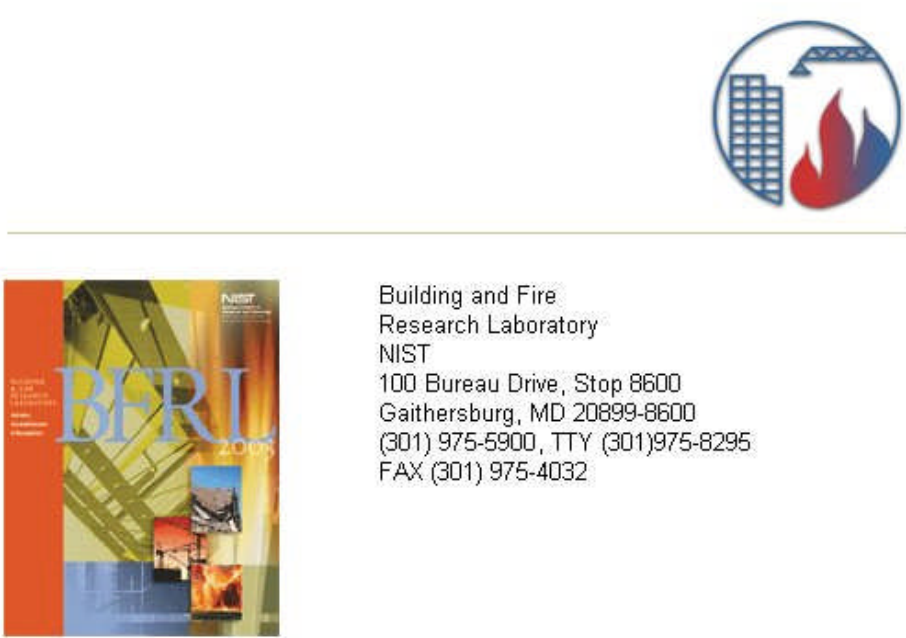

Building and Fire

Research Laboratory

NIST

100 Bureau Drive, Stop 8600

Gaithersburg, MD 20899-8600

(301) 975-5900, TTY (301)975-8295

FAX (301) 975-4032

Browse the latest BFRL report of Activities and Accomplishments.

(PDF format, 2,670 KB) 
Appendix A.

Draft Performance Standard for Thermal Exposure Sensors for Personal Alert Safety Systems (PASS).

\section{Section A - DESIGN REQUIREMENTS}

A.x Thermal Exposure Sensing Design Requirements for PASS.

A.x.1 PASS shall incorporate thermal sensing that shall detect high thermal environment near the person on whom the PASS is deployed and cause the activation of the sequence that leads to the sounding of the alarm signal when high thermal environment is detected for the specified time.

A.x.2 PASS shall sound the alarm signal specified in A.4.3 when the PASS does not sense the thermal environment for 10 seconds, $+2 /-0$ seconds.

A.x.3 PASS Thermal sensing shall function regardless of the angle of deployment of the PASS. A.x.4 PASS shall be designed so that any failure of the thermal sensing function shall cause the PASS to sound the alarm signal, specified in X.X.x, within 10 seconds, +2/-0 seconds, of such failure. The PASS manufacturer shall submit a failure modes analysis to the certification organization for verification of this requirement.

\section{Section B - PERFORMANCE REQUIREMENTS}

B.xx Thermal Exposure Sensor Test.

B.xx.1

PASS shall be tested for ability to sense the thermal environment as specified in Section C.xx, Thermal Sensor Tests, and shall function as follows:

(a) PASS shall emit the operational signal, as specified in A.x.x.

(b) Signals shall be evaluated for proper functioning as specified in Section X.X

(c) The alarm signal shall sound and continue to sound, as specified in A.x.x.

(d) Signals shall meet the sound pressure levels as specified Section B.x

(e) Nothing shall fall off the PASS, and the PASS shall not fall from its mounted position.

(f) At least two separate and distinct manual actions shall be required to change the mode selection device from alarm to sensing in order to silence the alarm as specified in A.X.X.

(g) The data logging functions specified in A.x.x shall operate properly.

(h) The transmitter within the PASS shall remain functional after completion of this test method.

(i) The data logging functions specified in A.X.X shall operate properly. 
Section C - TEST METHODS

C.x Thermal Sensor Test.

C.x.1 Application. This test method shall apply to all PASS.

C.x.2 Samples.

C.x.2.1 Samples shall be complete PASS.

C.x.2.2 Samples shall be conditioned as specified in C.x.x.

C.x.3 Specimens.

C.x.3.1 Specimens for testing shall be complete PASS.

C.x.3.2 A minimum of three specimens shall be tested.

C.x.4 Procedure.

C.x.4.1 Each specimen shall be subjected to a series of three thermal sensing tests

identified as C.x.5, Test Procedure 1 for static environment, C.x.6, Test Procedure 2 for flow environment, and C.x.7 Test Procedure 3 for radiation flux.

C.x.4.2 The same three specimens shall be used for all three test series. Each specimen tested shall be complete with power supply.

C.x.4.3 The test chamber or cabinet shall be capable of maintaining the required conditions specified in C.x.5, C.x.6, and C.x.7 throughout the envelope of air surrounding the specimen being tested, and these conditions shall be continuously monitored.

C.x.4.4Following each test, the specimen shall be allowed to stabilize at ambient conditions prior to proceeding to the next test.

C.x.5 Test Procedure 1 - Static Environment.

C.x.5.1 Specimens shall be removed following the specified conditioning, and testing shall begin within 30 seconds of removal from conditioning.

C.x.5.2 Specimens shall be placed in an electric resistance oven that has been stabilized at $150^{\circ} \mathrm{C}$ $\left.\left(120^{\circ} \mathrm{F}\right)+5 /-0^{\circ} \mathrm{F}\right)$.

C.x.5.3 Specimens shall remain in oven until thermal sensor activates alarm.

C.x.5.4 PASS Device shall not alarm before 10 minutes, but shall alarm before 15 minutes of exposure .

C.x.5.5 Failure of the alarm to activate within the specified time period shall constitute a failure.

C.x.5.6 This cycle shall be repeated twice for a total of three exposures.

C.x.5.7 Specimens shall be removed following the specified conditioning, and testing shall begin within 30 seconds of removal from conditioning.

C.x.5.8 Specimens shall be placed in an electric resistance oven that has been stabilized at $300^{\circ} \mathrm{C}$ $\left.\left(120^{\circ} \mathrm{F}\right)+5 /-0^{\circ} \mathrm{F}\right)$.

C.x.5.9 Specimens shall remain in oven until thermal sensor activates alarm.

C.x.5.10 PASS Device shall not alarm before 5 seconds, but shall alarm before 15 seconds of exposure.

C.x.5.11 Failure of the alarm to activate within the specified time period shall constitute a failure. 
C.x.5.12 This cycle shall be repeated twice for a total of three exposures.

C.x.6 Test Procedure 2 - Flow Environment.

C.x.6.1 Specimens shall be removed following the specified conditioning, and testing shall begin within 30 seconds of removal from conditioning.

C.x.6.2 Specimens shall be placed in a heated flow loop that has been stabilized at $125^{\circ} \mathrm{C}$

$\left.\left(250^{\circ} \mathrm{F}\right)+5 /-0^{\circ} \mathrm{F}\right)$ and a flow velocity of $0.22 \mathrm{~m} / \mathrm{s}$.

C.x.6.3 Specimens shall remain in oven until thermal sensor activates alarm.

C.x.6.4 PASS Device shall not alarm before 15 minutes, but shall alarm before 20 minutes of exposure .

C.x.6.5 Failure of the alarm to activate within the specified time period shall constitute a failure.

C.x.6.6 This cycle shall be repeated twice for a total of three exposures.

C.x.6.7 Specimens shall be removed following the specified conditioning, and testing shall begin within 30 seconds of removal from conditioning.

C.x.6.8 Specimens shall be placed in a heated flow loop that has been stabilized at $250^{\circ} \mathrm{C}$

$\left.\left(480^{\circ} \mathrm{F}\right)+5 /-0^{\circ} \mathrm{F}\right)$ with a flow velocity of $1 \mathrm{~m} / \mathrm{s}$.

C.x.6.9Specimens shall remain in oven until thermal sensor activates alarm.

PASS Device shall not alarm before 5 seconds, but shall alarm before 15 seconds of exposure.

C.x.6.10 Failure of the alarm to activate within the specified time period shall constitute a failure.

C.x.6.11This cycle shall be repeated twice for a total of three exposures.

C.x.7 Test Procedure 3 - Radiation Flux.

C.x.7.1 Specimens shall be removed following the specified conditioning, and testing shall begin within 30 seconds of removal from conditioning.

C.x.7.2 Specimens shall be placed in a thermal flux field that has been stabilized at $2.5 \mathrm{w} / \mathrm{m}^{2}$.

C.x.7.3 Specimens shall remain in oven until thermal sensor activates alarm.

C.x.7.4 PASS Device shall not alarm before 10 minutes, but shall alarm before 15 minutes of exposure .

C.x.7.5 Failure of the alarm to activate within the specified time period shall constitute a failure.

C.x.7.6 This cycle shall be repeated twice for a total of three exposures.

C.x.7.7 Specimens shall be removed following the specified conditioning, and testing shall begin within 30 seconds of removal from conditioning.

C.x.7.8 Specimens shall be placed in a thermal flux field that has been stabilized at $30 \mathrm{w} / \mathrm{m}^{2}$.

C.x.7.9 Specimens shall remain in oven until thermal sensor activates alarm.

PASS Device shall not alarm before 5 seconds, but shall alarm before 15 seconds of exposure.

C.x.7.10 Failure of the alarm to activate within the specified time period shall constitute a failure.

C.x.7.11 This cycle shall be repeated twice for a total of three exposures.

C.x.8.1 The functioning of the specimens shall be recorded and reported.

C.x.9 Interpretation.

C.x.9.1 Pass or fail performance shall be determined for each specimen.

C.x.9.2 One or more specimens failing this test shall constitute failing performance. 